\title{
INVESTIGATION OF PROPERTIES AND PERFORMANCE OF CERAMIC COMPOSITE COMPONENTS
}

\author{
June 15,1992 \\ Report Prepared by \\ W. W. Stinchcomb, K. L. Reifsnider ${ }_{4}$ T. J. Dunyak \\ Materials Response Group \\ Engineering Science and Mechanics Department \\ Virginia Polytechnic Institute and State University \\ Blacksburg, Virginia 24061-0219
}

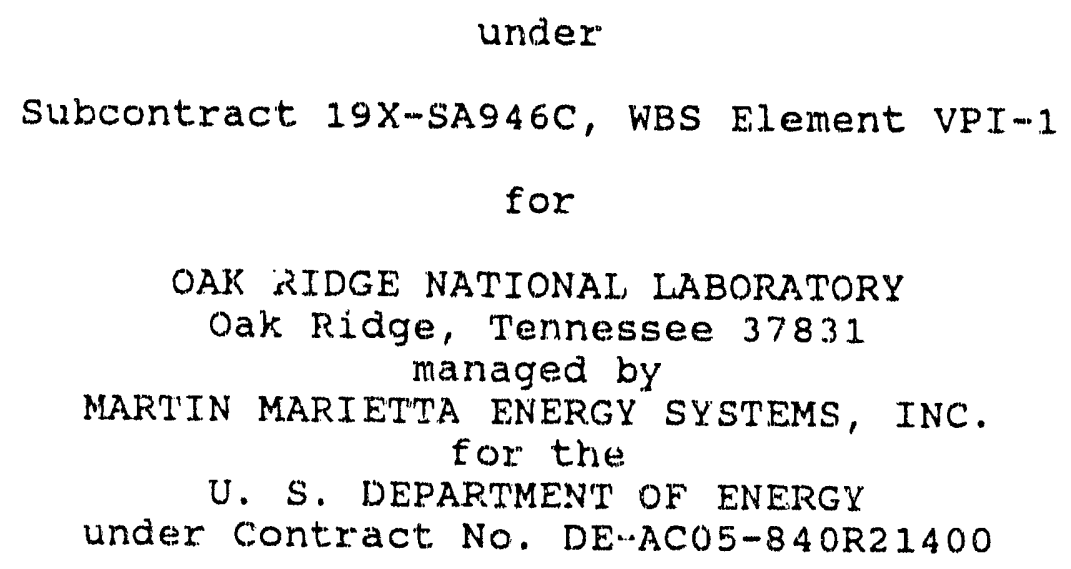

under

Subcontract 19X-SA946C, WBS Element VPI-1

for

OAK RIDGE NATIONAL LABORATORY

Oak Ridge, Tennessee 37831 managed by

MARTIN MARIETTA ENERGY SYSTEMS, INC.

for the

U. S. DEPARTMENT OF ENERGY

under Contract NO. DE $\cdots A C O 5-840 R 21400$ 
This report contains results of work performed during phase one of the program "Investigation of properties and performance of Ceramic composite components." The program addresses the need for reliable and durable structural ceramic composites to perform in high temperature fossil energy environments.

The objective of the work reported herein is to develop an understanding of the mechanical behavior of advanced ceramic composites subjected to elevated temperature and dynamic (cyclic) loading, to develop a test system and test methods to obtain the properties and performance information required to design engineering components made from ceramic composite materials, and to provide critical and comprehensive evaluations of such materials to material synthesizers and developers to support and enhance progress in ceramic composite material development.

The accomplishments of the investigation include the design, development, and demonstration of a high temperature, biaxial mechanical test facility for ceramic composite tubes and the development and validation of a performance simulation model (MRLife) for ceramic composites.

The results provilie a major step beyond the characterization of samples and coupons toward a comprehensive characterization of ceramic composite components. 
TABLE OF CONTENTS

\begin{tabular}{|c|c|c|}
\hline BSTR & RACT & $i$ \\
\hline LIST & OF FIGURES & iv \\
\hline LIST & OF TABLES & vii \\
\hline 1.0 & $\begin{array}{l}\text { INTRODUCTION } \\
1.1 \text { Objectives } \\
1.2 \text { Approach }\end{array}$ & $\begin{array}{l}1 \\
1 \\
3\end{array}$ \\
\hline 2.0 & $\begin{array}{l}\text { LITERATURE REVIEW } \\
2.1 \text { Test Methods and Specimen Design } \\
2.2 \text { Nondestructive Examination Methoc } \\
2.3 \text { Damage Process Charucterization lider long } \\
\text { Term Loading } \\
\text { 2.4 Tensile Strength Prediction Methods for } \\
\text { Injection Molded Composites } \\
2.5 \text { Summary }\end{array}$ & $\begin{array}{l}13 \\
17\end{array}$ \\
\hline 3.0 & $\begin{array}{l}\text { TEST SPECIMEN DESIGN, ANALYSIS AND FABRICATION } \\
3.1 \text { Specimen Design Options } \\
3.2 \text { Specimen Analysis } \\
\text { 3.2.1 Model Development } \\
3.2 .2 \text { Design Allowables } \\
3.2 .3 \text { Finite Element Results } \\
3.2 .4 \text { Model Verification } \\
3.3 \text { Final Design Selection } \\
3.4 \text { Materials and Specimen Fabrication } \\
\text { 3.4.1 Material Selection } \\
\text { 3.4.2 Fabrication Process }\end{array}$ & $\begin{array}{l}19 \\
19 \\
24 \\
24 \\
27 \\
29 \\
31 \\
35 \\
35 \\
36 \\
36\end{array}$ \\
\hline 4.0 & $\begin{array}{l}\text { TEST FACILITY DEVELOPMENT } \\
4.1 \text { The Test Frame } \\
4.2 \text { The Hydraulic Grips } \\
4.3 \text { Test System Control and Data Acquisition } \\
4.4 \text { Test Facility Performance }\end{array}$ & $\begin{array}{l}42 \\
42 \\
44 \\
44 \\
48\end{array}$ \\
\hline 5.0 & $\begin{array}{l}\text { TEST METHOD DEVELOPMENT } \\
5.1 \text { Evaluation and Application of } \\
\text { Nondestructive Examination Techniques } \\
5.2 \text { Mechanical Test Procedure Development } \\
5.2 .1 \text { Gripping and Alignment } \\
5.2 .2 \text { Quasi-static Testing Procedures } \\
5.2 .3 \text { Cyclic Testing Procedures } \\
5.2 .4 \text { Recommended Procedures }\end{array}$ & $\begin{array}{l}49 \\
53 \\
53 \\
55 \\
56 \\
58\end{array}$ \\
\hline
\end{tabular}


6.0 EXPERIMENTAL TEST RESULTS

6.1 Experimental Results for the Tubular

Test Specimens

6.1.1 NDE Prior to Testing

6.1 .2 Quasi-static Testing procedures and Results

6.1.3 Cyclic Testing Procedures

and Results

6.1.4 Residual. Tensile strength Results

6.1 .5 Post liest Evaluations of

the specimens

7.0 ANALYTICAL, MODELING OF DAMAGE DEVELOPMENT

IN COMPOSITE COMPONENTS

7.1 General Methodology

7.2 Mechanics

7.3 Application of the Method to Injection Molded Tubes

7.4 Discussion of the Modeling Approach

8.0 PERFORMANCE SIMULATION MODEL 105

8.I Background 106

8.2 Elements of the Critical Element Approach 112

8.3 Performance Simulation 125

8.4 Model Results--Performance 129

8.5 Some New Directions 135

8.5.1 Refinement of Mechanistic Models 136

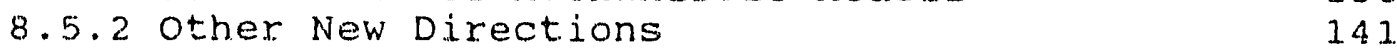

9.0 ACCOMPLISHMENTS AND DISCUSSION 145

9.1 Accomplishments 145

9.2 Discussion 146

9.2.1 Material System, Specimen Geometry,
and Test Method's

9.2.2 Characterization of performance, Including Defects ard Damage Development 147

9.2 .3 Models and predictions 148

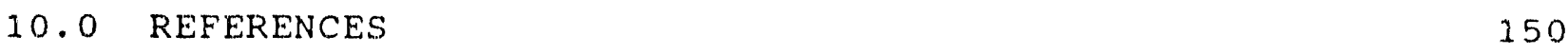

APPENDIX A: TEST FACILITY SPLCIFICATIONS A-1

APPENDIX B: DISTRIBUTION B $B$ 
3.1 The short conical specimen. 21

3.2 The tong conical specimen. 21

3.3 The short cylindrical specimen. 23

3.4 The Long Cylindrical specimen. 23

3.5 The Finite Element Mesies. 26

3.6 Boundary Conditions on the Long Conical Model. 28

3.7 Axial stress Contours for the Long Cylindrical Model subjected to Grip Plus Axial Loads.

3.8 Comparison of the Compressive Radial Stresses for the Finite Flement and Elasticity Solutions.

3.9 Comparison of the Compressive Hoop Stresses for the Finite Element and Elasticity solutions.

3.10 The Injection Molding Assembly.

3.11 Regions of the Tube.

3.12 Specimen 11.8-89 with Strain Gages Attached and End Plugs Removed.

3.13 Surface chips in specimen 118-89. 40

4.1 The Test Frame. 4.3

4.2 A Sectional View of the Hydraulic Grips. 45

$\begin{array}{lll}4.3 & \text { A Sample status screen Printout. } & 47\end{array}$

4.4 A Schematic Diagram of a Tensile Waveform containing Three Events, Two Blocks and one Sequence.

6.1 Radiograph of Specimen 118-89. 61

6.2 Radiograph of specimen 260-89. 62

6.3 Radiograph of specimen 264-89. 63

6.4 Out-of-plane Fiber swirling. $\quad 66$

6.5 C-scan Results for Specimen 261-89. 66 
6.6 Stress-Strain Responses for the Quasi-static specimens.

6.7 Cumulative AE counts as a Function of Applied Stress.

6.8 Normalized Secant Modulus as a Function of AE counts.

6.9 Stiffness Change as a Function of Cycles for Specimen 258-89.

6.10 Spate Images for Specinen 258-89.

6.11. Dye Penetrant Inspection Results for

specimen 258-89.

6.12 Residual strength Results After one Million cycles.

6.13 Radiograph of Downstream Failure Region of: Specimen 118-89.

6.14 Specimen 261-89 After Failure.

6.15 Specimen 260-89 Aiter Failure.

6.16 Specimen 258-89 After Failure.

6.17 Fiber Pullout Regions with Blunted Ends in specimen 118-89.

6.18 Straw-like Fiber Pullout Regions in Specimen 260-89.

6.19 Possib]e Failure Modes Associated with out-of-plane Fiber Swirling.

6.20 Micrograph of a Failure Region Where the Fibers are oriented Transverse to the Loading Direction.

6.21. Micrograph of a Failure Region where the Fibers are Aligned with the Loading Direction.

6.22 Postulated Wear-in Phenomenon for Specimen 258-89.

7.1 Flow chart of the Analytical solution Methodology. 
7.2 The Finite Element Model of the Tube. 96

7.3 Material Axes for the Elements in the Model. 97

7.4 Predicted Location of the Initial Damage. 100

$\begin{array}{lll}7.5 & \text { Predicted Damage Sites at } 1510 \text { Pounds. } & 101\end{array}$

7.6 Comparison of the Predicted and Observed
Failure Locations.

8.1 The Evolution of properties and Performance. 115

8.2 Distributed Matrix Cracking in a Composite

8.3 Three Dimensional Finite Element Analysis. 118

8.4 Micromechanical Stiffness prediction. $\quad 120$

8.5 Micromechanical Prediction of Poisson's ratio. 121

8.6 Viscoelastic Stiffness Reduction Master curve. 123

8.7 Critical Element Approach to Remaining Life Prediction

8.8 Performance Simulation Results for LAS-II glass Ceramic composites.

8.9 Predicted and Observed Fatigue Life of LAS-II glass Ceramic Composites.

8.10 Multifiber Penetration Method. $\quad 143$

8.11 Somparative Interfacial strength. $\quad 144$ 
3.1 Material Properties. 25

3.2 Allowable Design Stresses. 29

3.3 Grip stresses for the Long Cylindrical Model subjected to Grip and Loads Only. 30

3.4 Grip Stresses for the Long Cylindrical Model. Subjected to Grip and Axial Loads.

3.5 Physical Properties of Chopped Carbon Fiber Reinforced Borosilicate Glass T'ubes. 41

5.1 NDE Methods Evaluated. 52

6.1 Cyclic Test Results.

7.1 Material Properties for the Tube Analysis. 98 
"Research sponsored by the U.S. Department of Energy, Fossil Energy AR\&TD Materials Program, DOE/FE AA 1510100 , Work Breakdown Structure Element VPI-1"

\subsection{INTRODUCTION}

The anticipated use of ceramic vomposites in high temperature, structural applications requires the technical community to make the transition from properties of composite materials to the performance of engineering components. For composites in fossil energy applications, this transition requires comprehensive characterization and understanding (i.e., philosophy alia rigorous modelirig) of long-term behavior. For example, information from quasi-static tests, modulus of rupture tests, and fracture toughness tests is not sufficient to design a complex component such as a heat exchanger tube fabricated from anisotropic, fiber reinforced materials which will experience multiaxial stresses and elevated temperatures. The present research effort provides an experimental and analytical basis for the transition from properties to performance. In general, the program is a pioneering effort to make a first step beyond the limited characterization of small samples and coupons to the comprehensive mechanical characterization of complex engineering components such as ceramic composite tubes subjected to static and cyclic multiaxial loading and elevated temperature over various time periods.

\section{1 objectives}

The central objective of the present program is to develop an understanding of the mechanical behavior of advanced ceramic composites subjected to elevated temperature and dynamic ( $c_{i}$. ic) loading, to develop a test system and test methods $t$, obtain the properties and performance information required to design engineering components made from ceramic composite materials, and to provide critical and comprehensive evaluations of such materials 
to material synthesizers and developers to support and enhance progress in ceramic composite material development.

Specific objectives of the program are to:

1) Design and construct a mechanical test device, using a servohydraulic test frame designed for multiaxial loading.

2) Establish the room temperature response of several material types of ceramic composite tubes to quasi-static uniaxial loading, especially the strength, stiffness, and failure modes of those tubes, the statistical variations of those characteristics, and the mechanistic relationship of the microstructure and damage state associated with each material system to the observed response.

3) Establish the response (as described in 2) to cyclic loading.

4) Establish the response (as described in 2 and 3) at elevated temperature up to $1500^{\circ} \mathrm{C}$, in air.

5) Develop mechanistic models which are capable of predicting the strength (or residual strength) of ceramic composite tubes subjected to various load histories and temperatures as described above, using the disciplines of mechanics, physics, chemistry, statistics, and the understanding of behavior obtained from experimental investigations.

6) Establish the nature of the need for subsequent work dealing with additional parameters such as other generic compunent shapes, other atmospheres, other material systems, other loadings or load histories, or other response characteristics (dynamic, magnetic, etc.). 


\subsection{Approach}

The approach to the program is designed to meet the objectives of the program through a series of four coordinated and complementary tasks outlined in Table 1.

\section{Task 1:}

The program begins with a major thrust of planning, literature review, design and basic setup. A majox part of the Task 1 effort is directed towards the design, development, fabrication, and installation of a multiaxial test frame as a starting point for the construction of the high temperature test system. The quasi-static test series is planned based on a review of data from previous work. The basic design of the test chamber, grips and specimen is generated and construction initiated. The specimen design is a cooperative venture with the specimen supplier (United Technology Research Center), the Materials Response Group, and the test facility supplier (Instron Corporation).

Two major requirements of the program are the acquisition of data on the internal state of damage of the material and modeling the damage development in the material. Therefore, Task 1 involves a literature review and planning for nondestructive test methods, and a literature review of damage models for cyclic loading of brittle matrix composites.

\section{Task 2:}

The axial-torsional, load frame is used to conduct uniaxial, quasistatic room temperature tensile tests on ceramic composite specimens. These tests are used to establish baseline data for the material systems under quasi-static loading, to identify failure modes for subsequent modeling, and to make refinements in the mechanical test system and sperimen geometry if necessary. 
Concurrently, the high temperature equipment for the system is designed and construction initiated. In addition, development of nondestructive test methods is initiated during the test program to follow the damage development in the specimen. The final Task 2 activity includes planning for the room temperature cyclic test series.

\section{Task 3:}

The final step in the high temperature test system construction is conducted in Task 3. During the construction period, monotonic tensile testing at room temperature is conducted to initiate the study and modeling of the failure of ceramic composite specimens and the damage processes that lead to failure under sustained cyclic loading. Final material system choices are made, and the development of nondestructive test methods continues. The final. activity in the Task is the planning of a high temperature test series, to include high temperature, cyclic tension loading.

\section{Task 4:}

Primary objectives of Task 4 are to conduct a rigorous program of testing to refine the test specimen, and to begin formulation of a strength model that can be used for residual strength prediction after damage has occurred. This will be a fully operational shakedown phase with all systems in operation. The focus of the program will shift from construction of the test system to characterization of the material system selected in Task 3. special attention will be given to the interpretation of the results and the development of a mechanistic damage model. The final activity in Task 4 will be the planring of a test series for the purpose of verifying the validity of the model and associated concepts. 


\subsection{LITERATURE REVIEW}

Historically, the development of ceramic composites science and technology has been approached from several independent directions. On one hand, parts of the traditional composites cummunities have turned their attention to high temperature composites. On the other hand, the sintered ceramics communities have looked to fiber reinforcements as a means of increasing ceramic toughness. As the field continues to grow and mature, these two directions are blending, and a specific community dedicatid wo the development of ceramic matrix composites is forming.

Since both of these communities are well established, the Iiterature is profuse with information on composites and ceramics. Unfortunately, most of the information cannot be applied directly to ceramic composites. For example, test methods ror tensile strength of polymer matrix composites have been developrd and standardized by ASTM (1). Similarly, the ceramics community routinely measures tensile strength at elevated temperatures. Unfortunately, the two procedures are different, and neither method airectly applies to ceramic matrix composites. For polymeric composites, ASTM requires flat specimens loaded in uniaxial tension. However, precision alignment and gripping in a high temperature environment are not covered. The elevated temperature tensile strength (modulus of rupture) of sintered ceramics is typically measured in a flexure mode due to the brittleness of the material and the gripping limitations. However, flexure testing is totally unacceptable for composites. Eventually, the two procedures must be integrated, and the resulting problem areas resolved. The ceramics composites community is just beginning to tackle these types of issues; and although the field is rapidly growing, the amount of current literature directly applicable to ceramic composites is limited. 
The section is divided into five main areas. The first area reviews test methods and specimen design. The second area covers nondestructive test methods, and the third section describes damage characterization under long term cyclic loading. The fourth area reviews tensile strength prediction methods for injection molded components, and the final area presents a brief summary.

\subsection{Test Methods and Specimen Design}

The majority of high temperature tests conducted on ceramic matrix composites use flexural loading of beam specimens. For example, References 2 through 6 use fiexure specimens as a primary means of measuring quasi-static and fatigue properties. Several. advantages make flexure testing extremely attractive. First, flexure tests require a relatively small amount of material compared to other types of mechanical tests, and ceramic composites are very expensive. second, the fixturing is very simpln and capable of very precise alignment. Relatively low loads are required for flexure testing. As a result, the fixturing can be fabricated with high temperature materials which are capable of withstanding the test environment. In addition, since the loads are small and the deflections are relatively large, the crosshead travel provides a good measurement of the specimen deflection, which eliminates the need for high temperature extensometry.

Although these advantages contribute to a relatively simple and inexpensive test, they do not contribute to the quality of data produced by a flexure test. Flexural loading generates nonuniform stress and strain fields throughout the gage section of the specimen, and local failures can significantly change these fields. For example, as the outer ply on the tensile side of a specimen fails, the neutral axis shifts and changes the stress and strain fields. As a result, very little significant data are produced beyond the initial ply failure. Due to the limitations of flexure testing, investigators are turning toward uniaxial tension tests as 
the primary means of data generation, and several of the problem areas associated with high temperature tension testing are now being addressed.

References 7 through 11 discuss elevated testing techniques for uniaxial tension or fatigue. All authors except southern Research Institute (SRI) (7) recommend a rigid gripping system with precision alignment capabilities. SRI incorporates a flexible alignment systrem with a chain pivot to eliminate bending. Although the flexible system provides better alignment, it is difficult to use. In addition, the flexible system innot accommodate compressive loadings and is limited to a loading frequency of 30 seconds per cycle which does not permit high cycle fatigue testing. All of these researchers located the grips outside the heating unit.

Most authors incorporated some type of radiant heating unit. These units are relatively common and can be purchased from a variety of suppliers. Bartolotta et. al. (8) have developed an induction heating system for high temperature testing. They have shown that the induction system provides better specimen access and thermal control without affecting the material propexties of the specimen (12). Holres et. al. (9) used a combination induction-radiant heating system. A silicone carbide (SiC) susceptor is placed around the specimen and inductively heated. The sic susceptor then radiantly heats the gage length of the specimen. Holmes claims this system provides excellent temperature control, minimal furnace interference, and can be used for any composite system.

Most investigators used commercially available contacting extensometers. However, in some cases, the extensometers were modified with a counter balance to improve attachment or reduce out-of-plane loadings. Holmes et. al. (9) designed a new counter-force extensometer arrangement (13) to balance the bending 
moment induced by the extensometer rods. The tips of the extensometex and counter-loading rods contacted shallow conical depressions ground into the edge of the specimen. These conical depressions served to accurately locate the contacting rods and to prevent possible extensometer slippage. Holmes et. al. also noted the extensometer should contact the face of the specimen as opposed to the edges when edge delamination could occur. Although optical and laser extensometry is quickly developing, it is interesting to note that none of the investigators used an optical or laser extensometer.

Although all of the specimen designs were different, most of the designs have some very similar characteristics. They all consist of a dog-boned shaped plate specimen with a uniform gage section. Holmes (9) and Bartolotta (8) were able to use shorter specimens due the small size of the induction furnaces. Most of the specimens contained a single radius in the transition region. However, the specimen presented by Holmes contained two radii. In most cases, end tabs were attached to the specimens to facilitate gripping.

Larsen, Stuchly, and Adams (14) at the IIT Research Institute also investigated the development of elevated temperature test techniques. Generally, the methods they developed were significantly different from the methods described earlier. Therefore, their work will be considered separately. Larsen, stuchly, and Adams elected to place the grips inside the furnace. They believed this minimized the temperature gradients in the specimen, and reduced the amount of material required to perform the test. The testing in this program was limited to $900^{\circ} \mathrm{C}$. Therefore, hot grips were more easily used. They also strongly recommended an optical extensometer for elevatr: strain measurements. Sighting flags were bonded to the specimen to provide a displacement window. A dog-boned specimen was developed for uniaxial tension testing. In addition, a typical sic 
resistance furnace was used to heat the specimen and grips.

Aichough the work in references 7 through 14 relates to uniaxial testing of flat specimens as opposed to tubular component's, many of these developments provide the basis for the development of test methods for complex engineering components. In addition, Ellis and Gayda (15) associated with the Advanced High Temperature Engine Materials Technology Program (HITEMP) have identified the development of structural benchmark test methods as a primary goal over the next several years, and high temperature, multiaxial loading of tubular components is of key interest.

\subsection{Nondestructive Examination Methods}

The extension of nondestructive inspection (NDI) techniques from polymeric composites to ceramics composites has been relatively simple, and even the appliration of these techniques to complex engineering shapes is straight forward. Reference 16 provides a comprehensive review of relatively standard NDI techniques. Examples of the application of these techniques to ceramic composites are provided in references 17 to 24 , and two papers reviewing techniques developed for polymeric short fiber composites are provided in References 25 and 26 .

Most of the current work in NDI of ceramic matrix composites is related to the development and application of advanced techniques such as computed tomography, acousto-ultrasonics, or microfocus $x$-rays. References 27 and 28 provide good summaries of the recent work in these advanced technology areas. Although several NDI techniques have been developed to "see" into a material or specimen, very little work has been done to correlate the observed defects to the performance of ceramic matrix composites. For example, Kautz and Klima (28) have used microfocus $x$-rays to image voids and inclusions on the order of $20 \mu \mathrm{m}$. However, most performance limiting defects are much larger than this size. In 
light of this gap between NDI results and performance reported in the literature, one of the main goals of this program was to correlate the NDI results to performance and, based on this correlation, identify the critical defects which control performance.

\subsection{Damage Process Characterization Under Long Term Cyclic Loading}

In order to model the performance of injection molded ceramic matrix composites, the damage development process must be thoroughly characterized. However, not a single piece of literature on the damage development of injection molded ceramic matrix composites was located. Therefore, the literature search was expanded to include continuors fiber reinforced ceramics and short fiber polymeric composites. Three sources $(29,30,9)$ were located which considered the long term behavior of and damage development in continuous fiber ceramic matrix composites under fatigue loading.

Minfold and Prewo (29) investigated the room temperature fatigue behavior of unidirectional and crossply laminates of different LAS glass matrices reinforced with continuous SiC fiber, and prewo later continued this work in Reference 30 . Holmes et. al. (9) considered the elevated temperature fatigue behavior of Si3N4 reinforced with unidirectional, continuous SCS-6 SiC fibers. In addition to simple stress-life results, all three of the references provide excellent information on stiffness reduction versus cycles. Minford and prewo also show residual strength curves for the Sic/LAS composites. None of these references investigated fatigue crack propagation through the specimens.

References 30 and 9 describe an apparent fatigue limit at the matrix cracking stress for unidirectional materials. For cyclic loads below the matrix cracking stress, the stiffness of the 
unidirectional material did not change as a function of cycles, and all of the specimens survived 105 cycles without a failure. In addition, the residual tensile strength after fatigue loading was approximately the same as the strength of the as-fabricated material. For cyclic loads above the matrix cracking stress, all the unidirectional specimens failed in fatigue and showed stiffness degradations throughout the test.

Several sources were located on the damage development of short fiber polymeric composites (31.37). Two of these papers $(36,37)$ were extremely informative and will be covered in greater detail. Wang and chim (36) investigited the fatigue damage and degradation in fiber reinforced sheet molding compound (SMC) with random fiber distributions. The observed fatigue damage was generally characterized by microcrack density, characteristic crack length, and distribution of crack orientations. Typically, high cyclic stresses induced fatigue damage with large microcrack densities and short characteristic crack lengths. However, low cyclic stresses tended to produce low microcrack densities and long characteristic cracks. In addition, the structural response of the SMC illustrated continuous stiffness degradations, and higher cyclic stresses produced higher magnitudes and rates of stiffness reduction and shorter fatigue lives.

Although the SMC is generally considered macroscopically isotopic, Wang and chim observed several local phenomena which are expected to correlate more closely with the damage development in injection molded components. In matrix dominated areas, the microcracking and crack propagation was found to be predominantly normal to the loading direction. In fiber dominated regions with fibers oriented parallel to the loading direction, the microcracks developed mainly in the matrix parallel to the loading. However, the microcracks had very short lengths limited by the interfiber spacing. In a chopped fiber strand oriented at an angle to the loading direction, microcracks with long characteristic lengths 
initiated and grew along the fiber/matrix interface. Overall, the predominate failure modes were matrix failure and fiber pullout. Fiber fractures were rarely observed in the SMC material.

Lang, Manson, and Hertzberg (37) investigated fatigue fracture in injection molded polymeric composites. Their specimens had known non-homogeneous fiber orientations throughout the specimens. They looked at several types of specimens with variations in fiber volume, matrix ductility, and fibre-matrix adhesion. Depending on the combination of these parameters, completely different fracture patterns were observed. For example, a specimen with a "semi-ductile" matrix, $18 \%$ fiber volume fraction, and "good" fiber-matrix adhesion exhibited crack growth perpendicular to the loading direction regardless of the fiber orientations. However, the same material and geometry with $26 \%$ fiber volume showed crack growths parallel to the fiber orientations and parallel to the loading directions indicating failure at the fiber-matrix interface. A specimen with a "brittle" matrix, 18\% fiber volume, and poor fiber-matrix adhesion also exhibited crack growth parallel to the fiber orientations and parallel to the loading directions. This review will forus on the results of the "brittle" matrix specimens.

SEM investigation of the fracture surfaces for the brittle matrix specimen indicates variations in the surface depending on fracture mode. Lang, Manson and Hertzberg considered three different fiber orientations with respect to the crack plane. In areas of fibers oriented at large angles to the crack plane, fiber pullout was much more apparent under monotonic or fast fracture loadings than under stable crack growth conditions. Detailed examination of the fiber-matrix interface regions also indicated interface failure under fast fracture and matrix failure near the interface under stable crack propagation conditions. For fibers at intermediate angles to the crack plane, damage was predominantly characterized by shear failure of the fiber-matrix interface. In 
some cases, fiber failures due to bending were observed. For fibers at small angles to the crack plane, no significant difference in the fracture surfaces were observed between stable crack growth and fast fracture. In both cases, the damage was primarily characterized by failure of the fiber-matrix interface.

Overall, References 36 and 37 provide the best insight into the damage development process for injection molded composites. As shown in these papers, nonhomogeneous fiber orientations clearly hive a significant effect of the failure process. For the case of injection molded ceramic composites, similar observations are required in order to characterize the damage development process under long term cyclic loading.

\subsection{Tensile strength Prediction Methods for Injection Molded Composites}

The development of strength prediction methods for fiber reinforced injection molded composites is a very complicated but relevant problem which has received littlo attention. The application of strength prediction techniques to injection molded ceramic matrix composites has not been addressed at all. Typically, two different classifications of short fiber composites are considered. The first class considers short fibers which are aligned in the loading direction. The second class of problems considers randomly orientated short fiber composites which are isotropic in the plane of the specimen. Unfortunately, neither of these classifications directly applies to injection molded components where the flow of the molding compound generates non-uniform fiber orientations throughout the component.

This section will describe four general approaches to the short fiber problem. Although several papers exist for each approach, this review will be limited to seven papers which form the basis of these approaches. For each approach, a brief summary 
of the method will be presented. Then, the limitations of each approach and the applicability to injection molded ceramic matrix composites will be discussed.

One of the first strength prediction methods for short fiber composites was proposed by H. T. Hahn in octoher of 1975 (38). Hahn proposed that the uniaxial tensile strength (X) can be determined from

$$
X=\int_{0}^{\pi} h(\theta) X_{\theta} d \theta
$$

where $h(\theta)$ is the through-the-thickness fiber distribution function and $x_{\theta}$ is the off-axis failure stress. The basic unit in this formulation is a ply reinforced with discontinuous fibers aligned in a direction $(\theta)$ with respect to the load axis. In Reference 38 , Hahn shows relatively good correlation between the predicted and experimental strength data for random fiber composites. Hahn assumes the orientation of each ply in the laminate is arbitrary so that the laminate as a whole is isotropic in its plane. Unfortunately, this assumption is not valid for injection molded components. Due to the flow of the material, the laminate is not isotropic in its plane. Therefore, the theory must be modified to be used for fiber reinforced, injection molded components.

In 1981, Fukuda and chou (39) proposed a theory for the strength of aligned short fiber composites based on a modified rule of mixtures approach. They proposed the uniaxial tensile strength (X) can be expressed as

$$
X=\left(\sigma_{f u} / K\right) V_{f}+\sigma_{m}^{\prime}\left(1-V_{f}\right)
$$

Where $\sigma_{f u}$ is the ultimate tensile strength of the fiber, $v_{f}$ is the fiber volume fraction, $\sigma_{m}^{\prime}$ is the matrix stress at the ultimate 
tensile strain of the fibers, and $K$ is the stress concentration of the fiber ends on an adjacent fiber. The stress concentration factor can th'n be found based on the work by Hedgepeth (40), Hedgepeth and Van Dyke (41), or Fukuda and Kawata (42). Fukuda and Chou also determined probability distributions for the aligninent of fiber ends. In 1982, Manders and chou (43) expanded this approach to include the probability of strength distributions along the length of the fibers.

Unfortunately, this method has three major assumptions which are violated in injection molded ceramic composites. First, Fukuda and chou define $\sigma_{m}$ ' as the matrix stress at fiber failure thereby assuming the fibers fail before the matrix. In ceramic composites, generally the reverse is true, and the matrix fails before the fibers. Second, Fukuda and chou assume the specimen fails entirely by fiber failure. However, for short fiber ceramic composites, fiber pullout may be the predominare failure mode. lastly, the method is restricted to axially aligned fibexs systems, and off-axis fiber orientations are not considered. Sanadi and Piggott (44 and 45) proposed a similar approach based on the rule mixtures. In this case,

$$
X=B_{3} B_{4} V_{f} \sigma_{f u}+V_{m} \sigma_{m u}
$$

where $B_{3}$ is a fiber direction factor, $B_{4}$ is a fiber length factor, $V_{f}$ is the fiber volume fraction, $\sigma_{f u}$ is the ultimate fiber strength, $V m$ is the matrix volume fraction, omu is the matrix stress at fiber failure. In reference 36 , sanadi and pigott assume $B_{3}$ and $\beta_{4}$ are independent of each other. $B_{3}$ is based on matrix transformation equations, and $B_{4}$ is based on a shear lag analysis. Later, Sanadi and Piggott (45) combine the two factors in a slip coefficient. Although this approach eliminates the restriction of aligned fiber systems, the approach still does not consider fiber pullout, matrix failure prior to fiber failures, and non-homogeneous fiber 
distributions in the plane of the specimen.

S.S. Wang et. al. (46) approached the strength of randomly oriented sheet molding compound from a fracture mechanics viewpoint. They considered the random short fiber SMC as a macroscopically planer, isctropic, elastic solid and determined the critical stress interibiry factors, $\mathrm{K}_{\mathrm{IQ}}$ and $\mathrm{K}_{\mathrm{IlQ}}$. They found both of these values were independent of crack length and could be used as material constants. For mixed-mode fracture, they found the stress intensity factors, $\mathrm{K}_{\mathrm{I}}$ and $\mathrm{K}_{\mathrm{II}}$, follow the relationship:

$$
\left(\mathrm{K}_{\mathrm{I}} / \mathrm{K}_{\mathrm{IQ}}\right)+\left(\mathrm{K}_{\mathrm{Il}} / \mathrm{K}_{\mathrm{IQQ}}\right)^{2}=1
$$

By modelling the SMC as an mi, roscopically isotropic solid, wang et. al. smeared the local orientation effects into global fracture toughness values. Unfortunately, for the injection molded composite problem, the material is not macroscopically isotropic, and the local orientation effects dominate the failure. Therefore, this approach cannot be used for the strength prediction of injection molded composites.

In 1987, Kageyama and Chou (47) also investigated the fracture toughness of short fiber composites. In this case, they considered whisker reinforced ceramic matrix composites and looked at the local effects of fiber orientations and locations. Their work incorporates a fracture mechanics analysis with both fiber pullout and crack deflection. Based on a distributed dislocation method, Kageyama and chou calculated $K_{I}$ and $K_{I I}$ as a function of fiber orientation. orce the fiber distribution is known, they can calculate an equivalent stress intensity factor, $K_{e q}$, and failure occurs when

$$
\mathrm{K}_{\mathrm{eq}}>\mathrm{K}_{\mathrm{cm}}
$$


where $k_{c m}$ is the critical stress intensity factor for the matrix. Unfortunately, $\mathrm{K}_{\mathrm{cm}}$ may be difficult to determine, and the interphase region may have an entirely different $\mathrm{K}_{\mathrm{cm}}$ for fiber pullout than for crack deflection. In addition, Kageyama and chou limited their analysis to random fiber distributions and orientations. Therefore, the method must be applied to known, nonhomogeneous fiber distributions.

All of these methods assume a weakest link concept for specimen failure. In other words, once a single point fails on the specimen, the entire specimen fails. However, for injection molded components, a progressive failure may be more apparent. For example, locations with fibers oriented at 90 degrees to the loading axis may fail at relatively low loads. However, the load from the failed regions is simply transferred to locations with more highly aligned fibers, and complete failure of the component occurs at a much higher load than the initial failure. Unfortunately, analysis of a progressive failure is mucil more difficult than a weakest link analysis.

Overall, four different approaches to predict strength of aligned or random short fiber reinforced composites have been considered. Hahn's approach and Kageyama and Chou's approach may be expanded to injection molded composites. In both cases, the methods must be modified to include the effects of known fiber distributions and orientations. In addition, the question of progressive failure must be addressed.

\subsection{Summary}

This literature review summarizes the available literature applicable to this research project. Several works were discussed in the areas of test methods, nondestructive examination and testing, strength prediction methods and damage development 
characterization. Although a significant amount of work has been completed in each of these areas, applications to injection molded ceramic matrix composites are very limited and sometimes nonexistent. Nevertheless, these works still provide a very strong foundation for the research effort. 


\subsection{TEST SPECIMENS AND MATERIALS}

Task 1 included a coordinated effort between the Materials Response Group, United Technology Research Center, and the Instron corporation to develop a testing capability for ceramic composite components. Major parallel parts of the effort were the design, analysis, and fabrication of a ceramic composite test specimen and the selection of an appropriate ceramic composite material for study.

A tubular test spcimen configuxation was selected to represent an engineering component. Several variations of the tubular specimen design were evaluated. All of the designs were analyzed using half-length, axisymmetric finite element models to determine the siress distributions in the specimen. Based on the results from these analyses and on input from the grip manufacturer, a final tube design was selected for fabrication. The following sections present detailed descriptions of the design options, analysis of each design, final design selection and fabrication of the selected design.

\subsection{Specimen Design Options}

Prior to developing candidate specimen designs, a set of design criteria was established. Due to manufacturing considerations, the length of the tube cannot exceed 8.00 inches. In acition, the ininimum length of the specimen is 6.00 inches in order to accommodate a 4.0 inch slot furnace and 1.0 inch length grip regions external to the furnace. The galge section was limited to a 1.00 inch minimum inside diameter and a 0.100 inch maximum wall thickness. This combination of gage section diameter and wall thickness should provide a relatively uniform shear stress distribution through the thickness when subjected to torsional loadings. The furnace will produce a 1.00 inch uniform temperature region. As a result, a minimum 1.00 inch uniform gage length was 
specified. Finally, in order to reduce bending stresses due to the gripping loads, graphite plugs will be inserted in the ends of the tube.

Based on this set of criteria, four designs were developed and analyzed in detail. All of the designs consist of an 8.00 inch molded tube with a 1.0 inside diameter. However, all of the designs have slightly different grip and grip to gage section transition regions.

The first design, shown in Figure 3.1, includes 1.4 inch long, molded conical grip regions which are tapered from 2.0 inches diameter at the outside end of the grip region to 1.50 inches diameter at the inside of the grip region adjacent to the transition region. The gage section is 2.0 inches long with a 0.100 inch wall thickness, and the transition from the grip region to the gage section is provided by a circular arc with an 8.92 inch radius. This circular arc forms a transition region which is tangent at both the gage section interface and the conical grip region interface. The specimen has 1.4 inch graphite plugs bonded into the ends of the molded tube. The design configuration will be called the short conical specimen.

The second design, shown in Figure 3.2 , is based on 1.9 inch long, molded conical grip regions which are tapered from 2.21 inches diameter at the outside end of the grip region to 1.50 


\section{-}

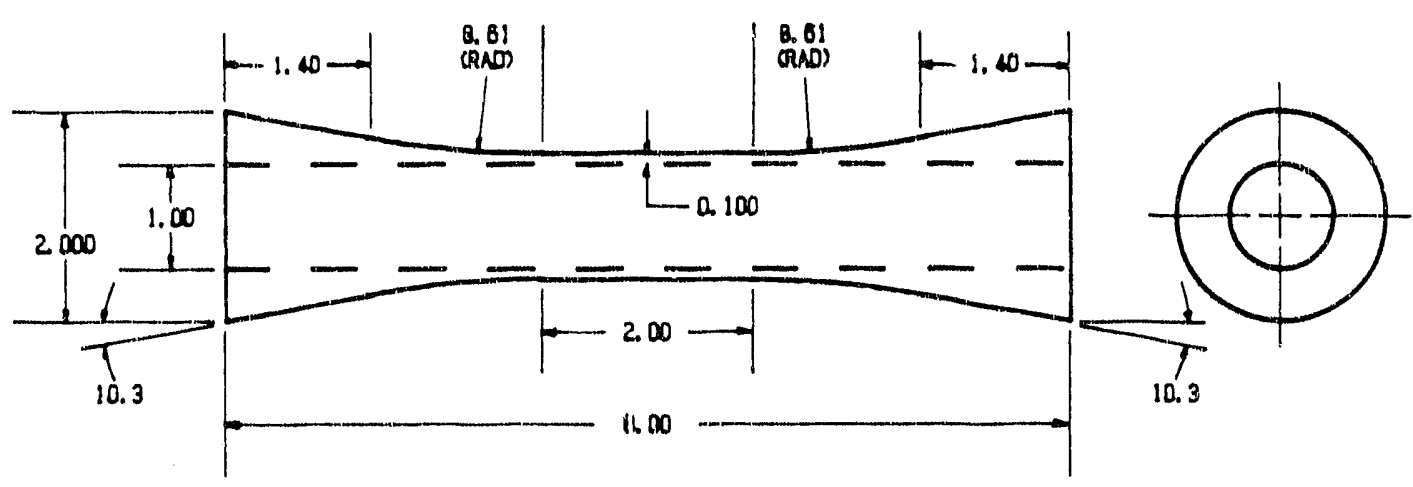

dimensions in inches

Fig. 3.I The short conical specimen.

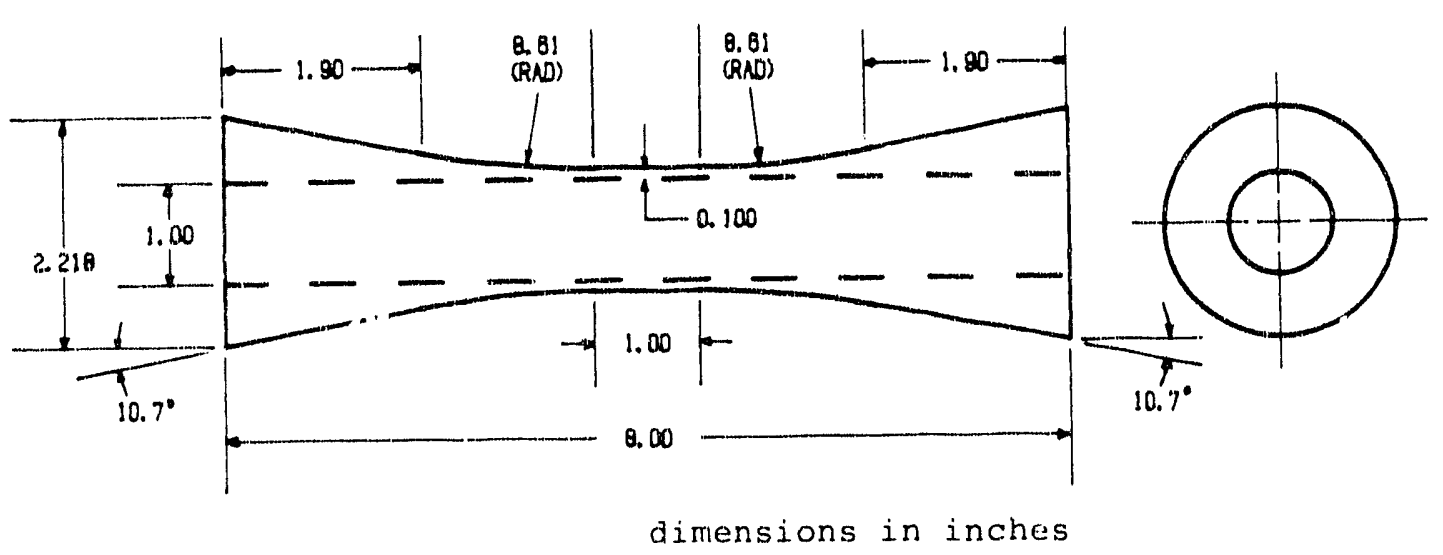

Fig. 3.2 The Long Conical specimen. 
inches diameter at the inside of the grip region adjacent to the transition region. The gage section is 1.0 inch long with a 0.100 inch wall thickness, and the transition from the grip region to the gage section is provided by a circular arc with an 8.61 inch radius. The circular arc also forms a transition region which is tangent at both the gage section interface and the conical grip region interface. The specimen has 1.9 inch graphite plugs bonded into the ends of the molded tube. The design configuration will be called the long conical specimen.

The third design contains a cylindrical grip region as shown in Figure 3.3. In this case, the molded grip regions are 1.35 inches in length with a uniform outside diameter of 1.52 inches. The grip regions are connected to a 2.00 inch gage section by circular transition regions with an 8.92 inch radius. The wall thickness in the gage section is also 0.100 inches. After molding, the grip regions are machined to $1.5000+.0005$ inch diameter, and 1.40 inch graphite plugs are bonded into the ends. The design will be termed the short cylindrical specimen.

The fourth design, shown in Figure 3.4, is based on longer cylindrical grip regions where the molded grip regions are 1.85 inches in length with a uniform outside diameter of 1.52 inches. The grip regions are connected to a 1.00 inch gage length by circular transition regions with an 8.92 inch radius. Again, the 

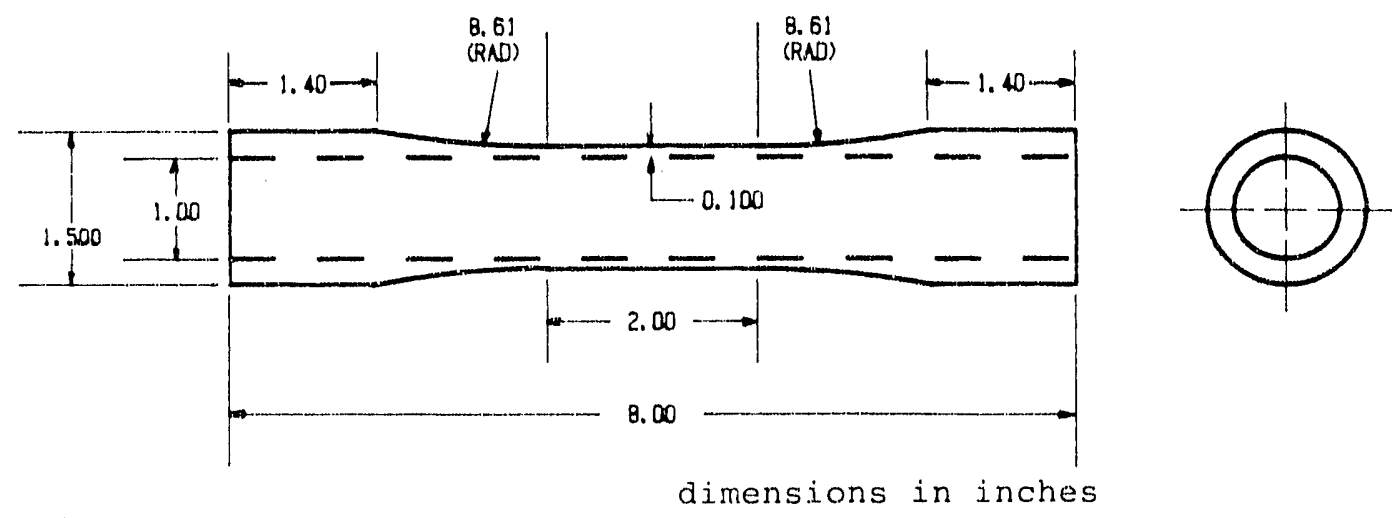

Fig. 3.3 The short Cylindrical specimen.
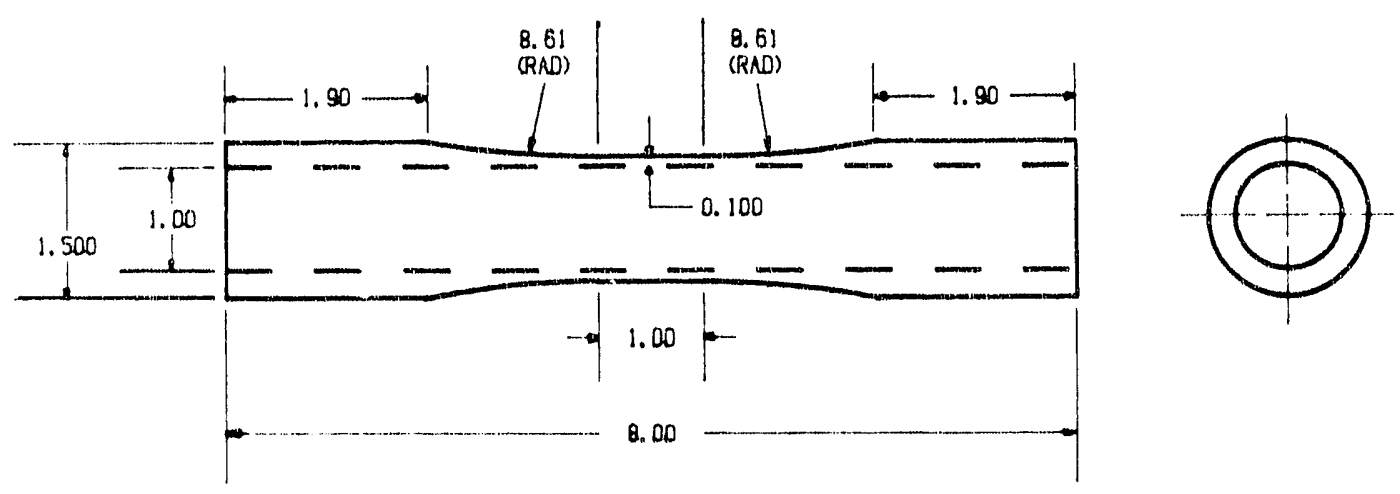

Fig. 3.4 The Long Cylindrical Specimen. 
wall thickness in the gage section is 0.100 inches. After molding, the grip regions are then machined to $1.5000+.0005$ inch diameter, and 1.90 inch graphite plugs are then bonded into the ends. The design will be termed the long cylindrical specimen.

\subsection{Specimen Analysis}

\subsubsection{Model Development.}

The four designs were analyzed using the ANSYS PC/LINEAR finite element code (48). Half-length, axisymmetric models of the tube assemblies (including plugs) were developed for all four specimens using 4-node isoparametric elements (STIF 42) The finite element meshes for each of these models are shown in Figure 3.5 . Typical material properties for HMU graphite fibers in a borosilicate glass matrix ( 0.5 inch fiber length, 25 to $30 \%$ fiber volume), based on tensile test data provided by UTRC (United Technologies Research center), are shown in Table 3.1. For this analysis, $r, \phi$, and $z$ are the cylindrical coordinates in the radial, hoop and axial directions respectively. E, G, and $v$ are Young's modulus, shear modulus, and Poisson's ratio respectively. 
Table 3.1 Material Properties.

HMU Graphite Fibers in a Borosilicate Glass Matrix ( 0.5 inch Fiber Length, 25 to $30 \%$ Fiber Volume)

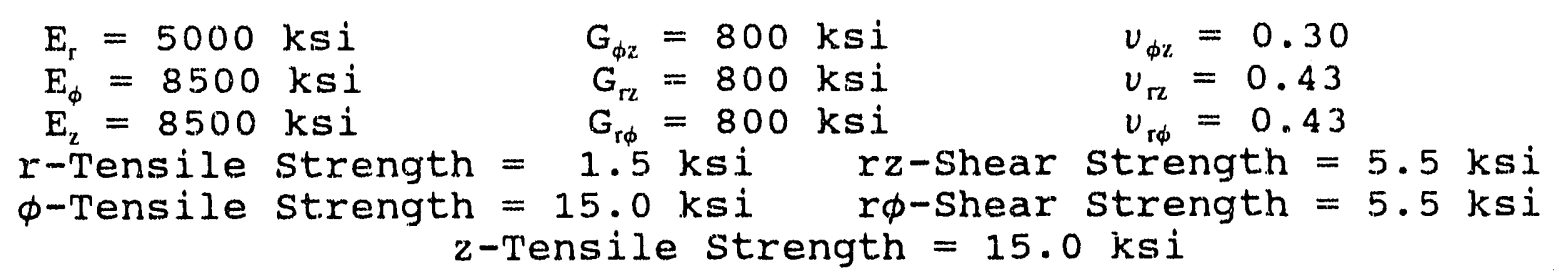

HLM Grade Graphite

$\begin{array}{llll}\mathrm{E}_{\mathrm{r}}=2300 \mathrm{ksi} & \mathrm{G}_{\phi \mathrm{z}}=880 \mathrm{ksi} & v_{\phi \mathrm{z}}=0.30 \\ \mathrm{E}_{\phi}=2300 \mathrm{ksi} & \mathrm{G}_{\mathrm{rz}}=880 \mathrm{ksi} & v_{\mathrm{rz}}=0.30 \\ \mathrm{E}_{\mathrm{z}}=2300 \mathrm{ksi} & \mathrm{G}_{\mathrm{r}}=880 \mathrm{ksi} & v_{\mathrm{r} \phi}=0.30 \\ \mathrm{r}-\text { Tensile Strength } & =2.5 \mathrm{ksi} & \text { r-Compressive Strength }=6.2 \mathrm{ksi} \\ \phi \text {-Tensile Strength } & =2.5 \mathrm{ksi} & \phi \text {-Compressive Strength }=6.1 \mathrm{ksi} \\ \text { z-Tensile strength } & =2.5 \mathrm{ksi} & \text { z-Compressive Strength }=6.1 \mathrm{ksi}\end{array}$

The material properties of the plug are based on a HLM grade graphite supplied by the Great Lakes Carbon Corporation. These properties are also shown in Table 3.1. Although shear strengths of the graphite plugs were not available, the shear stresses in the graphite plugs were very small; and therefore, shear failure of the plug was not considered.

Displacements are denoted as $U_{r}, U_{\theta}$, and $U_{z}$. Two displacement boundary conditions and one loading condition were imposed on the models. The first displacement boundary condition corresponds to the base of the conical specimens contacting the bottom of the grip as a result of the preloading. In this case, $\mathrm{U}_{\mathrm{z}}=0$ along the base of the conical tube. The second displacement boundary conditions arises from the symmetry of the specimen about the z-axis. In order to satisfy compatibility along the centerline of the specimen, $U_{r}=0$ at $r=0$. These boundary conditions are shown in Figure 3.6 for the long conical specimen. 

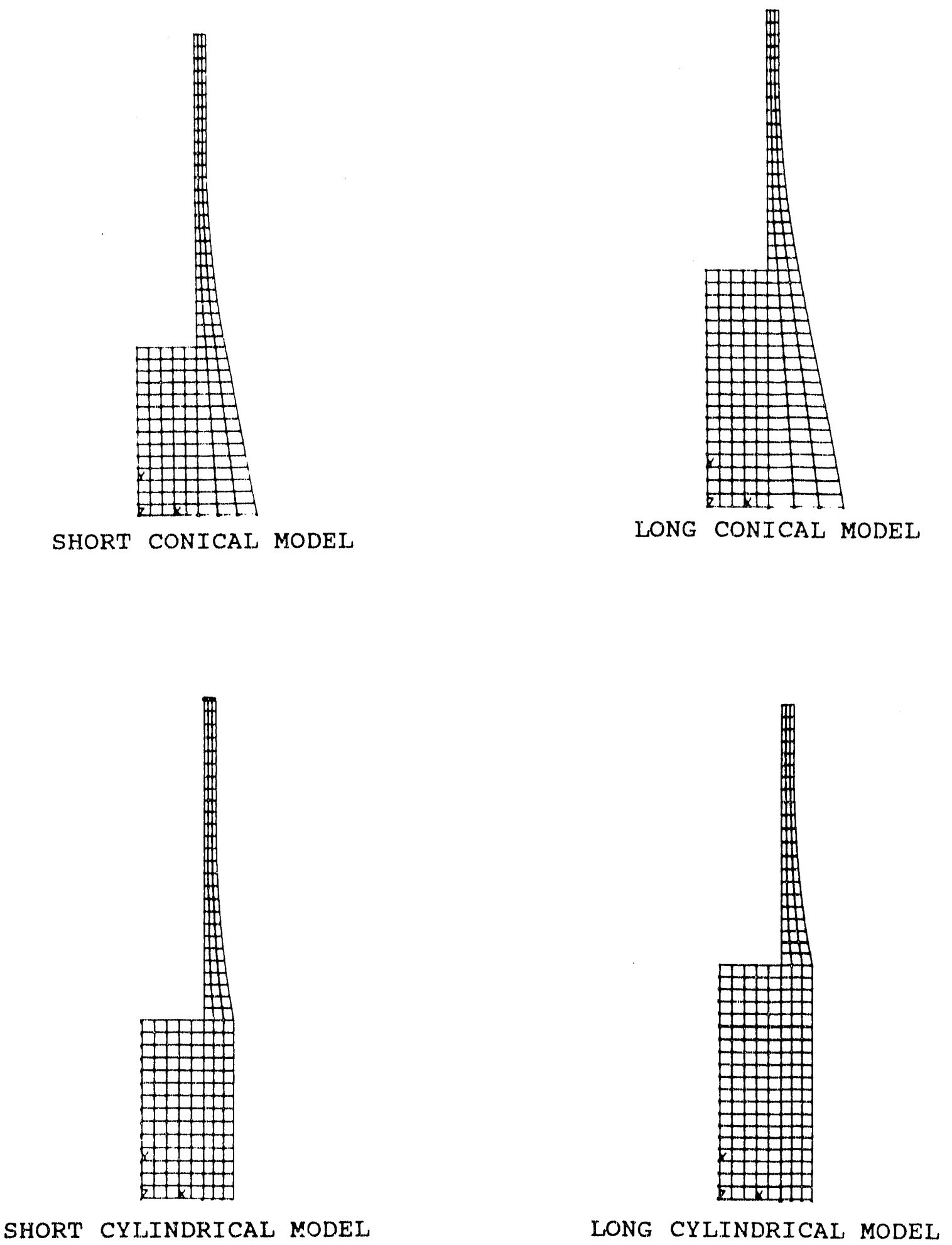

SHORT CYI.INDRICAL MODEL

LONG CONICAL MODEL

\section{-}

SHORT CONICAL MODEL

Fig. 3.5 The Finite Element Meshes. 
The loads in the specimen consist of axial, tensile loads in the gage section and grip loads in the grip region. The axial loads in the gage section were applied by means of a distributed pressure load $\sigma_{z}$ along the top of the specimen. The magnitude of the pressure loads equals the tensile failure stress of the material (15.0 ksi) in the gage section. For all of these designs, the $15.0 \mathrm{ksi}$ failure stress is produced by a $5.18 \mathrm{kip}$ axial load. The grip loads consist of uniformly distributed radial and axial loads at the grip interface nodes. In the case of the conical specimens, a compliant layer will be placed between the specimen and the grip housing in order to absorb some of the manufacturing variations. Therefore, as a first approximation, this compliant layer cannot transfer shear or frictional forces leaving normal forces as the only type of forces acting across the interface.

For the two cylindrical specimens, the axial failure load ( 5.18 kips) must be counteracted by frictional forces along the gripping length. If a friction factor of 0.6 between the tube material and the grip housing, based on Reference 50 for glass on steel, the minimum radial load to hold the specimen is given by $5.18 / 0.6$ or $8.64 \mathrm{kips}$. In order to provide some margin above the minimum grip load, a $10 \mathrm{kip}$ total radial, grip load is applied on the model. This completes the development of the ANSYS PC/LINEAR finite element models. All of these analyses were then executed on a HP VECTRA personnel computer. The results of these analyses are described in the following sections.

\subsubsection{Design Allowables}

In order to evaluate the acceptability of each of the designs, two types of stress criteria must be specified. First, a 1.05 maximum allowable stress concentration factor is specified in the transition regior near the gage section. Second, the allowable 


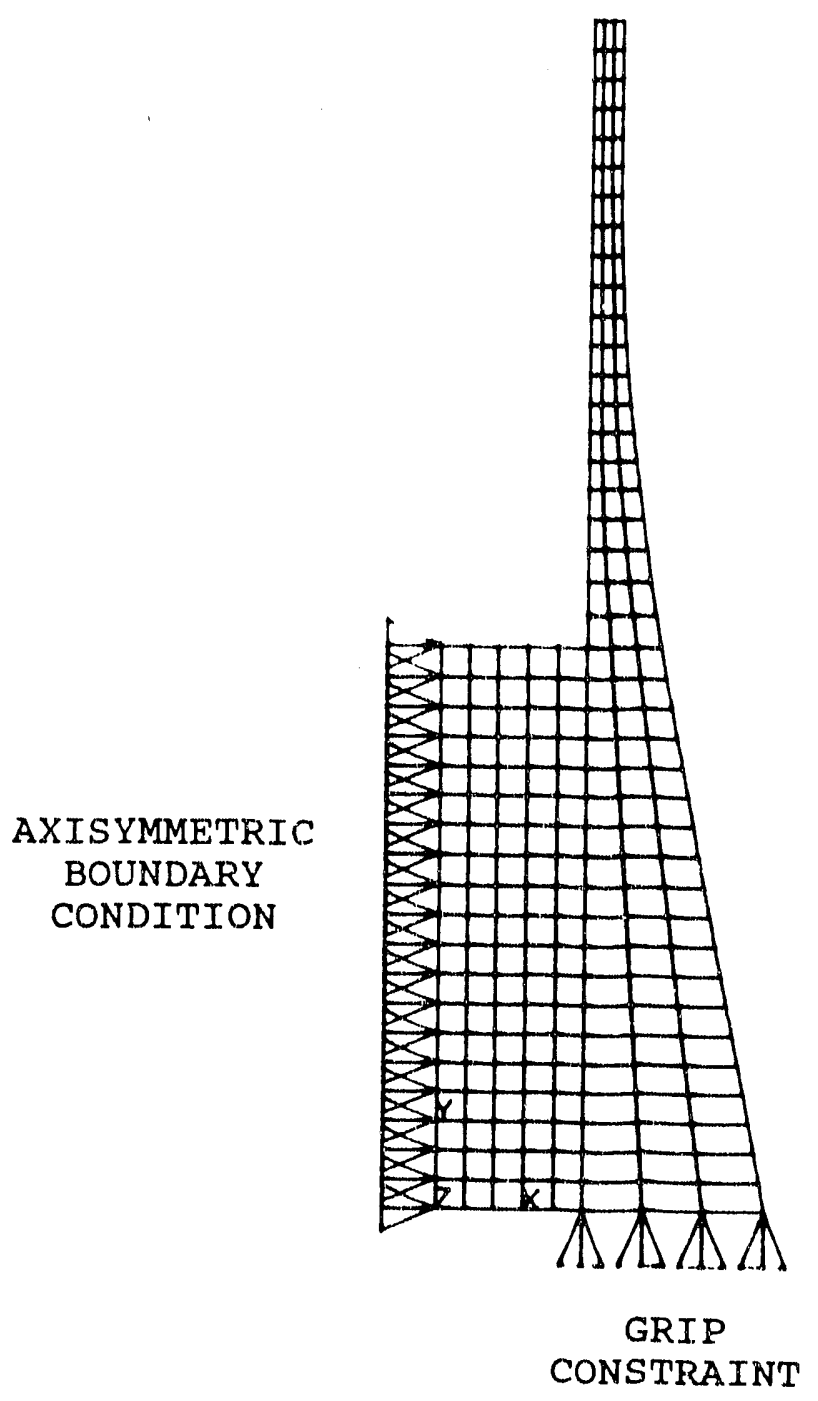

Fig. 3.6 Boundary Conditions on the Long Conical Model. 
design stresses for the tube and the plug in the grip region must be specified. Unfortunately, the failure stresses provided by UTRC and Great Lakes Carbon are approximate and, in some cases, nonexistent. Therefore, a set of allowable design stresses based on the information provided were developed. For the tube, a design tensile stress of $50 \%$ of the tensile strengths, and the design compressive stresses of $100 \%$ of the tensile strengths were specified. The design shear stresses were $50 \%$ of the shear strengths. For the plug, the design tensile stresses were $50 \%$ of the tensile strengths, and the design compressive stresses were $50 \%$ of the compressive strengths. The design shear stress of the plug was $25 \%$ of the tensile strength. The resultiny allowable design stresses are shown in Table 3.2. Notice, these design stresses will only be used in the vicinity of the grip region and the plug since the applied stresses in the gage section equal the provided failure stress. As a result, the stress in the grip region should have a $100 \%$ safety factor at failure in the gage section.

Table 3.2 Allowable Design Stresses.

$\begin{array}{ccc}\text { Component } & \text { Mode } & \text { Design Stress (Ksi) } \\ \text { Tube } & r-\text { Tens } & 0.75 \\ \text { Tube } & r-\text { Comp } & 1.5 \\ \text { Tube } & \phi-\text { Tens } & 7.5 \\ \text { Tube } & \phi-\text { Comp } & 15.0 \\ \text { Tube } & z-\text { Tens } & 7.5 \\ \text { Tube } & z-\text { Comp } & 15.0 \\ \text { Tube } & r z-\text { Shr } & 2.3 \\ \text { Plug } & r-\text { Tens } & 1.2 \\ \text { Plug } & r-\text { Comp } & 3.1 \\ \text { Plug } & \phi-\text { Tens } & 1.2 \\ \text { Plug } & \phi-\text { Comp } & 3.0 \\ \text { Plug } & z-\text { Tens } & 1.2 \\ \text { Plug } & z-\text { Comp } & 3.0 \\ \text { Plug } & r z-\text { Shr } & 0.63 \\ & & \end{array}$

\section{2 .3 Finite Element Results.}

All four models were used for detailed analyses of the stress distributions due to two different load cases. The first load case 
considered grip loads only, and the second load case considered grip loads plus axial loads. The short models and the long conical model exhibited higher stresses than the long cylindrical models. In addition, the radial compressive stresses did not meet the design criteria in either the tube or the plug. Therefore, only the results for the long cylindrical model are presented.

The first load case investigates the internal stresses in the long cylindrical model when subjected to radial grip loads only. The maximum stresses for this load case are presented in Table 3.3 . Next the combined grip loads plus axial loads on the long cylindrical model, and Table 3.4 summarizes the maximum grip stresses for this load case. Notice, the predicted stresses for both load cases are less than the allowable design stresses. Figure 3.7 presents the axial stress contours in the tube as a result of the combined loading. As shown in Figure 3.7 , the stress concentration factor at the gage section is 1.03, which is acceptable. Therefore, this design meets all of the design criteria.

$\begin{array}{ccccc}\text { Table 3.3 } & \text { Grip Stresses for the Long Cylindrical Model } \\ \text { Subjected to Grip Loads Only. } \\ \text { COMPONENT } & \text { STRESS } & \text { TENS/COMP } & \text { MAGNITUDE (Ksi) } & \text { ALLOWABLE (Ksi) } \\ \text { Tube } & \sigma_{\mathrm{r}} & \text { Tens } & 0.07 & 0.75 \\ \text { Tube } & \sigma_{\mathrm{r}} & \text { Comp } & 1.49 & 1.50 \\ \text { Tube } & \sigma_{\mathrm{z}} & \text { Tens } & 0.48 & 7.50 \\ \text { Tube } & \sigma_{\mathrm{z}} & \text { Comp } & 0.55 & 15.00 \\ \text { Tube } & \sigma_{\phi} & \text { Tens } & 0.14 & 7.50 \\ \text { Tube } & \sigma_{\phi} & \text { Comp } & 2.60 & 15.00 \\ \text { Tube } & \tau_{\mathrm{r}} & \text { Shear } & 0.21 & 2.30 \\ \text { Plug } & \sigma_{\mathrm{r}} & \text { Tens } & 0.13 & 1.20 \\ \text { Plug } & \sigma_{\mathrm{r}} & \text { Comp } & 0.95 & 3.00 \\ \text { Plug } & \sigma_{\mathrm{z}} & \text { Tens } & 0.04 & 1.20 \\ \text { Plug } & \sigma_{\mathrm{z}} & \text { Comp } & 0.26 & 3.00 \\ \text { Plug } & \sigma_{\phi} & \text { Tens } & 0.13 & 1.20 \\ \text { Plug } & \sigma_{\phi} & \text { Comp } & 0.95 & 3.00 \\ \text { Plug } & \tau_{\mathrm{rz}} & \text { Shear } & 0.17 & 0.63\end{array}$




\begin{tabular}{|c|c|c|c|c|}
\hline COMPONENT & STRESS & TENS / COHP & MAGNITUDE (Ksi) & ALLOWABLE (Ksi) \\
\hline Tube & $\sigma_{r}$ & Tens & 0.13 & 0.75 \\
\hline Tube & $\sigma_{r}$ & Comp & 1.49 & 1.50 \\
\hline Tube & $\sigma_{z}^{2}$ & Tens & 7.37 & 7.50 \\
\hline Tube & $\sigma_{z}$ & Comp & 3.05 & 15.00 \\
\hline Tube & $\sigma_{\phi}^{2}$ & Tens & 0.64 & 7.50 \\
\hline Tube & $\sigma_{\phi}^{\dagger}$ & Comp & 3.88 & 15.00 \\
\hline Tube & $\tau_{r z}^{\varphi}$ & Shear & 1.03 & 2.30 \\
\hline Plug & $\sigma_{r}$ & Tens & 0.00 & 1.20 \\
\hline Plug & $\sigma_{r}^{2}$ & Comp & 1.28 & 3.00 \\
\hline Plug & $\sigma_{z}$ & Tens & 1.15 & 1.20 \\
\hline Plug & $\sigma_{z}$ & Comp & 0.08 & 3.00 \\
\hline Plug & $\sigma_{\phi}$ & Tens & 0.00 & 1.20 \\
\hline Plug & $\sigma_{\phi}$ & comp & 1.28 & 3.00 \\
\hline Plug & $\tau_{\mathrm{rz}}$ & Shear & 0.35 & 0.63 \\
\hline
\end{tabular}

\subsubsection{Model Verification}

In order to verify the sensitivity of the models, several parameter studies were performed using the long cylindrical model. The first study considered the effects of a refined mesh throughout the tube. The second parameter study investigated the effects of variations in the shear stiffness of the material. The shear stiffness used throughout the previous analyses was based on an engineering judgement by UTRC. Therefore, the effect of increasing the shear stiffness from $800 \mathrm{ksi}$ to $2500 \mathrm{ksi}$ was considered. The third parameter study investigated the effects of the distribution of the applied loads along the grip length.

In this study, a ramp loading distribution was considered instead of a uniform distribution, as in the original model. Comparison of the results of each of these parameter studies to the original finite element results indicated that the parameters had no significant effects on the stress distributions within the model. 


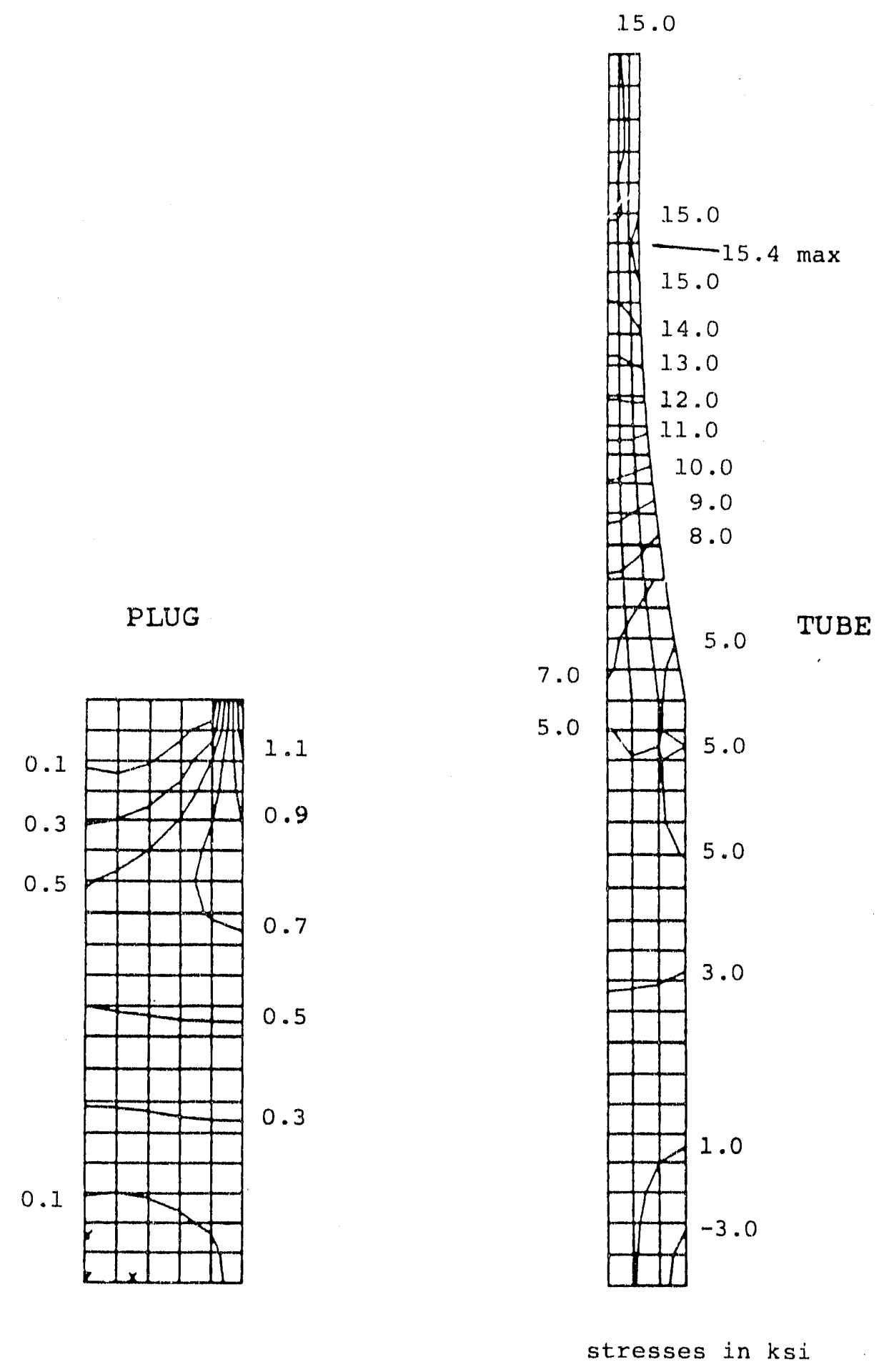

Fig. 3.7 Axial stress Contours for the Long Cylindrical Model Subjected to Grip Plus Axial Loads. 
As a final verification check, the finite element results were compared with the results of a plane deformation elasticity solution for an infinite tube. The development of the plane deformation elasticity solution is described in Reference 49. For the finite element results, the load case had a $10 \mathrm{kip}$ grip load uniformly distributed throughout the grip region. The uniform grip load is equivalent to a uniform external pressure of $1.41 \mathrm{ksi}$. The elasticity solution considers an infinite tube with two layers subjected to a $1.41 \mathrm{ksi}$ external pressure. The inner layer models the graphite plug with an inner radius of 0.00 inches and a outer radius of 1.00 inches. The outer layer models the reinforced tube with an inner radius of 1.00 inches and an outer radius of 1.50 inches. The material properties for two layers are identical to the material properties used in the finite element analyses.

Figures 3.8 and 3.9 compare the compressive radial stresses and the compressive hoop stresses for the two solutions. The finite element results are taken at $z=0.75$ which corresponds to the center of the grip. Comparison of the two sets of results shows excellent agreement between the two solutions.

Based on these parameter studies and the verification check, the finite element models behave correctly and produce accurate results for the assumptions used in the development of the models. Unfortunately, some of these assumptions cannot be verified with these types of analyses. The two main assumptions which fall into this category are the assumption of a uniform applied load distribution in the grips and the assumption of uniform material properties throughout the tube. As will be described later, the material properties are not uniform along the length of the tube. As a result, the specimens consistently failed outside the gage section. 


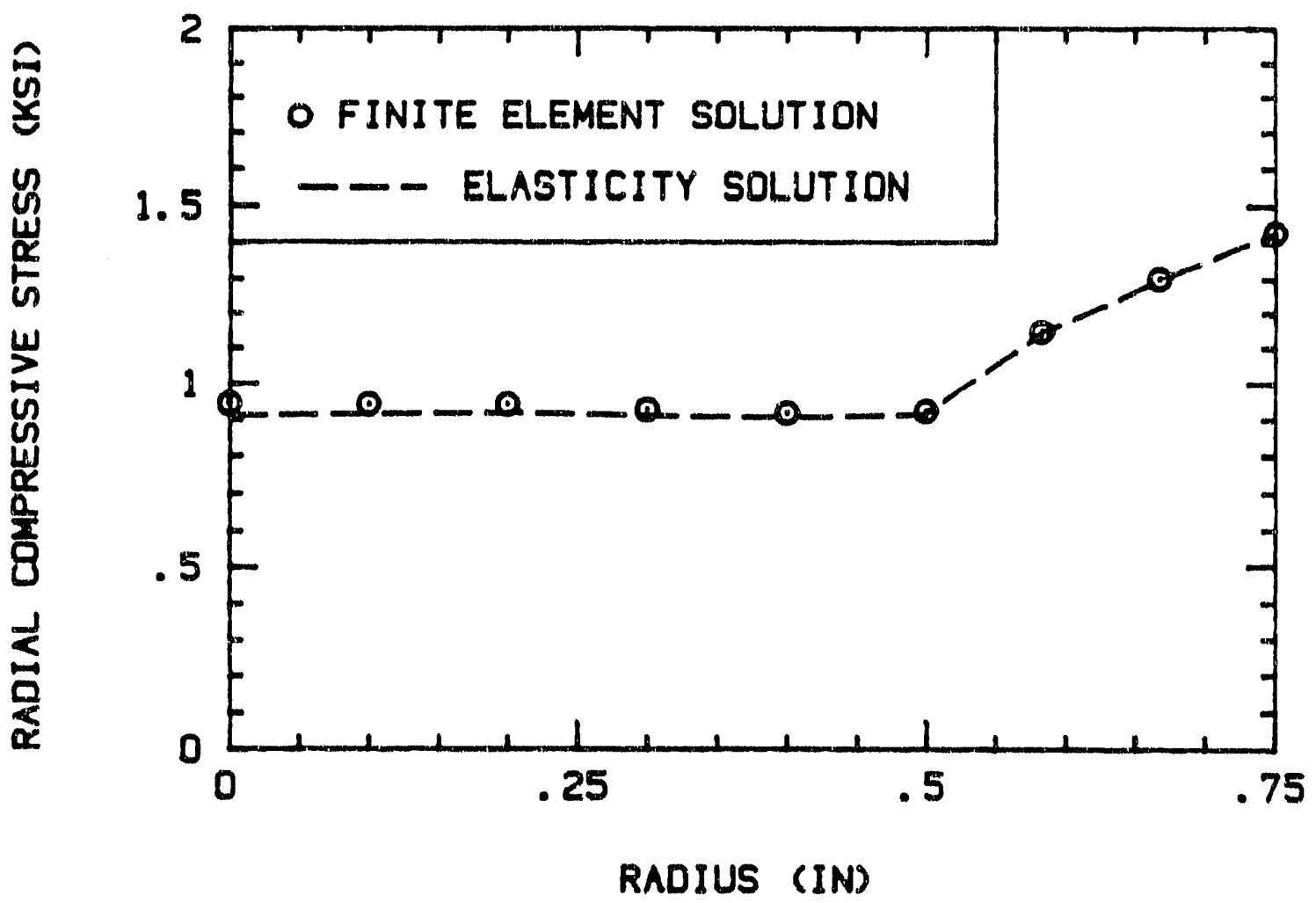

Fig. 3.8 Comparison of the Compressive Radial stresses for the Finite Element and Elasticity Solutions.

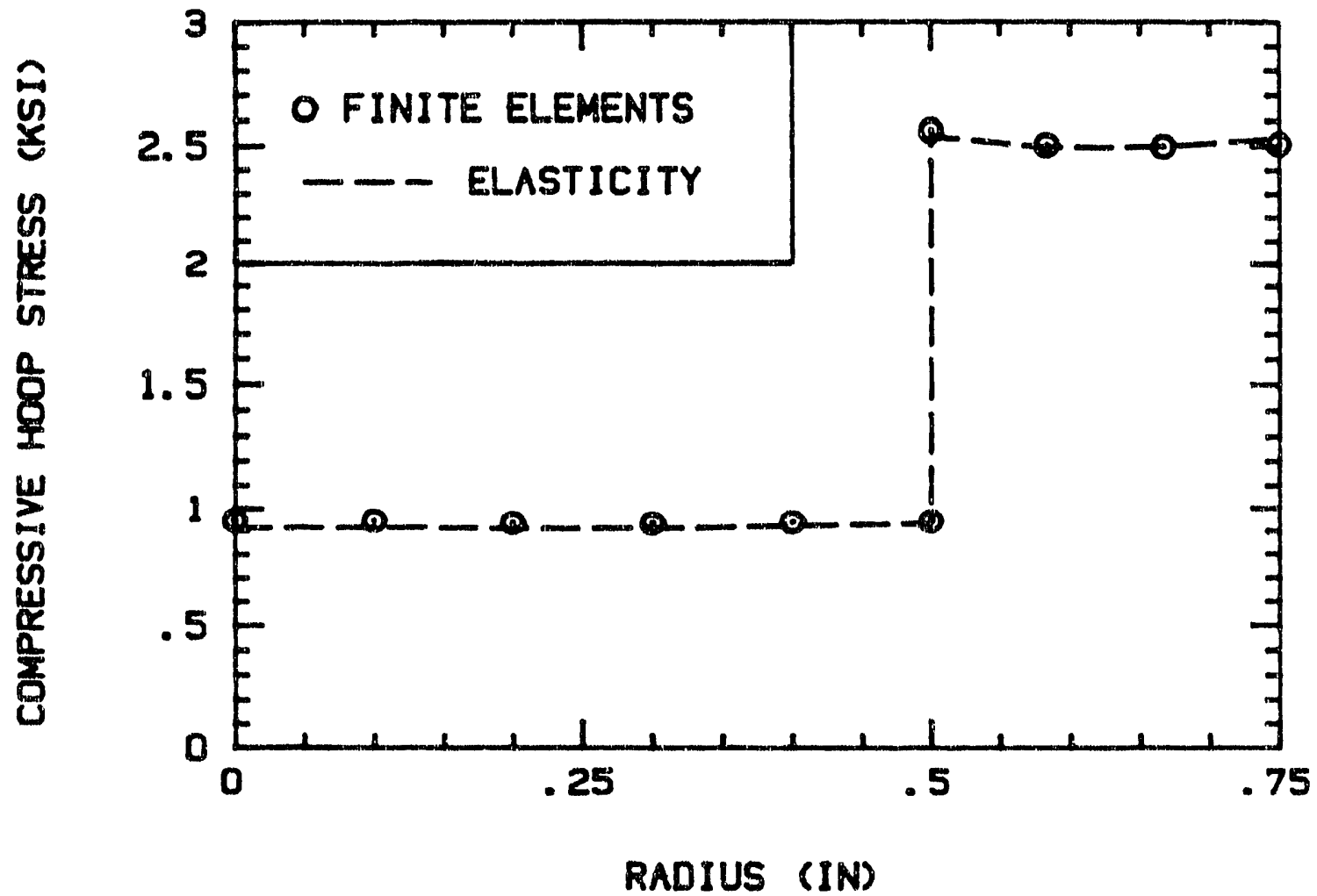

Fig. 3.9 Comparison of the compressive Hoop stresses for the Finite Element and Elasticity Solutions. 


\subsection{Final Design Selection}

Based on the finite element analyses, the only design which satisfied all of the design criteria was the long cylindrical specimen. In addition, the grip manufacturer (Instron corporation) strongly recommended a cylindrical grip region. The conical designs require very high tolerances on the cone angle, and these tolerances are difficult, if not impossible, to hold. The cylindrical designs are not as sensitive to machining tolerances. Therefore, based on the finite element analyses and Instron's recommendation, the long cylindrical design was selected for fabrication.

\subsection{Materials and specimen Fabrication}

Several methods were investigated for fabrication of the test specimens. These methods include chemical vapor infiltration (CVI), hot pressing, matrix transfer, and injection molding. All of the these methods are summarized in Reference 3. The first three meshods can be used to fabricate a continuous fiber reinforced specimen. However, injection molding is limited to chopped fiber materials. Although all of these methods are still in the highly developmental stages, the injection molding process was further developed and was capable of producing the complex tubular shape.

Therefore, in order to avoid a long and costly specimen fabrication program, the specimens were fabricated by an injection molding process with chopped fiber reinforcement. Unfortunately, an injection molding process offers very little control over fiber distribution and fiber directions in the finished specimen. The fiber distributions vary through the thickness, along the length and around the circumference. These variations are dependent on the flow of the composite compound into the mold. As a result, detailed and crucial identification of the fiber flow pattern is 
difficult. Variability between individual chopped fiber reinforced specimens will also be greater than that between continuous reinforced specimens. To avoid most of the fiber distribution concerns with chopped fibers and to work with a higher strength component, we recommend a change to a continuous fiber reinforced specimen when the material systems have been developed and fabrication methods have been successfully demonstrated.

\subsubsection{Material Selection.}

Several material systems, including SiC/SiC, LAS Glass/SiC, LAS Glass/Graphite, and Borosilicate Glass/Graphite were considered for the specimens. Sic/Sic was not compatible with the injection molding process and was immediately ruled out. Although the LAS Glass systems were very attractive, the specimen manufacturer (United Technologies Research Center - UTRC) was not experienced with fabrication of complex tubular configurations using this material. However, UTRC did have experience with the fabrication of straight sided tubes with the Borosilicate Glass/Graphite system. Therefore, in order to avoid an extensive and costly material development program, a Borosilicate Glass/Graphite system was selected for the specimens. Although the Borosilicate Glass/Graphite system is limited to $600^{\circ} \mathrm{F}$, it does provide an excellent fiber reinforced brittle matrix composite for room temperature investigations. In addition, all of the damage characteristics of ceramic matrix composites including fiber bridging, fiber pullout, and fiber matrix disbonding can be observed in the Borosilicate Glass/Graphite system.

\subsubsection{Fabrication Process.}

The details of the fabrication process are considered proprietary by UTRC and will not be covered in this report. However, since the fabrication process is critical to the state of material of the specimen, a brief summary of the process is 
provided. A diagram of the injection molding assembly is shown in Figure 3.10. Glass beads and chopped fibers are thoroughly mixed and then added to the reservoir. The mixture is heated to produce a viscous molding compound and pushed from the reservoir, through four symmetrically placed holes in the end plate, and into the mold. This end plate with four holes is very important to the fiber flow pattern and should be remembered when viewing the results of the NDE methods. The assembly is then cooled prior to removing the interior rod and exterior mold. The exterior mold is a continuous piece of graphite and must be machined in half for removal. The surface finish on the outside of the tube is very good and no additional machining is required in the gage section or transition regions. The inside rod is also made of graphite and must be removed by machining. In some cases, a scale was left on the inside sur zce of the tube, and this scale will affect some of the NDE results as will be discussed later. The outside of the grip regions are then machined in order to obtain proper gripping tolerances. In retrospect, the outside machining of the grip areas is probably unnecessary.

In order to accurately reference the various parts of the tube, the tube is divided into five regions (Figure 3.11). The terms upstream and downstream are based on the flow direction of the molding compound and are required due to differences in the fiber distributions in the different regions. For example, the fiber distribution in the upstream transition region is significantly different than the distribution in the downstream transition region. These differences have a major effect on the failure location in the specimen and are readily observed by some of the NDE methods.

Eight specimens were fabricated and were used throughout this investigation. The first specimen (118-89) was fabricated with 0.5 inch chopped graphite fibers. Figure 3.12 presents a photograph of specimen 118-89 with strain gages attached and the end plugs 
removed. During fabrication, the specimen did not release cleanly from the mold, and several large chips were taken from the surface of the specimen. Examples of these types of chips are shown in Figure 3.13. Specimen 119-89 was fabricated with 0.38 inch fibers and also contained chips. Further investigation of the molding assembly indicated the chips were due to a poor surface finish in the transition regions of the graphite mold. The molds were then reworked, and the chip problem was nearly eliminated. All the subsequent specimens were fabricated with a 0.38 inch chopped graphite fiber. Ir addition to the chips in specimens $118-89$ and 119-89, specimen 262-89 contained a small 1.0 inch axial stress crack extending from the downstream transition region and halfway into the gage section. Similarly, specimen 264-89 contained a 3.0 inch axial crack extending from the downstream transition region, through the gage section, and nearly along the entire length of the upstream transition region. These cracks are thought to be the result of final machining of the inside diameter. Specimens 258-89 through 261-89 did not have any visible defects on the surface. Physical property data for all of the test specimens are summarized in Table 3.5 . 


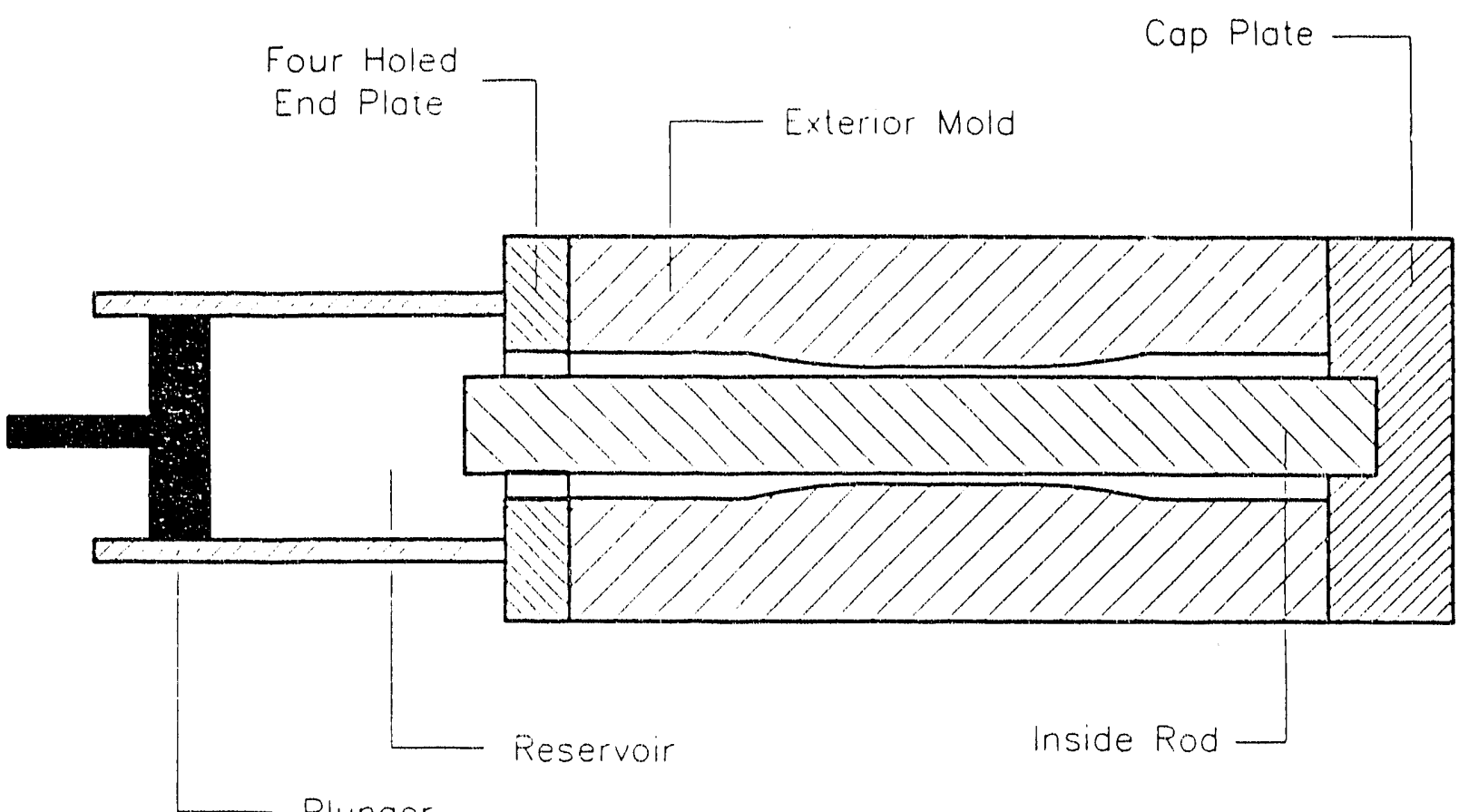

Plunger

Fig. 3.10 The Injection Molding Assembly.

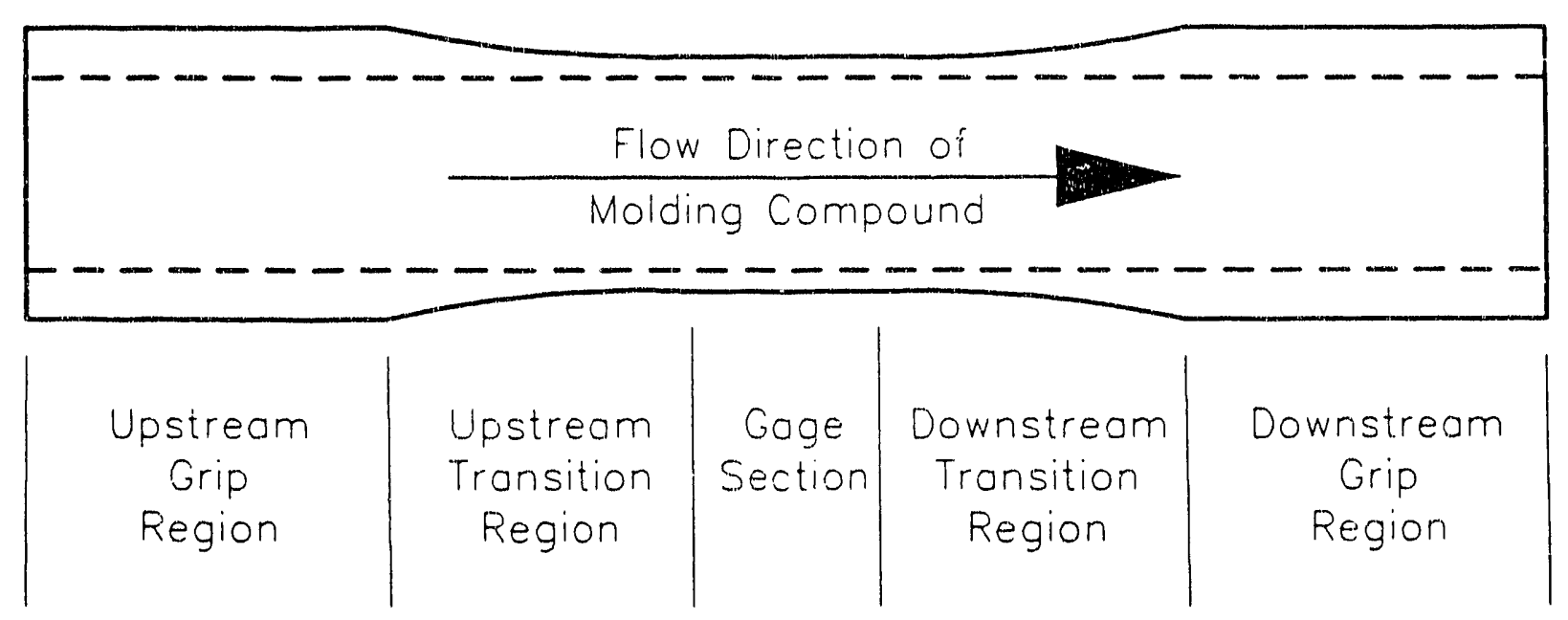

Fig. 3.11 Regions of the Tube. 


\section{SPECIMEN}

1/8-89

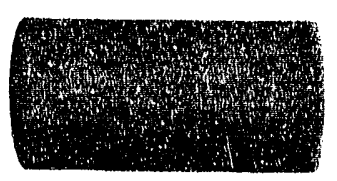

GRAPHITE

PLUG

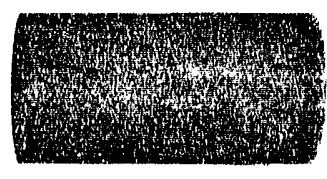

GRAPHITE

PLUG

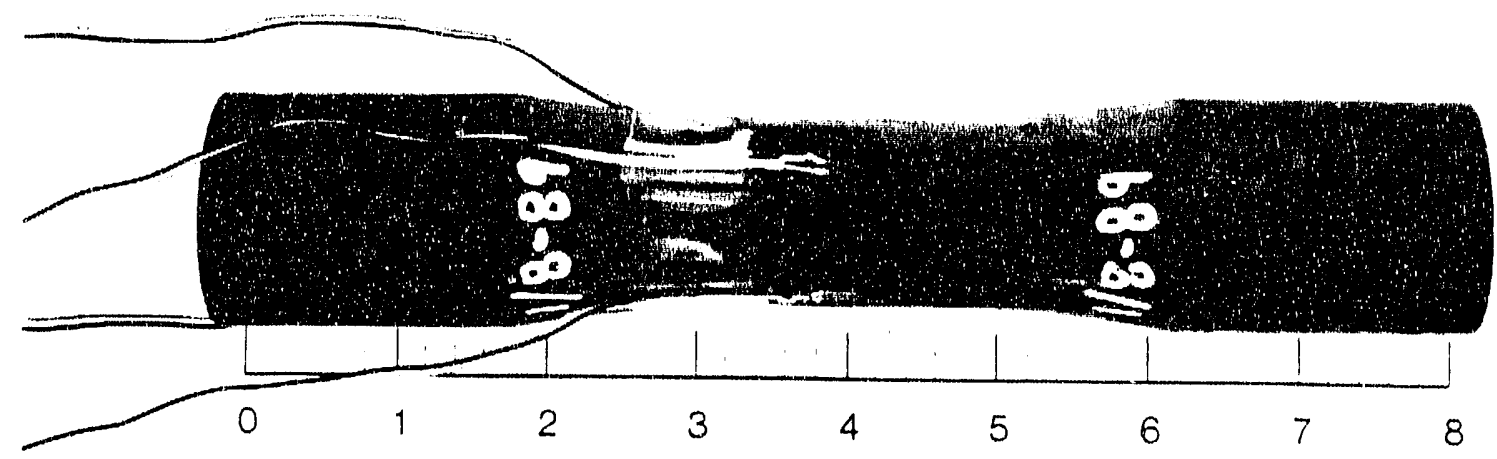

Fig. 3.12 Specimen 118-89 with Strain Gages Attached and End Plugs Removed.

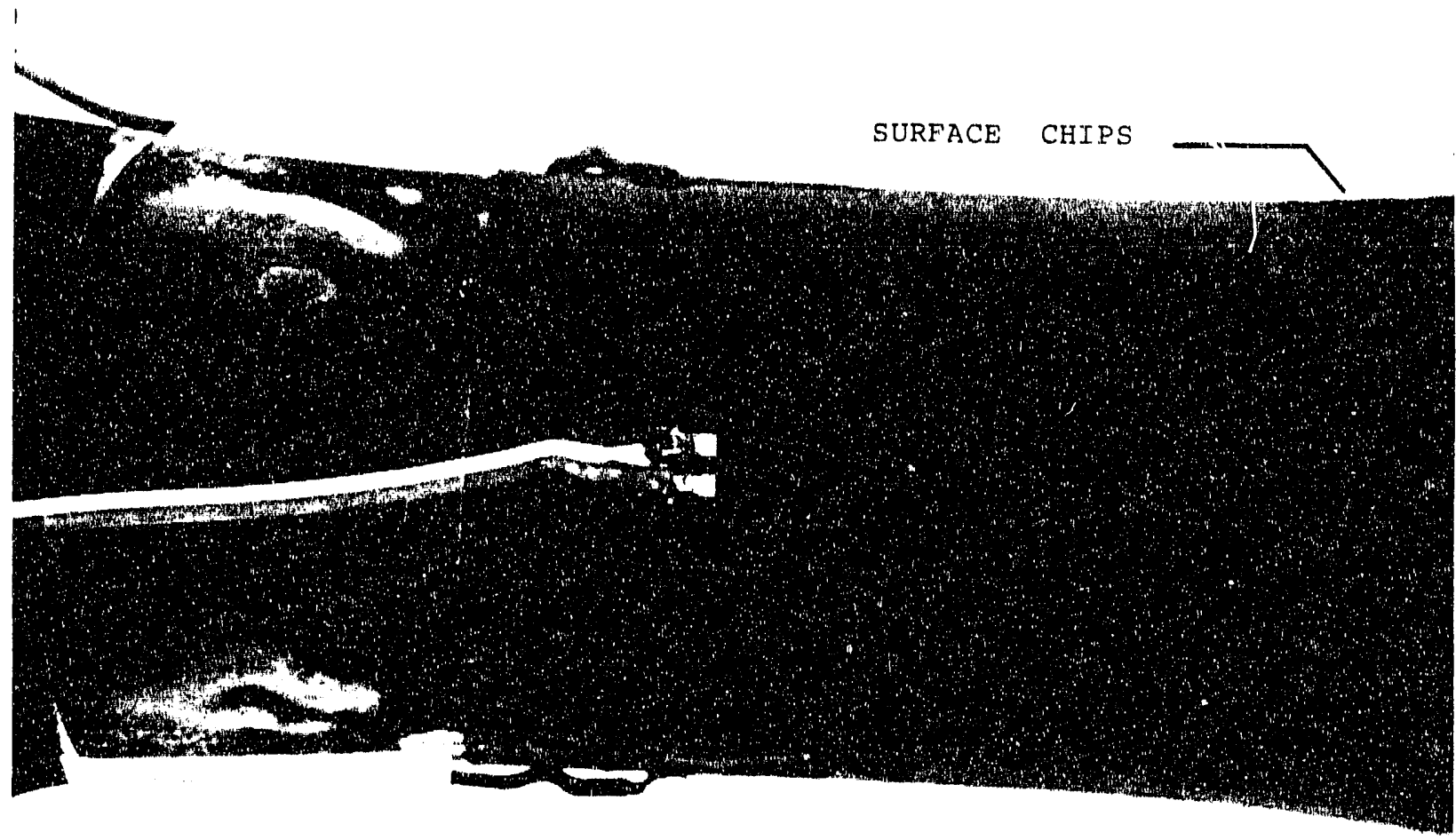

Fig. 3.13 surface Chips in Specimen 118-89. 


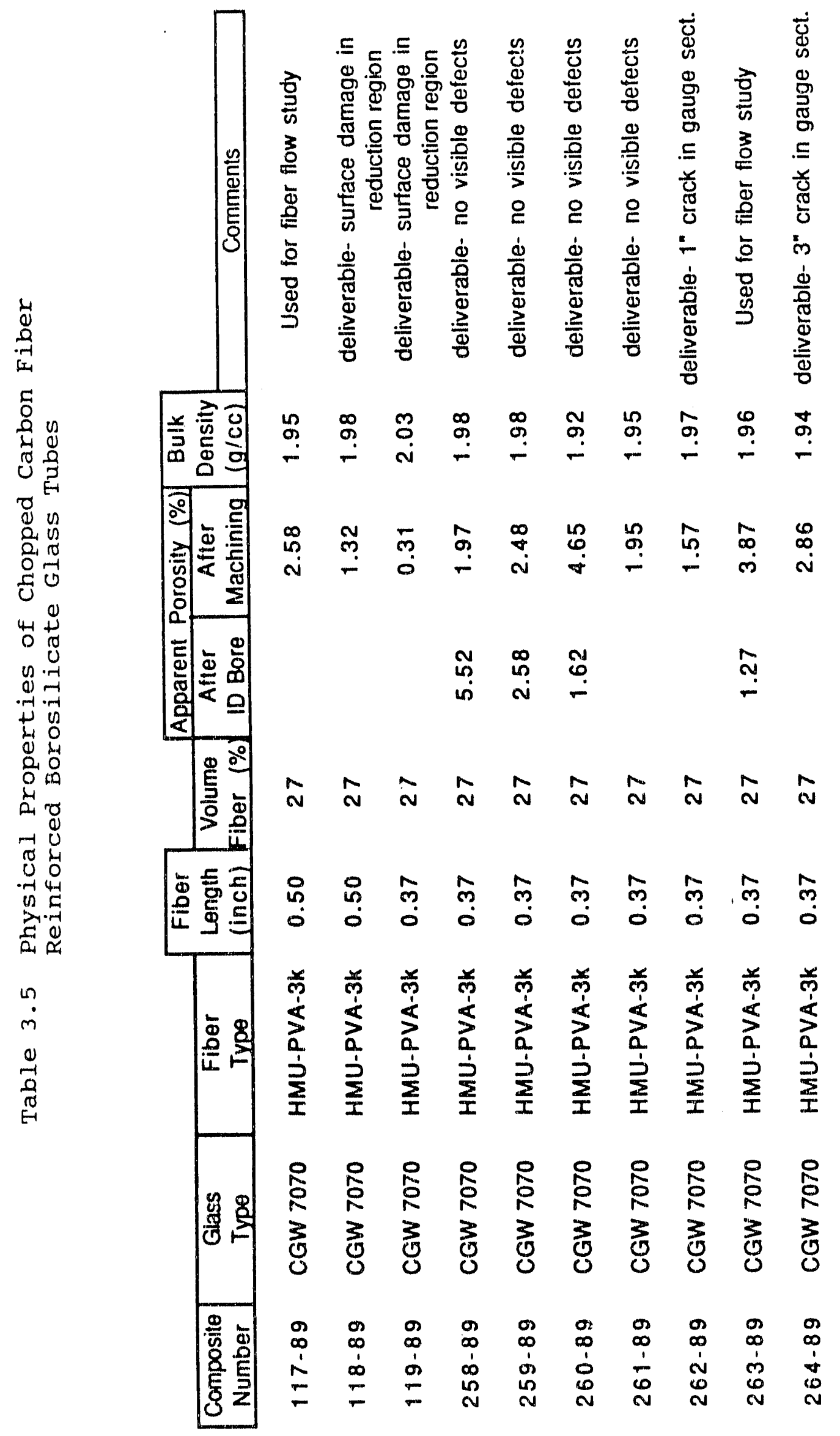




\subsection{TEST FACILITY DEVELOPMENT}

one of the major objectives achieved in this program was the development, installation, and performance verification of a high temperature, multiaxial mechanical test facility for ceramic composites. This facility combines the complexity of a biaxial test frame with the stringent alignment and stiffness requirements needed to successfully test ceramic materials. The development of the facility was a cooperative effort between the Materials Response Group at Virginia Tech, Instron Corporation, and United Technologies Research center (UTRC). The result of this cooperative effort is a high stiffness test frame and advanced hydraulic grips with precision alignment capabilities. The entire test facility can be completely controlled with a digital computer, and is equipped with an Instron short furnace and a capacitance extensometer for high temperature testing up to $1500^{\circ} \mathrm{C}$ in an oxidative environment.

\subsection{The Test Frame}

The test frame is a two post system rated for $100 \mathrm{kips}$ axial and $50 \mathrm{kip}$-inches torsional loads (Figure 4.1). A high stiffness frame was required to minimize the twist in the crosshead under rated loads. The stiffness of the frame is rated at $5.0 \times 106$ lbs/inch axial and $3.8 \times 106$ inch-lbs/deg torsional at 40 inches separation between crosshead and base. The load cell and actuators are rated at $50 \mathrm{kips}$ axial and $25 \mathrm{kip}$-inches torsional. The actuators are top mounted to also reduce the amount of twist, and a hydraulic bearing for the actuator has been included to improve the alignment and compressive stability of the actuator piston. 
-

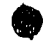

$\rightarrow$

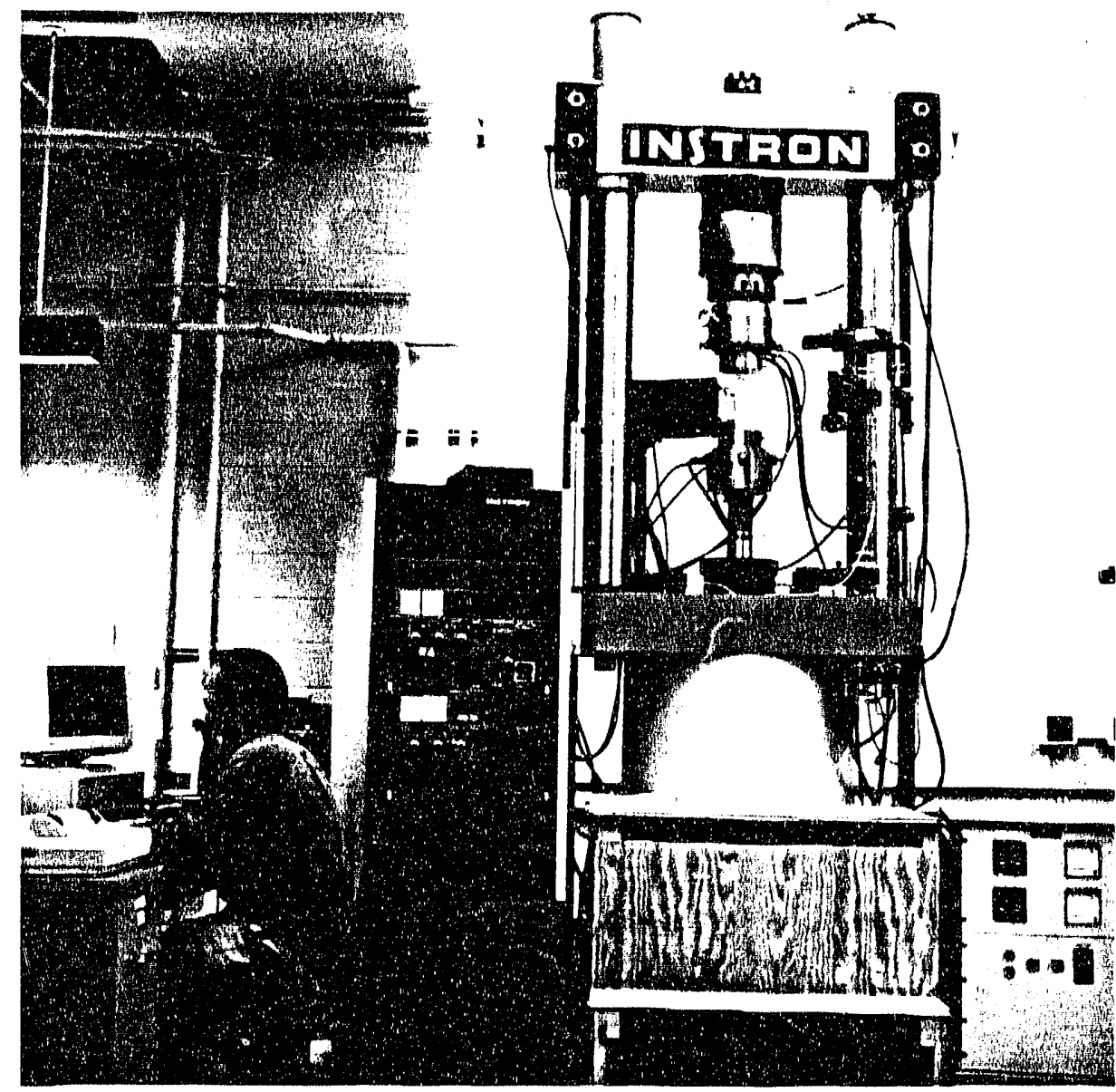

Fig. 4.1 The Test Frame. 


\subsection{The Hydraulic Grips}

The major thrust of the cooperative effort was the development of the hydraulic grips. The grips contain a collet assembly designed to hold a 1.5 inch diameter cylinder 1.5 inches long. Figure 4.2 shows a sectional view of the grips without a specimen. When activated, the piston moves upward forcing the collet into the head assembly and thereby causing the collet to grip the specimen. The piston travel and, hence, the gripping load is limited by the aluminum spacer plate shown in Figure 4.2. The base of the grips are water cooled to enable them to operate in close proximity to the high temperature furnace.

The grips are also equipped with precision alignment capabilities. The $\mathrm{X}$-axis translational alignment is controlled by adjusting the alignment screws shown in Figure 4.2. A similar set of adjustments controls the Y-axis alignment. The rotational alignment is controlled by the alignment screws located on the bottom of the grip. This set of adjustments permits the grips to be aligned about an axis out of the page. A similar set of adjustments controls the rotational alignment about the $\mathrm{x}$-axis. with this combination of alignment controls, we can easily align the system and essentially eliminate all of the bending moments except those which are induced by the curvature of the specimen itself. As a result, the probability of premature failure due to specimen misalignment is greatly reduced.

\subsection{Test System Control and Data Acquisition}

In addition to the standard control console, the test facility is equipped with the Instron Inteligent Interface. The Intelligent Interface permits control of the test frame with a personal computer through an HP-IB bus, and Instron has a variety of software packages for system control. All of these packages are written in HP Basic and, therefore, require the HP operating 


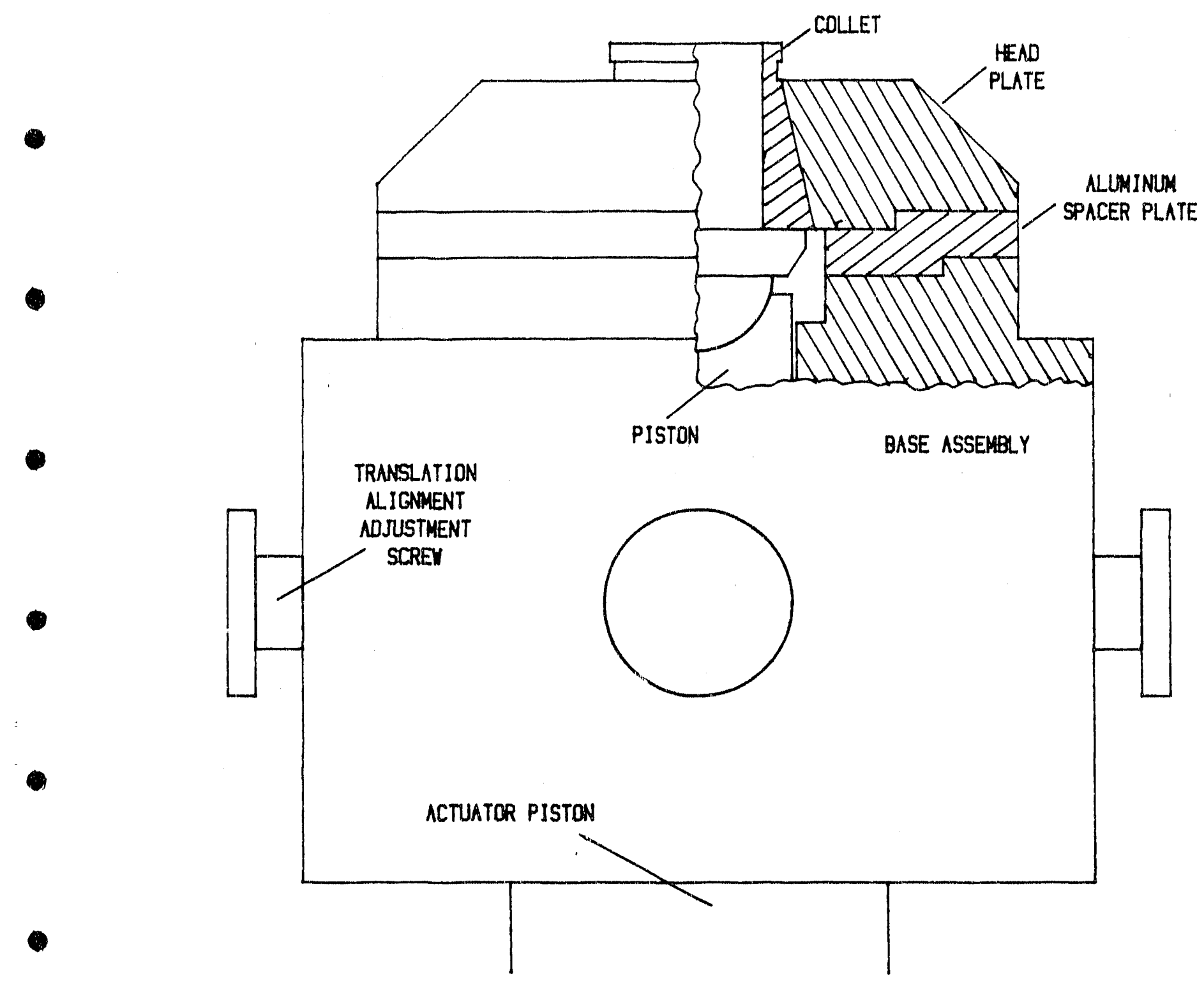

Fig. 4.2 A Sectional View of the Hydraulic Grips. 
system. An HP Vectra ES12 (an MS-DOS machine) was equipped with an HP viper board which contains the HP operating system. This combination of an MS-DOS computer and an HP board provides a wide range of flexibility. All of the application programs can be run in an HP environment, and the data can be transferred into a MS-DOS format for use with any of the MS-DOS programs such as LOTUS 1-2-3, and Harvard Graphics.

Two Instron Application Packages were used in this program. The first package is called the Proof-Test Package. This program is used to conduct quasi-static, uniaxial tensile tests. It combines test system control with data acquisition and data reduction to produce a very complete package. The second Instron Application Package used in this program was the Biaxial-Block Program. The package is configured to control the test frame for cyclic loading spectrums. In addition, the Biaxial Block Program also monitors the currenc status of the test on the computer screen. Figure 4.3 contains a printout of a sample status screen from a test conducted in this program.

The loading spectrum is divided into events, blocks, and sequences. An event is defined by the control modes (for example load and torque), the minimum and maximums for the waveforms, the type of waveforms (sine, square, triangular, etc), the cycling frequencies, the phase lag between the axial and the torsional channel, and the number of waveform repeats. A block consists of a collection of events, and a sequence is made up of a collection of blocks. Figure 4.4 diagrams a tensile waveform for three events, two blocks and one sequence. The first event (EV1) consists of two relatively slow, high loading cycles. The second event (EV2) consists of four medium loading cycles at a faster rate, and the third event consists of eight low loading cycles. The first block (BL1) consists of the events EV1-EV2-EV1, and the second block (BL2) consists of the events EV1-EV1-EV3-EV1-EV1. The two blocks are then combined in order to form a sequence. As can 


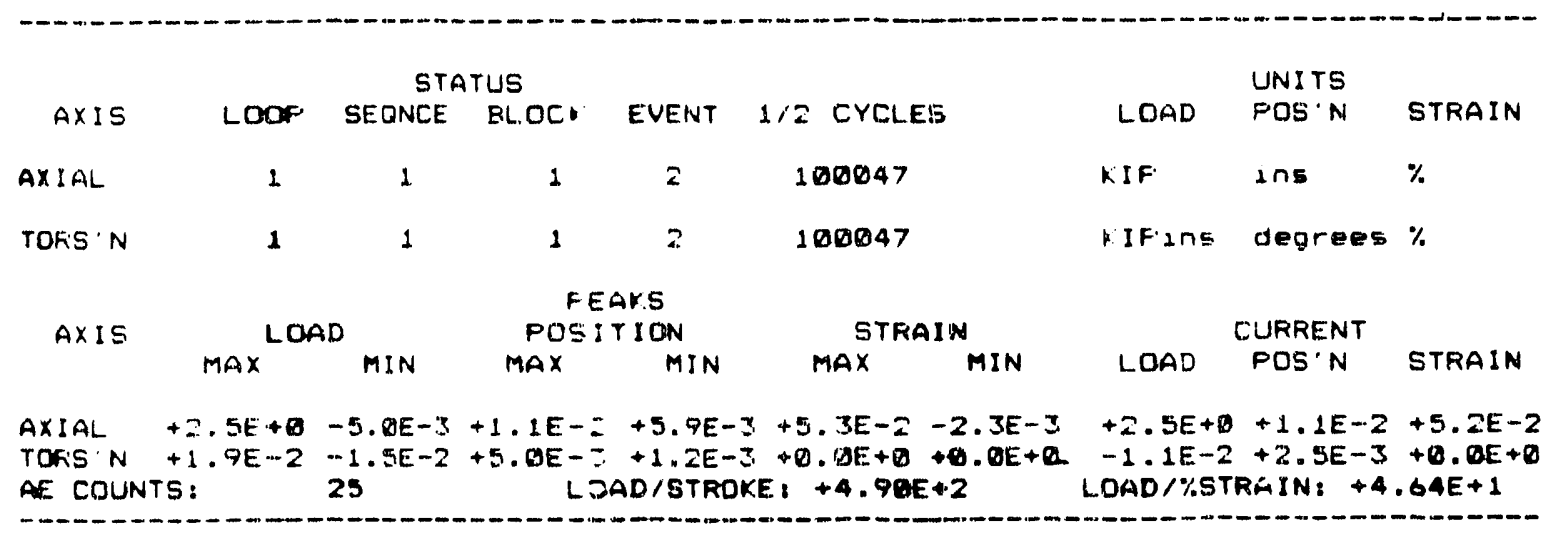

Fig. 4.3 A Sample status screen Printout.

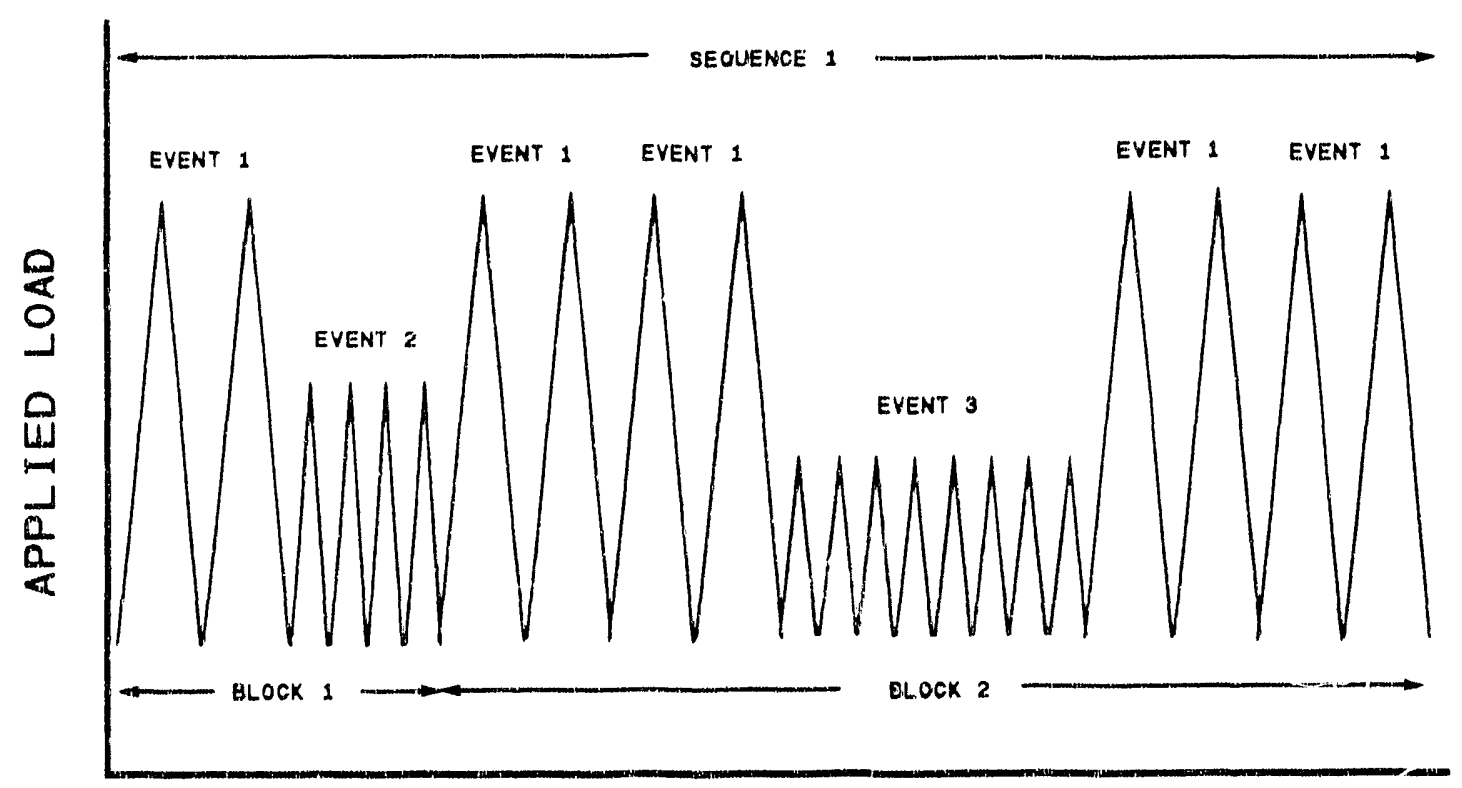

TIME

Fig. 4.4 A Schematic Diagram of a Tensile Waveform Containing 'Ihree Events, Two Blocks and one sequence. 
be imagined, events can be defined and linked to simulate almost any form of spectrum loading. Therefore, this control package can be a very important tool for any program involving performance simulation in a testing frame.

The Biaxial Block program has been up-graded to collect up to 9000 data points (1000 measurements on nine channels) and store these data points on disk for post-processing. One of the data channels could be from an external source such as the Acoustic Emission counts from an $A E$ system through an $H P$ voltmeter. In addition to data collection, the computer also monitors stiffness in the form of stroke/Load and strain/load. overall, the Instron Intelligent Interface and its supporting software provide a wide variety of flexibility and capabilities not available with the standard control console.

\subsection{Test Facility Performance}

A complete summary of the test facility specifications is contained in Appendix A. The performance of the system was evaluated through a series of tests conducted at the Instron facility in Canton, Massachusetts and at Virginia Tech. Axial and axial-torsional mechanical tests were conducted at room temperature and at elevated temperatures. In general, the performance of the test facility was excellent. The machine exhibited excellent control and very little "bumping" when switching control modes. In a cyclic load control mode, the machined operated very smoothly at $5 \mathrm{hz}$ with little of no discortion of the response signal as compared to the input control signal. 


\subsection{TEST METHOD DEVELOPMENT}

Tasks 2 and 3 address testing and characterizing the ceramic composite tubes. A major part of these tasks includes the development and verification of test methods for uniaxial and biaxial loading at room temperature and at high temperatures and the selection and application of suitable nondestructive methods to measure and characterize damage in the tubes. In general, the methods developed for use in this investigation are based on standard or commonly practiced techniques used for testing and characterizing other materials such as metals, polymer matrix composites, and monolithic ceramics. The techniques were modified as appropriate to accommodate specific and unique features of ceramic composites.

Two major elements of test method development--design of the specimen and development of the test facility--were addressed in section 4. The elements to be addressed in section 5 are nondestructive inspection and testing methods and mechanical testing procedures.

\subsection{Evaluation and Application of Nondestructive Examination Techniques}

In order to fully understand, model, and simulate the performance of a ceramic composite component, the development of damage in the test specimens must be thoroughly characterized. This characterization includes the evaluation of the initial state of material, the identification of damage modes, the determination of the interaction between damage modes, and the identification of final state of material. In addition, an understanding of the progression from the initial state to the final state of the material is required. This section summarizes an extensive report on nondestructive test methods for ceramic composites (50) prepared for the Fossil Energy Program. 
The initial state of material consists of a wide variety of factors, including porosity distribution, fiber orientation and distribution, initial defects (large voids, microcracks, etc), residual stress states, and the quality of fiber/matrix bonding. As the specimen is tesied under mechanical and/or thermal loading, the initial state of material will change and damage may develop. For example, the stiffness of a material may change during fatigue loading due to the development of matrix microcracks. Eventually, the specimen will fail, and the specimen must again be examined in order to determine the failure modes and the final state of material.

In order to monitor the various states of material and characterize the damage development process, nondestructive evaluation (NDE) of the component must be performed. NDE results are used to determine the critical defects which control and limit the performance of the specimen. currently, a wide variety of defects can be located and identified in a ceramic composite specimen. However, the effects of these defects on the damage development process in and, hence, performance of a ceramic composite are virtually unknown. For example, failure of an unreinforced ceramic or glass can be governed by a small void or a crack of a few microns. However, ceramic composites can be insensitive to flaws on the order of a few millimeters, or larger.

Some of the first information on the sensitivity of ceramic composites to initial defects was provided by Marshall and Evans (51). They introduced controlled surface flaws into specimens by Vickers and knoop indentations. Some of these flaws produced cracks and chipping which extended across more than 10 fibers. In all of their tests, the crack initiation stress level was not altered by the presence of the induced flaws, and in most cases, the first matrix cracks did not even initiate from the indentations. 
Similar results were observed in this program. Specimen 118-89 contained several larg-surface chips produced in the manufacturing process, as shown in Figure 3.13. The largest chip was on the order of 0.25 inches in diameter and 0.015 inches deep. Nevertheless, the failure due to quasi-static tensile loading occurred in a region far from the defects. In addition, the failure load of specimen 118-89, which contained these large surface defects, was nearly identical to the failure load of specimen 261-89 which contained no surface defects. Under cyclic loading, the specimen performance also did not appear to be affected by the surface defects. In addition, the one inch axial stress crack in the gage section of specimen 264-89 did not appear to influence the tensile performance of the specimen under cyclic loading. However, the three inch initial crack in specimen 262-89 significantly lowered the performance of the specimen. All of these results will be discussed in detail in the following section. Based on the observed results, the performance of the ceramic composite tubes is less sensitive to large surface chips and cracks than manufacturing defects in the transition region. However, as indicated by specimen 262-89, the performance is not completely insensitive to defects.

A very broad based examination of NDE methods for ceramic composites was conducted to identify defects in the injection molded tubes. A list of the methods examined is shown in Table 5.1. Each of these methods was applied to specimen 118-89 to determine the applicability of the method to ceramic composite components. In some cases, the methods required modifications to accommodate the tubular configurations. Detailed descriptions of the applied methods and results of the investigations are contained in Reference 50.

In addition to the NDE techniques examined above, a form of thermography known as stress Pattern Analysis of Thermographic Emissions (SPATE) was investigated and used throughout the cyclic 
test series. SPATE is an in-situ test method which lends itself very well to monitoring damage development during cyclic testing (52). In short, the SPATE system measures the cyclic variations in the thermal emissions in a specimen and correlates these emissions to the applied cyclic loads. For isotropic materials subjected to fully reversed loading, the measured emissions can be related to stresses producing a full field stress pattern in the specimen. Damage development can be directly monitored by changes in the stress field due to changes in load paths and internal redistribution of stress. In the case of non-isotropic materials, the conversion from thermal emissions to stresses is not straight-forward; and in the casf of the injection molded specimens with large variations in fiber orientations, a

Table 5.1 NDE Methods Evaluated.

Acoustic Methods

C-Scans

Scanning Acoustic Microscopy

Acoustic Emissions

Acousto-Ultrasonics

\section{X-Ray Methods}

Film Radiography

Computed Tomography

\section{other Methods}

Thermography

SPATE

Optical. Microscopy

Scanning Electron Microscopy

direct conversion from emissions to stresses is impossible. Nevertheless, the evolution of darnage can be monitored by changes in the observed, albeit inaccurate, stress fields. Therefore, the method is still extremely va?uable for locating damage regions and for monitoring damage growth until failure.

overall, a wide variety of NDE methods were investigated in this program, and based on the results of this investigation, a 
combination of several methods was used to characterize and monitor the state of material in a specimen throughout its life. Prior to testing, $x$-ray radiographs of each specimen were taken to determine the fiber orientations throughout the specimen. During quasi-static testing, acoustic emissions were monitored on specimen 118-89. Unfortunately, the testing program required testing the final two quasi-static specimens at the Instron facility in Canton, Massachusetts, and acoustic emission monitoring equipment was not available for these two tests. During cyclic testing, acoustic emissions were monitored and SPATE was applied. After testing, both optical and scanning electron microscopy were used to investigate the failure surfaces. In order to better correlate the damage state and its effect on the performance of the specimen, the actual NDE results for each of the test specimens are presented with the mechanical test results in the following section.

\subsection{Mechanical Test Procedure Development}

Although ASTM has developed an excellent set of testing procedures for polymeric composites, the application of these procedures to ceramic composites is not alwiys direct because of the brittleness of the material and the neeu for high temperature characterization. In addition, ASTM has not standardized procedures for multiaxial testing of composites. Therefore, as part of this research program, a number of procedures were examined. Gripping, quasi-static test procedures, and cyclic test procedures are discussed in this section. Extensometry, control modes, data acquisition, and the effectiveness of the in-situ NDE methods are also discussed.

\subsubsection{Gripping and Alignment.}

As described in Section 4, the hydraulic grips were specially designed by Instron for this program, and Instron provided detailed instructions on specimen insertion. These instructions are fairly 
complex, and should be followed rigorously. overall, once the spacer plate in the top grip was ground down 0.010 inches, the grips worked extremely well. While operating the grips, special care must be taken not force or even slightly push the specimen into the grips. The specimen must be able to slide freely into the grip before clamping. If the specimen requires pushing it into the grips, it will be extremely difficult to remove, and may even require disassembly of the grip for removal the specimen.

In this program, grip pressures from 1500 psi for the low stress cyclic test up to 3000 psi for monotonic tensile tests were used. None of the specimens exhibited grip damage in the form of crushing. Although the 3000 psi grip pressure seems very high, the grips are deflection limited due to the spacer plate. Tolerances in the grip regions of the specimens will also significantly affect the actual grip load applied to the specimen. Since the grips are deflection limited, a specimen with a grip diameter of 1.495 inches may have a significantly lower grip load than a specimen with a 1.499 inch grip diameter. Actual applied grip loads and grip tolerances should be more thoroughly investigated to prevent specimen slippage or unnecessary crushing of a weak specimen.

The last area of concern associated with specimen gripping involves the alignment verification. For this program, the system was aligned at installation and one time during the course of the program. An alignment check as part of the standard test procedure should be added. ASTM Procedure E1012-89 "Standard Practice for Verification of specimen Alignment under Tensile Loading" (53), contains an excellent description of alignment procedures for flat tensile loaded specimens and would require only minor modifications to develop a procedure for both tensile and torsional alignment verification with tubular specimens. 


\section{2 .2 Quasi-static Testing Procedures.}

The quasi-static test series consisted of three tension tests conducted at the Instron facility in Canton, Massachusetts. All three tests used the Instron capacitance extensometer for strain measurements. The first test was performed using the Instron "Proof-Test" package for data acquisition and control. Data were also recorded on an $X-Y$ recorder. This test was run in load control, and acoustic emissions were monitored throughout the test. The second and third tests were controlled from the console and were run in stroke control at two different stroke rates. Acoustic emissions were not recorded for these tests, and data were recorded with an $X-Y$ recorder. The capacitance extensometer performed very well for all of the tests. The extensometer mounted very easily, and showed no signs of slippage during the test. In addition, bending loads exerted on the specimen by the extensometer are very small. This extensometer is also capable of testing in elevated temperatures up to $1600^{\circ} \mathrm{C}$. Unfortunately, this extensometer is a single axis unit and will require significant modifications in order to measure both axial elongation and angular twist.

The first test was conducted in load control with a loading rate of $20 \mathrm{lbs} / \mathrm{sec}(0.8 \%$ full scale per sec) and produced a very smooth loading curve up to failure. Unfortunately, a load controlled test does not show the "graceful" failure beyond the ultimate stress for a ceramic composite when compared to a sintered ceramic. Therefore, the remaining two tests were conducted in stroke control. The second test was condusted at $0.00002 \mathrm{in} / \mathrm{sec}$ $(0.02 \%$ full scale per sec). This extremely low rate of loading produced a rough loading curve due to noise or chatter in the control mechanism. The third test was conducted at $0.00005 \mathrm{in} / \mathrm{sec}$ (0.05\% full scale per sec). Although the loading curve was smoother than that of the second test, it still contained a fairly large amount of noise. Based on the results of these tests, the load control mode is recommended for all tests. 
The Instron Proof-Test package for axial loading used for the first test provided excellent test system control, data acquisition, and data reduction capability. The program also stores the data in an HP format. Therefore, with some additional work, the stored HP-ASCII data can be translated into an MS-DOS format for use in a spreadsheet such as LOTUS 1-2-3. This data reduction capability is extremely valuable in generating high quality reports and papers for publication.

For the first quasi-static test, a single acoustic emissions transducer was mounted on the specimen to record AE counts as a function of load. Although, the $A E$ system recorded an occasional extraneous electronic signal, the system produced very valuable information with a small amount of set-up time. As a result, AE monitoring during all quasi-static testing should be conducted, whenever possible.

\section{2 .3 Cyclic Testing Procedures.}

All of the cyclic testing was conducted at Virginia Tech. In all room temperature tests, an MTS extensometer with a 1.000 inch gage length was used to measure strains; and all of the tests were conducted in load control with the Instron Biaxial Block program controlling the test facility. A small bead of adhesive added along the knife edge of the extensometer kept the extensometer in place during quasi-static and cyclic loading.

As stated previously, the Biaxial Block program was used to control the facility for all of the tests, and in some cases, the biaxial block program was also used to record stress-strain data. The cycling frequency of $5 \mathrm{~Hz}$ was reduced to 0.1 cycles per second at selected cyclic intervals to record two cyclic stress strain curves with 50 data points each. 
For the final two tests, the Biaxial Block program was used for test frame control, and a stand-alone system was used for data acquisition. The first cycle was run at 0.1 cycles per second to capture the initial stress-strain response. Then, the Biaxial Block program was set to cycle at $5.0 \mathrm{~Hz}$ until failure or runout without interruptions. The data acquisition system recorded the initial stress-strain response as if it was a quasi-static test and then recorded cyclic data (40 points on two channels for one cyclic stress-strain loop at $5.0 \mathrm{~Hz}$ ) whenever required. Overall, this combination of the Biaxial Block program and a stand-alone data acquisition system provided the most effective means of test control and data collection. The block program provides all of its capability such as spectrum loading, phasing, and stiffness monitoring. The stand-alone data acquisition system can record data without interrupting the test.

The final area of cyclic test procedures involves the application of NDE methods. Two in-situ methods were considered during the cyclic testing, $A E$ monitoring and SPATE. There were several problems with AE monitoring throughout the entire cyclic test series. First, interfacing the AE system with the Biaxial Block program was difficult. Secondly, and most importantly, the rate of $\mathrm{AE}$ count accumulation due to damage development in the specimen was very slow. As a result, the occasional extraneous signal described in the quasi-static test procedures produced a significant number of erroneous $A E$ counts which completely masked the real AE counts. Therefore, AE monitoring during cyclic tests with the AE system used in this program in not recommended.

Although SPATE worked very well for some of the high cycle (low stress) fatigue specimens, the SPATE system had 1 imitations in monitoring the damage development for the low cycle fatigue specimens and in the early stages of life in the high cycle (high stress) fatigue specimens. For a relatively large area on the surface of the specimen, SPATE requires approximately 20 minutes 
$(6000$ cycles at $5.0 \mathrm{~Hz})$ in order to generate a scan with acceptable resolution. Typically, for highly loaded specimens or early in its life, the specimen is cycled at the specified load level for a predetermined number of cycles. The load level is then significantly reduced in order to perform the SPATE scan. Ideally, the reduced cyclic stress is selected such that specimen is not additionally damaged while the SPATE scan is taken. Unfortunately, for this material, the specimen had to be cycled at approximately $60 \%$ of the UTS in order to generate a signal strong enough to be read by the SPATE, and this load level was high enough to potentially further damage the specimen and cloud the cyclic test results. Therefore, the SPATE could not effectively be used for specimens with very short lives or early in the life of a specimen when damage was accumulating at a fairly high rate. Nevertheless, for long life fatigue specimens which show very little damage development over the scanning time, the SPATE system worked very well and should be used in further work.

\subsubsection{Recommended Procedures.}

Overall, the gripping and alignment verification procedures are straight forward and fairly well established. The major remaining question concerns the gripping pressure for the specimens. One approach to characterize the gripping pressure is to map slippage loads for a steel rod as a function of grip pressure and diameter to develop a relationship between grip pressure, grip diameter, and maximum load for a steel rod. For other materials, the same relationship can be used by shifting the curves up or down based on the relative coefficient of friction and the bulk modulus for the new material as compared to steel. As a result, a specification for the required tolerances in the grip region can be developed. Crushing the specimen in the grips or having the specimen slip out of the grips in the middle of a test can be minimized. 
For monotonic testing procedures, the test facility should be operated in load control. For biaxial quasi-static testing, the test should be controlled from the console, and a stand-alone data acquisition system should be used to record axial load, axial strain, axial stroke, torque, angular twist and rotation. In addition, if $\mathrm{AE}$ is monitored, the $\mathrm{AE}$ counts can also be recorded by the data acquisition system. For axial loading the capacitance extensometer should provide excellent performance even at high temperatures. However, for biaxial loading, extensometry is an area which must be addressed.

For cyclic testing, the test should be controlled with the biaxial-block program developed by Instron and, the data should be monitored with a stand-alone data acquisition system. For biaxial tests where six channels must be monitored, a high speed data acquisition is required, and the data acquisition program developed for the cyclic tests performed in this program needs to be modified. As with the monotonic tests, high temperature biaxial extensometry is a major concern to be investigated further. 


\subsection{EXPERIMENTAI TEST RESULTS}

Several types of mechanical tests were conducted in this program. The majority of the experimental program consisted of room temperature, quasi-static and cyclic tests on tubular specimens. Detailed resules of this portion of the experimental program are presented in section 6.1 . The results of room temperature and elevated temperature biaxial demonstration tests are reported in section 6.2 .

\subsection{Experimental Results for Tubular Test specimens}

A detailed test plan was developed to investigate the performance of ceramic composite tubes. The goal of the plan was to maximize the amount of information to be obtained from the limited number of specimens available to this program. The test plan consisted of a combination of nondestructive tests, mechanical tests, and post-test fractography of the specimens. Each of these areas is discussed in this section. Section 6.1.1 presents the NDE results prior to testing. Sections 6.1 .2 and 6.1 .3 present the mechanical and in-situ NDE test results for the quasi-static and cyclic test series respectively. Section 6.1 .4 contains the post-test inspections and fractography results. Throughout these sections, critical defects and failure modes for the ceramic composite tubes are discussed.

\subsubsection{NDE Inspection Prior to Testing.}

As discussed in section 5.1, a very extensive evaluation of NDE methods for the composite tubes was made. As a result of this investigation, two methods, $x$-ray radiography and ultrasonic C-scans, were selected and used to nondestructively inspect the tubes. Radiographs of specimens 118-89, 260-89 and 264-89 are shown in Figures 6.1 through 6.3 . These radiographs are typical of 


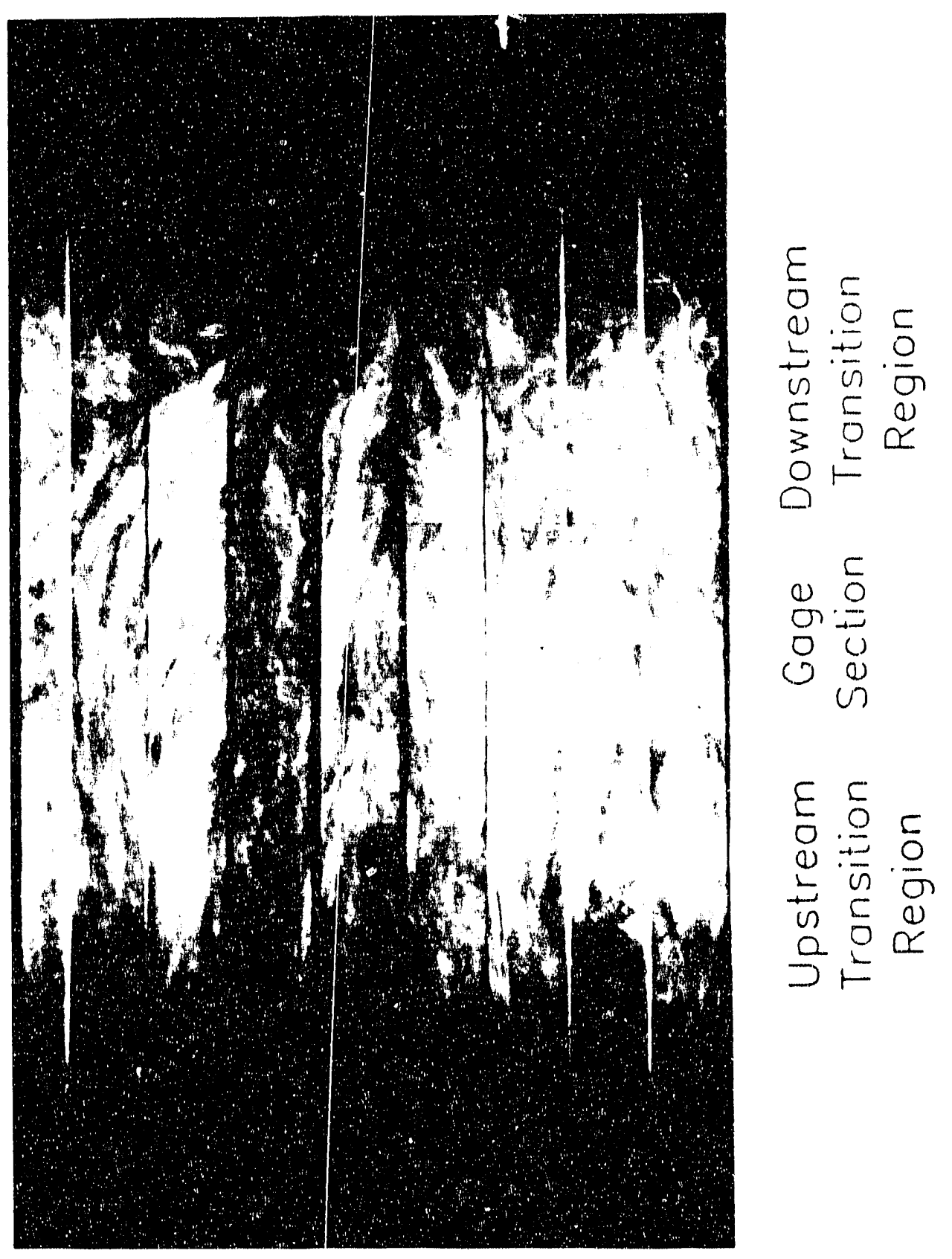

Fig. 6.1 Radiograph of Specimen 118-89. 


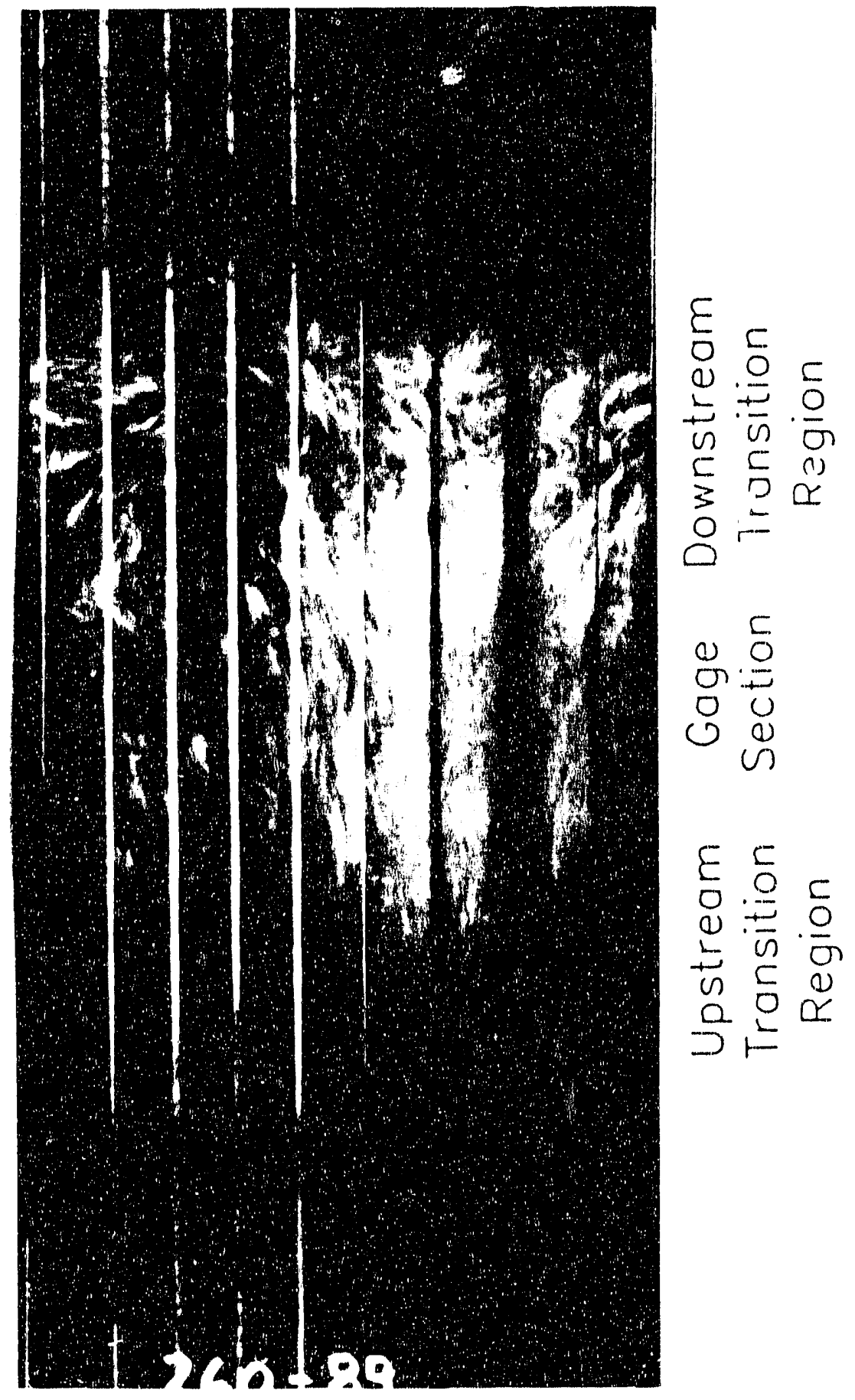

Fig. 6.2 Radiograph of specimen 260-89. 




Fig. 6.3 Radiograph of specimen 2.64-89. 
the radiography results for all of the tubes. The radiographs were taken by placing the $x$-ray film along the inside circumference of the specimen. The length of the film was one inch shorter than the eight inch tube length. As a result, the outside half inch of the grip regions do not appear in the radiograph. The width of the radiograph corresponds to $0-360^{\circ}$ around the circumference. Evaluation of Figures 6.1 through 6.3 clearly shows the injection molding process produces highly va:iable fiber orientations throughout the tubular specimens.

Four areas of axially aligned fiber flow regions (termed knit lines) can be seen in the upstream grip regions (located at the bottom of the figures. These regions are produced by the four holes in the end plate of the molding apparatus. In some cases, the knit lines extend through the gage section and tend to cusp in the downstream transition region. The knit lines even produced axial cracks in specimens 262-89 and 264-89. The location of a crack in specimen 264-89 is highlighted in Figure 6.3. In addition to the knit lines, a large amount of in-plane fiber swirling is evident in the downstream transition regions of the tubes. Similar fiber swirling was observed in all of the tubes manufactured in this program. Radial cross-sections of the tubes also indicate a significant amount of out-of-plane fiber swirling in the downstream transition region. An example of this out-of-plane swirling is shown in Figure 6.4. In retrospect, the combination of in-plane and out-of-plane fiber swirling was the dominate, performance limiting defect in every specimen except 264-89 which contained the 3.0 inch axial crack along a knjt line. Unfortunately, the NDE methods used did not provide an indication of the out-of-plane swirling. As a result, one of the critical defects, out-of-plane fiber swirling, was not detected prior to mechanical testing.

C-scans were also performed on several specimens. Due to the nature of ultrasonic c-scans, curved surfaces with normals at large angles to the incident wave direction disperse the ultrasonic 
signals, and these curved regions can not be imaged. As a result, the c-scans of the tubes are limited to the gage length and only part of the transition regions. Figure 6.5 presents the C-scan results for specimen 261-89. This c-scan image is typical of all of the c-scan results. The light regions in Figure 6.5 are the result of attenuation of the ultrasonic signal due to property variations. Comparison of the c-scan and the radiograph for specimen 261-89 (Figure 6.2) indicates the light regions match with the knit jines. Therefore, these knit lines probably have some type of material variations, compared to the rest of the specimen, such as different fiber volumes, different porosity, or even large amounts of microcracking. Although these property variations appear significant in the c-scan images, the mechanical test results indicate the variations were not critical defects in these specimens under axial loading, and therefore, they were not investigated in more detail.

\section{1 .2 Quasi-static Testing Procedures and Results.}

Specimens 118-89, 119-89, and 261-89 were tested at room temperature under quasi-static tension until failure. Specimen 118-89 was tested in load control at $1000 \mathrm{lbs} / \mathrm{min}$, Specimens 119-89 and 261-89 were tested in stroke control at 0.00002 and 0.00005 in/sec, respectively. Stress-strain results for the three tests are shown in Figure 6.6. The strains where measured with an 1.0 inch extensometer, and the stress calculations were based on the 


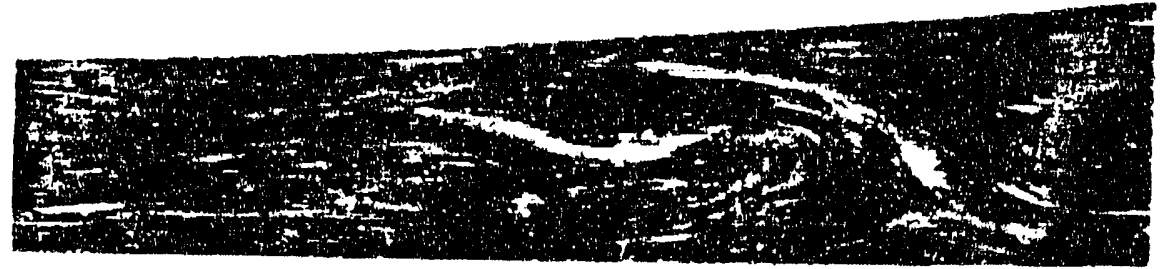

Fig. 6.4 Out-of-plane Fiber swirling.

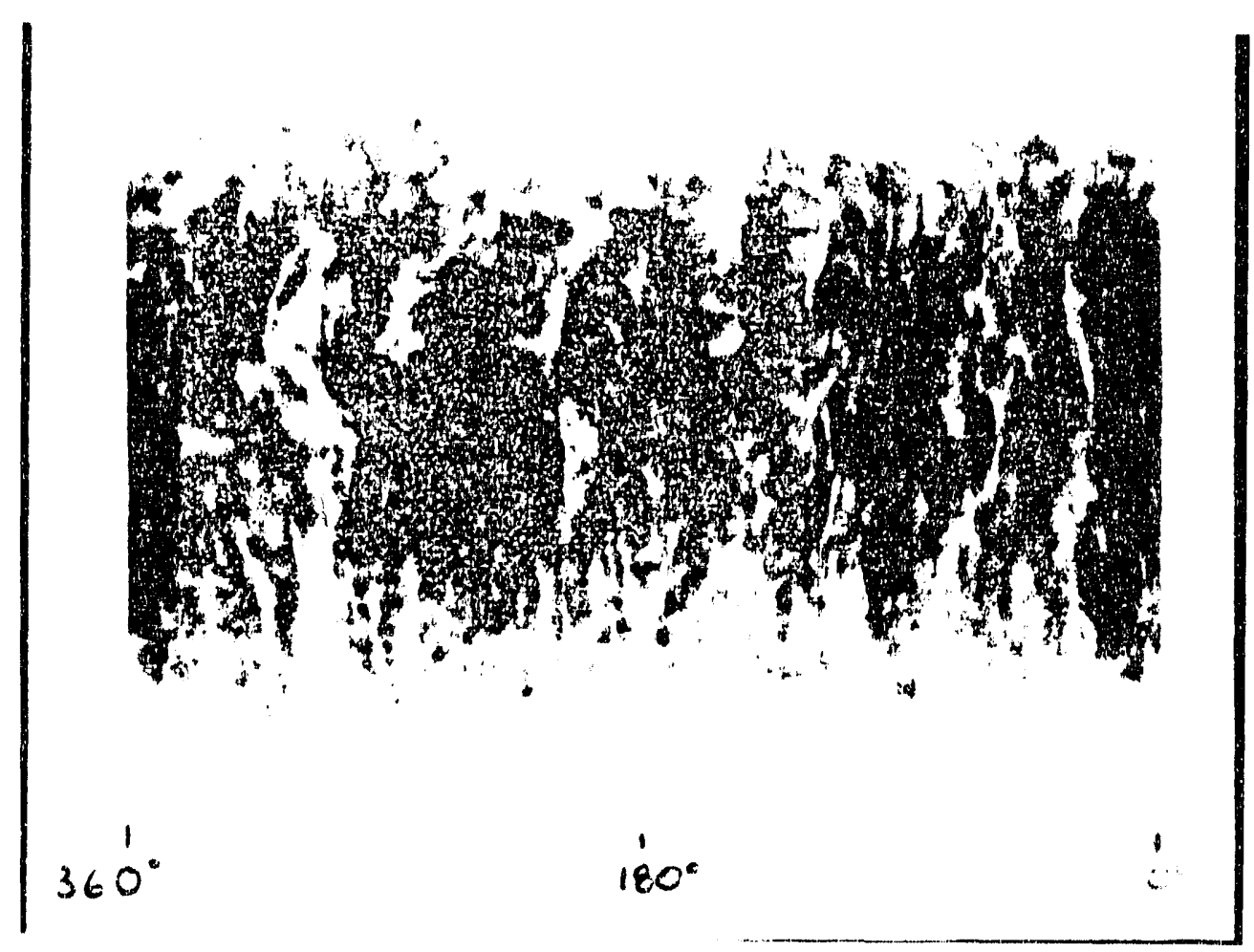

Fig. 6.5 C-scan Results for specimen $261-89$. 
cross-sectional area of the gage length. All three specimens failed in the downstream transition region. Therefore, the peak stresses shown on the stress-strain curves do not correspond to the failure stress of the material since the stresses in transition regions are different than those in the gage section. In addition, variations in the fiber orientations around the circumference and along the length of the tubes produce non-uniform stress distributions throughout the specimens. Therefore, the stresses at failure should be considered as nominal stresses in the gage section. The mean nominal stress at failure was $12.3 \mathrm{ksi}$, with a scatter of $+0.40 \mathrm{ksi}$ and $-0.29 \mathrm{ksi}$.

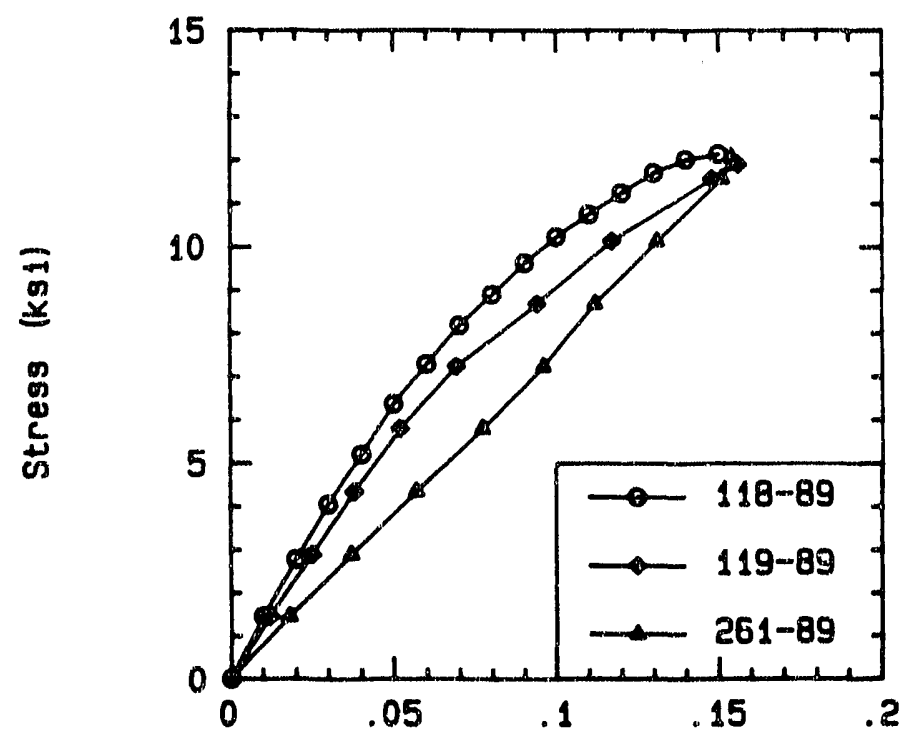

Strain (x)

Fig. 6.6 Stress-strain Responses for the Quasi-static specimens. 
During testing of specimen $118-89$ an acoustic emission (AE) transducer was mounted on the specimen, and cumulative AE counts versus load were recorded. The load levels were then converted to nominal stress levels based on the cross-sectional area of the gage section to determine cumulative $\mathrm{AE}$ counts as a function of stress (Figure 6.7). Figure 6.8 presents the normalized secant modulus as a function of AE counts for specimen 118-189. In this case, the secant modulus is defined as the slope of the line connecting the origin and the point on the stress-strain curve corresponding to the AE count. This secant modulus is then divided by the tangent modulus at the origin of the stress-strain curve to produce a normalized secant modulus. Figures 6.7 and 6.8 show that damage, indicated by the acoustic emissions, begins at relatively low stresses and continues to grow at a small rate until a stress of approximately $7.0 \mathrm{ksi}$. Although the AE counts at $7.0 \mathrm{ksi}$ appear relatively small compared to the total AE counts at failure, the stiffness of the specimen decreased 20\%. Above a stress of 7.0 ksi, the number of acoustic emissions begins to increase exponentially, indicating the damage is growing very rapidly. Conversely, the rate of stiffness reduction as a function of $A E$ counts is decreasing.

As with any $A E$ method, monitoring the emissions is relatively simple. However, determining the source of the emission is extremely difficult. In this case, the transition at a stress level of $7.0 \mathrm{ksi}$ may indicate the failure mode of the specimen is 


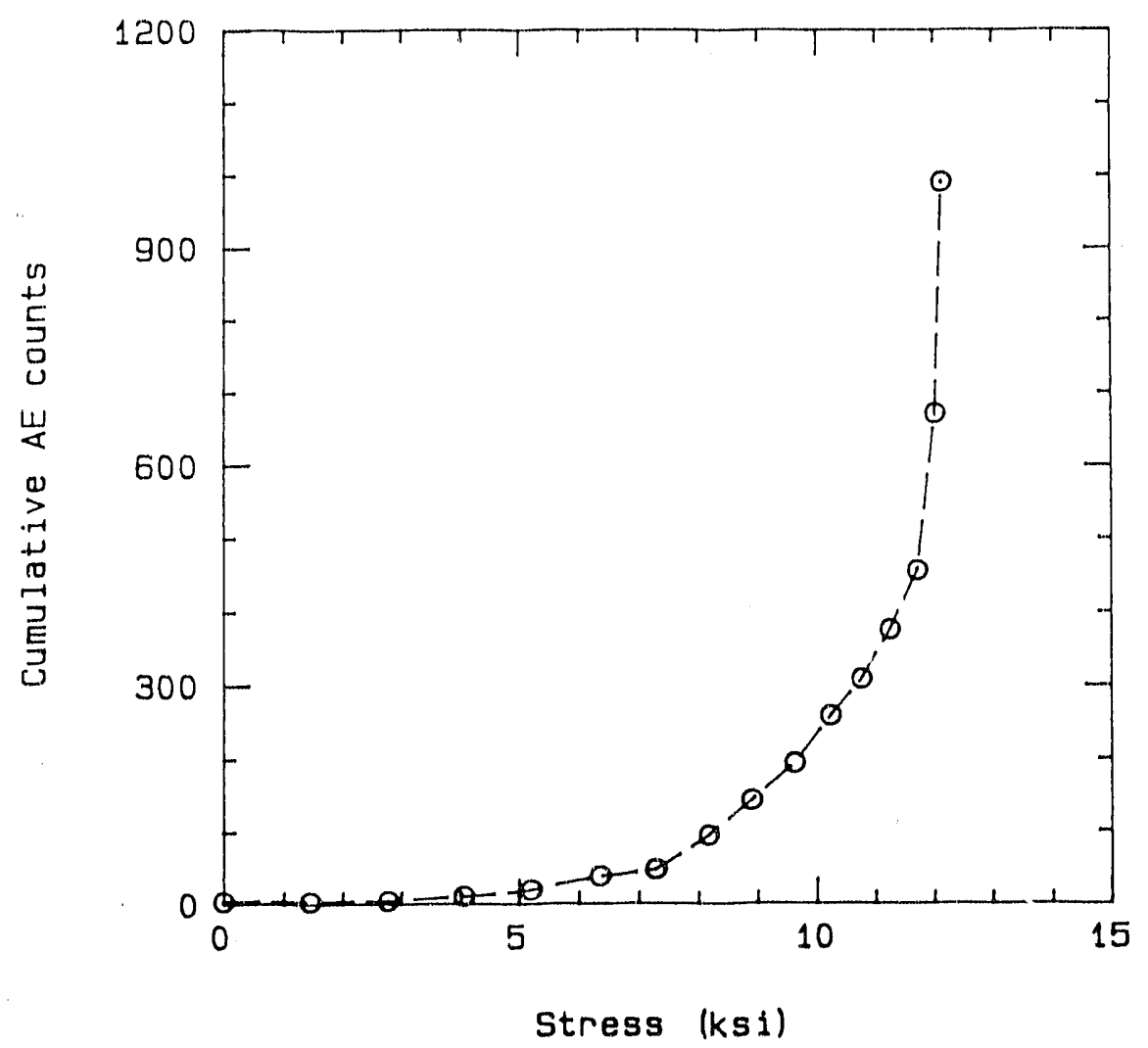

Fig. 6.- Cumulative AE counts as a Function of Applied stress.

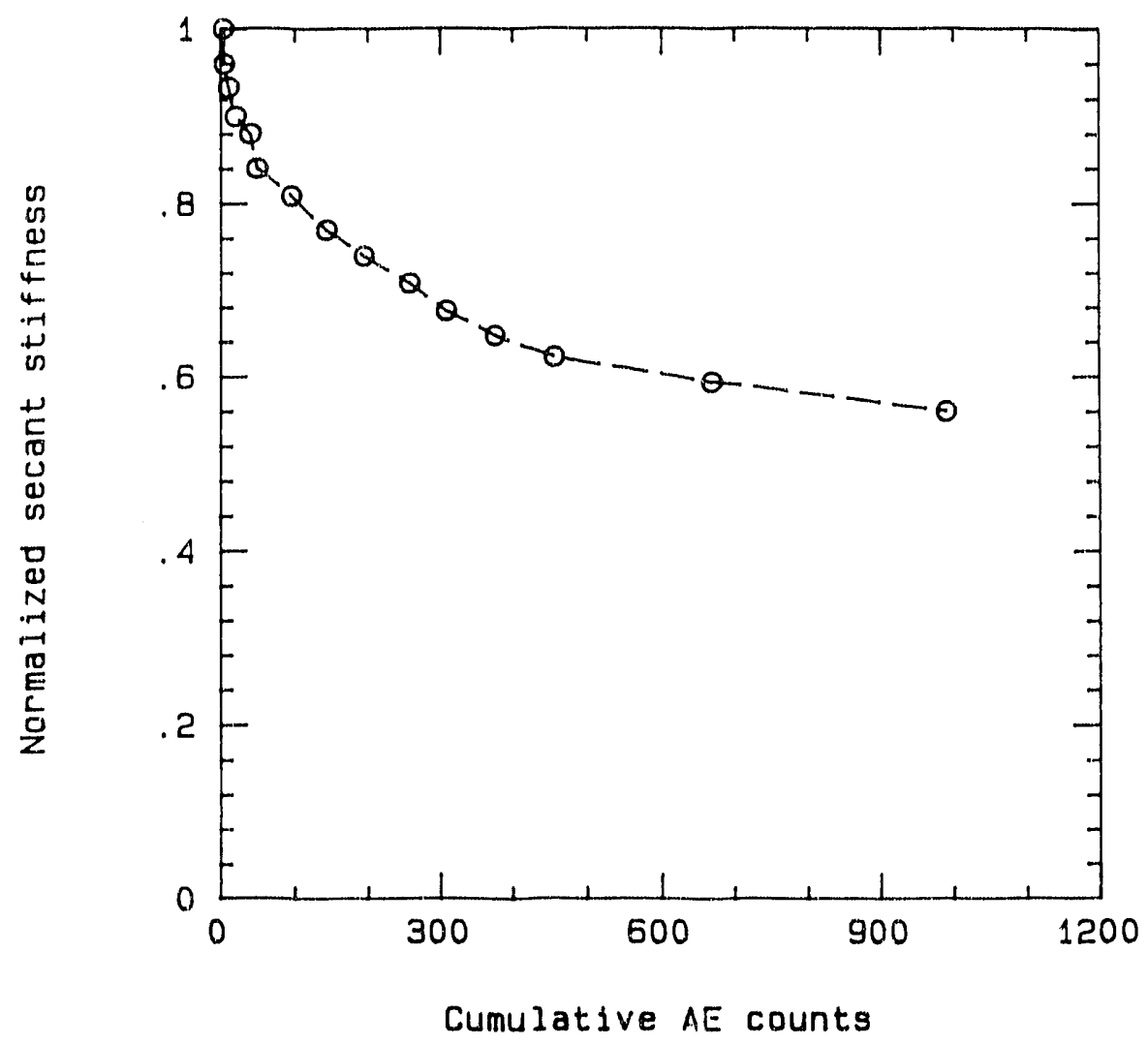

Fig. 6.8 Normalized Secant Modulus as a Function of AE Counts. 
changing. At low stress levels, the acoustic emissions may correspond to matrix failures as a result of axial loading and residual thermal stresses. This type of failure would occur predominantly along the knit lines in the gage section where there are regions of highly axially aligned fibers and the smallest cross-sectional area. A small amount of this type of damage in the gage section could generate large stiffness reductions. At higher stress levels, the acoustic emissions may correspond to matrix or shear failure in the swirled fiber regions where the fibers are oriented transversely to the axial direction. Since the swirled regions are outside the gage length, damage in these areas would not greatly affect the stiffness measured across the gage length. The large increase in AE counts for stress levels above $12.0 \mathrm{ksi}$ probably indicates the failed locations throughout the swirled fiber regions are linking together leading to failure.

\subsubsection{Cyclic Testing Procedures and Results.}

Five tubes were tested under tension-tension $(R=0.1)$ cyclic loading at room temperature. The tubes were cycled at $5 \mathrm{~Hz}$, and a 1.0 inch extensometer was attached to the gage section. Periodically, the cycling rate was slowed to $0.05 \mathrm{~Hz}$ to capture the cyclic stress-strain response and to monitor the stiffness change as a function of life. Loading conditions, fatigue lives, and residual strengths for each specimen are summarized in Table 6.1. In this case, a runout is defined as one million cycles without a 
failure. After a runout, the specimen was loaded in quasi-static tension to failure to determine its residual tensile strength. As in the quasi-static test series, all of the specimens failed in the downstream transition region. Therefore, the above stresses or strengths should again be considered as nominal gage section values and are not the actual cyclic stresses or strengths at the point of failure.

Table 6.1 Cyclic Test Results.

\begin{tabular}{lcccc} 
Maximum Cyclic & & $\begin{array}{c}\text { Cycles to } \\
\text { Failure }\end{array}$ & $\begin{array}{l}\text { Residual } \\
\text { Tensile } \\
\text { Strength }\end{array}$ \\
\hline $260-89$ & $7.3-60 \%$ UTS & 0.1 & runout** & $10.9 \mathrm{Ksi}$ \\
$259-89$ & $8.5-70 \%$ UTS & 0.1 & runout & $12.4 \mathrm{Ksi}$ \\
$258-89$ & $10.3-85 \%$ UTS & 0.1 & runout & $14.7 \mathrm{Ksi}$ \\
$262-89$ & $11.6-95 \%$ UTS & 0.1 & 600 Cycles & --- \\
$264-89 *$ & $10.3-85 \%$ UTS & 0.1 & 385 Cycles & $-\cdots$
\end{tabular}

* Specimen 264-89 contained a 3.0 inch longitudinal crack extending from the gage section into the downstream transition region.

* Ultimate Tensile strength (UTS) $=12.3 \mathrm{ksi}$

*** Runout $=10^{6}$ cycles

Evaluation of the fatigue data indicates two extremely interesting results. First, the material is very insensitive to fatigue loading as evidenced by the run outs when cycled at very high percentages of the UTS. Even Specimen 264-89 which contained a 3.0 inch longitudinal crack extending into the downstream transition region survived over 300 cycles at $85 \%$ of the UTS.

Throughout all of the cyclic tests, stiffness changes were monitored to indicate damage development. Figure 6.9 presents the stiffness change as a function of cycles for specimen 258-89 which 
stiffness change as a function of cycles for specimen 258-89 which was cycled at $85 \%$ of UTS for one million cycles. Notice the stiffness of the specimen measured across the gage length is essentially constant throughout the duration of the tests. Therefore, the amount of damage in the gage section of the specimen is probably minimal as a result of the cyclic loading. Notice this conclusion is limited to the gage section of the specimen since stiffness monitoring gives virtually no information of the damage development outside of the gage length. These results are typical of the stiffness change results for specimens 259-89 and 260-89.

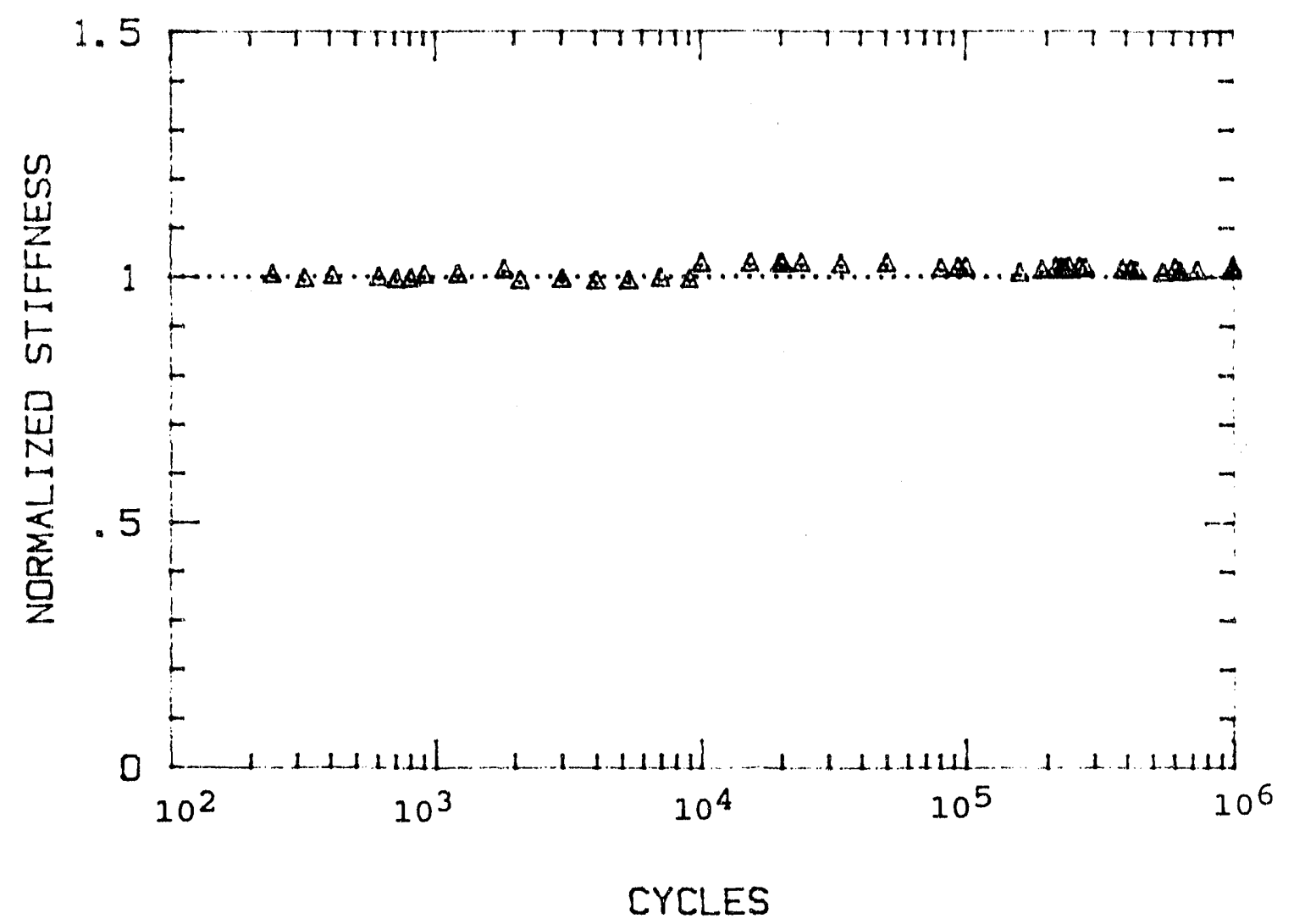

Fig. 6.9 Stiffness Change as a Function of Cycles for Specimen 258-89. 
Unfortunately, the fatigue lives of the other two specimens were too short to collect sufficient data to produce any meaningful stiffness change results.

In order to monitor damage development in the downstream transition region which is outside the gage length, the thermal emissions were monitored by means of the SPATE system described in section 5. As noted in section 5, a change in the thermal emission pattern is an indication of a change in the stress state in the specimen. Figure 6.10 presents SPATE images for the same region of Specimen 258-85 at four stages in the load history. The appearance of the last image is slightly different because the imaging time was doubled to generate a finer image.

The areas labeled "A" and "B" in the first image are of primary importance. First, note the damage progression in the area marked "A" containing a linear discontinuity in the thermal emissions pattern which probably indicates a crack. Notice, as the number of cycles increases, the crack appears to grow and begins to link up with other cracks outside the imaging window. Region "B" contains a more pronounced nucleation and crack development throughout the load history. At 20,000 cycles, the crack at "B" is virtually nonexistent; but at 1,000,000 cycles, a crack has developed and is linking up with another crack growing in from the upper left.

After one million cycles, the specimens were removed from the test frame and inspected with a dye penetrant. The penetrant confirmed the existence of fatigue cracks in all of the specimens (Figure 6.11). The locations "A" and "B" from the SPATE images are shown on specimen 258-89 in Figure 6.11. These results confirm the location of the cracks first observed with the SPATE system. Notice, the fatigue cracks in specimen 258-89 are closer to the gage section than are the cracks in specimen 260-89. Correlation of the failure surfaces after the residual strength tests with the 

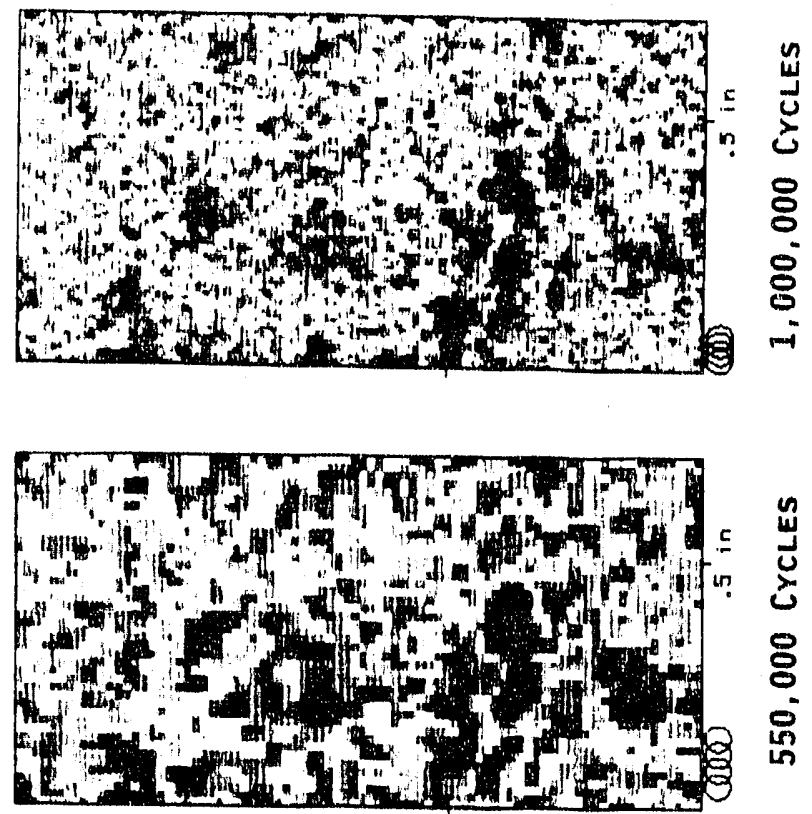

0
0
1
0
0
0
5
0
0
-1
0
0
0
0
4
0
4
0
0
0
0
0
0
0
0
0
0
0
0

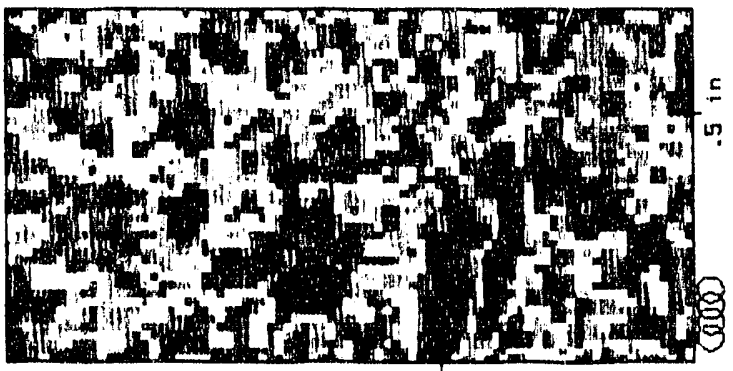

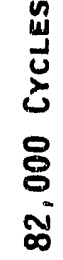

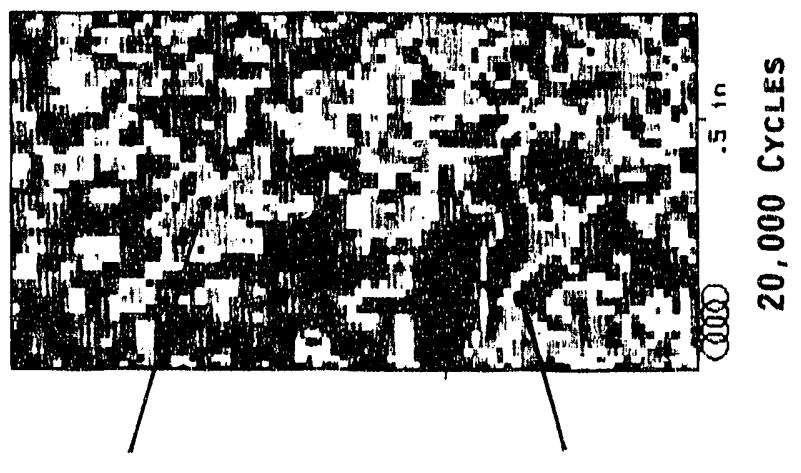

0
0
0
$\dot{0}$
$\dot{0}$
$\dot{x}$

$\infty$

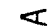




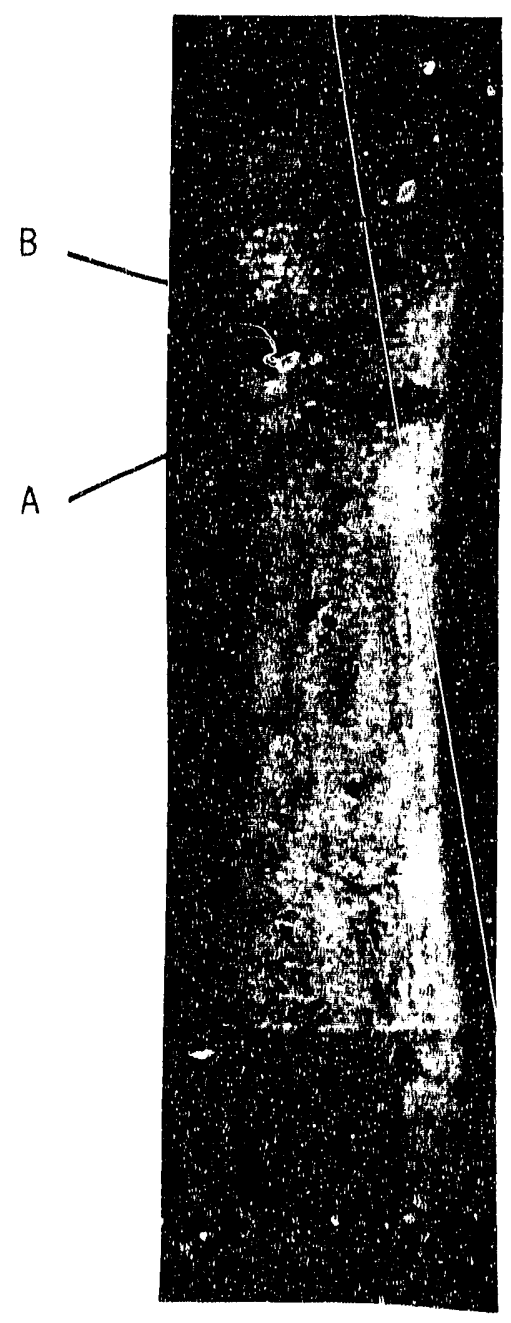

Fig. 6.11 Dye Penetrant Inspection Results for Specimen 258-89. 
penetrant inspections results, indicates the failure surfaces for Specimens 258-89 and 259-89 went through the observed cracks. The failure surface for specimen 260-89 onily partially followed thes observed cracks, indicating that the fatigue cracks developed under cyclic loads at $60 \%$ of U'S were not directly related to the locations of the strength limiting defects.

\subsubsection{Residual Tensile Strength Results.}

After the completion of the dye penetrant inspections the specimens were loaded in quasi-static tension for residual tensile strength. Figure 6.12 presents the results of the residual

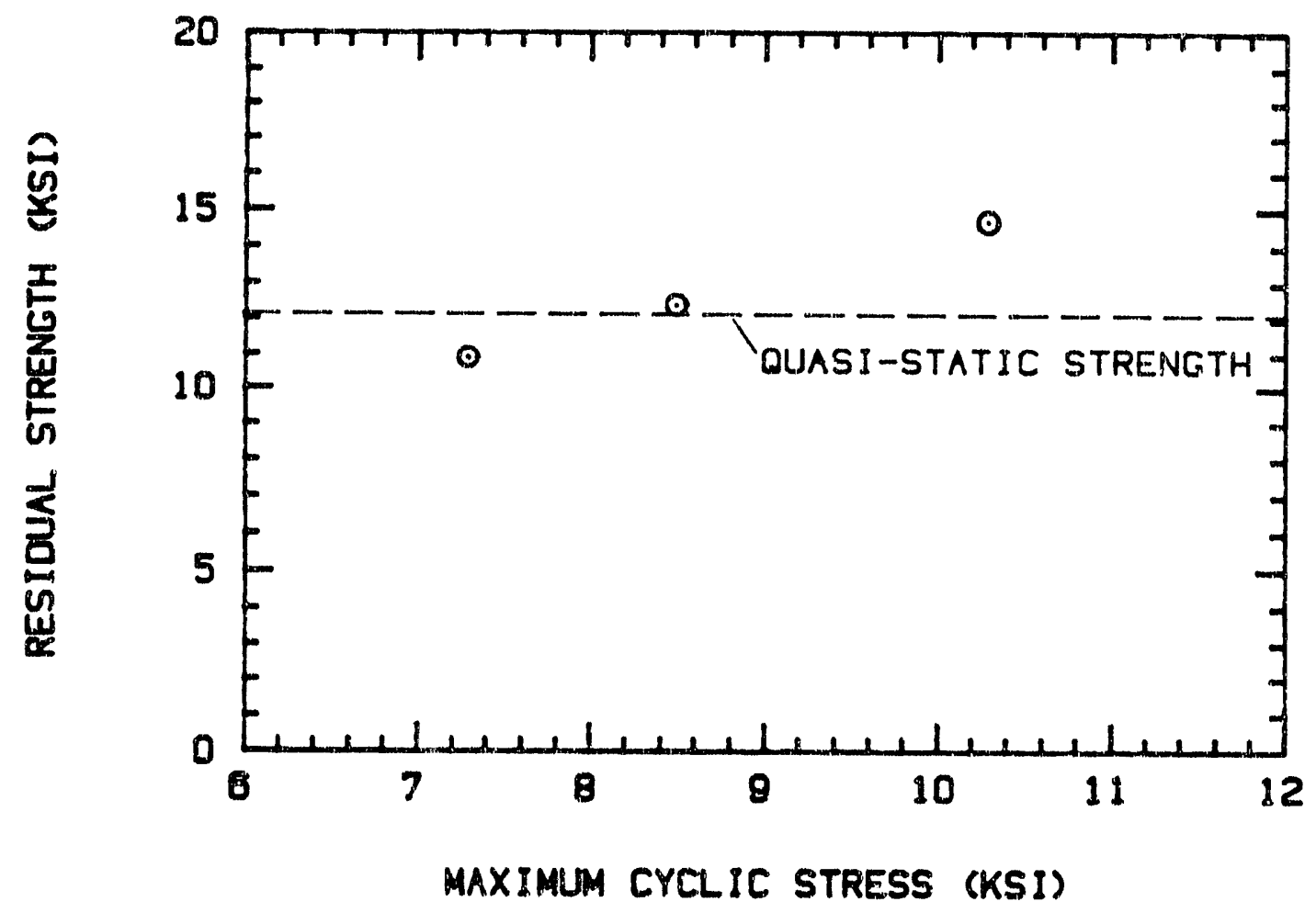

Fig. 6.1.2 Residual Strength Results After one Million Cycles. 
strength tests compared to the quasi-static tensile results on the uncycled specimens. Not only is the residual strength of Specimen258-89 (cycled at 85\% of UTS) greater than the residual strengths of the other two fatigue specimens, it is $21 \%$ greater than the mean quasi-static strength. Note that the scatter in quasi-static strength values is small (UTS $=12.3 \pm 0.4 \mathrm{ksi}$ ). clearly, a type of wear-in phenomenon has occurred.

\subsubsection{Post-test Evaluation of the Specimens.}

The post-test evaluation of the specimens consisted of a fractography investigation of the failed surfaces and radiography of the failed specimens. Figure 6.13 presents a radiograph of a failed half of specimen 118-89 which failed under a monotonically increasing tensile load. Evaluation of this figure shows the failure surface closely follows the fiber swirling in the downstream transition region. Similar results were observed in all of the quasi-static specimens. Therefore, in-plane fiber swirling should be considered a critical defect for these tubes.

The majority of the post-test evaluation focused on the fractographic analysis of the failure surfaces. Figures 6.14 through 6.16 present photographs of failed specimens. The downstream grip end of specimen 261-89 has been removed for the bar tests described in the next section. Recall, specimen 261-89 was loaderi in quasi-static tension. Specimen 260-89 was cycled at $65 \%$ of the UTS for one million cycles and then loaded in quasi-static tension. Specimen 258-89 was cycled at 85\% of UTS for one million cycles and then loaded in quasi-static tension. visual comparison of the failure surfaces yields two major differences. First, the failure surfaces for specimens 261-89 and 260-89 tend to vary in axial location around the circumference; whereas, the failure surface in specimen 258-89 tends to be located at the same axial location around the entire cixcumference. Second, the 


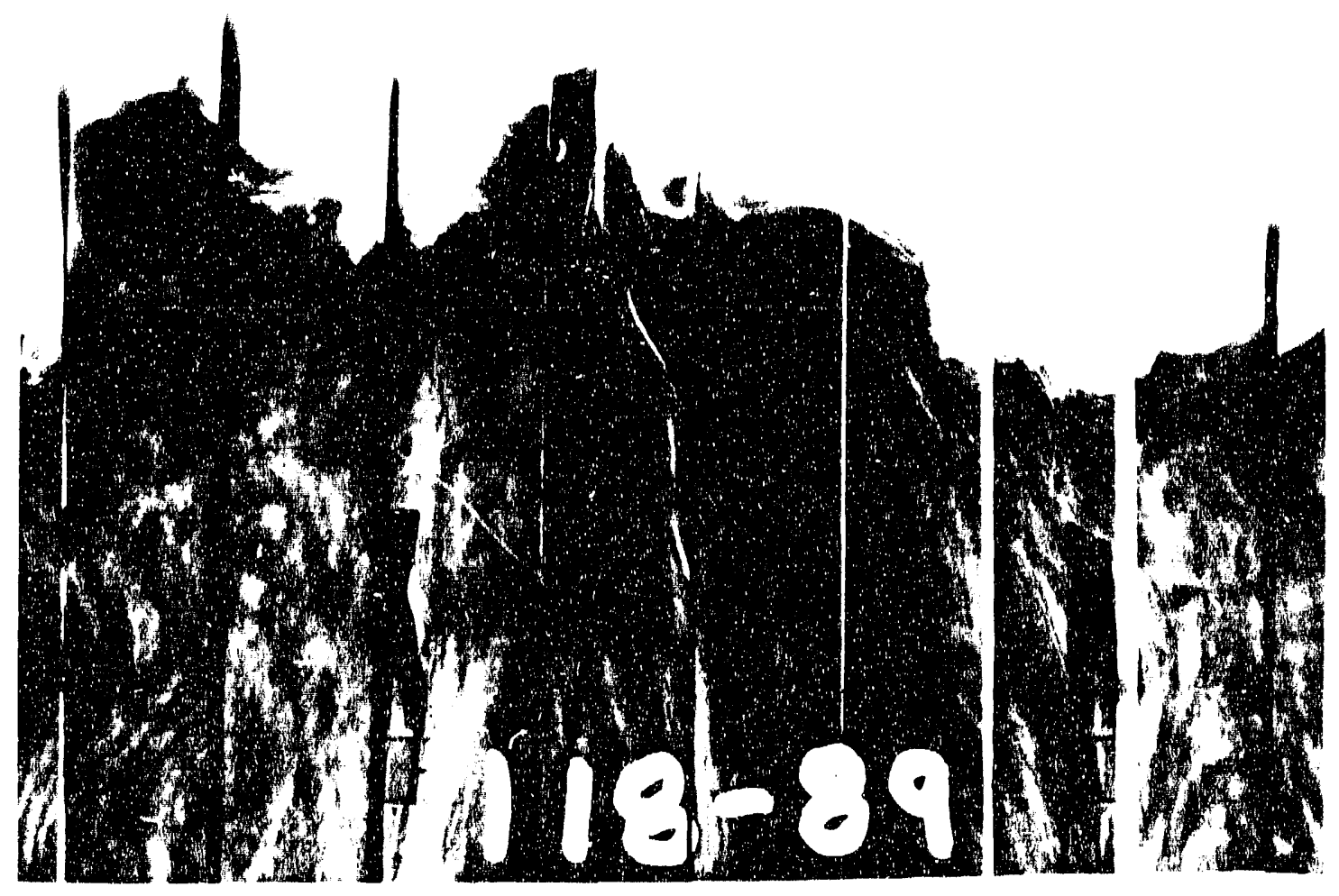

Fig. 6.13 Radiograph of Downstream Failure Region of specimen 118-89. 


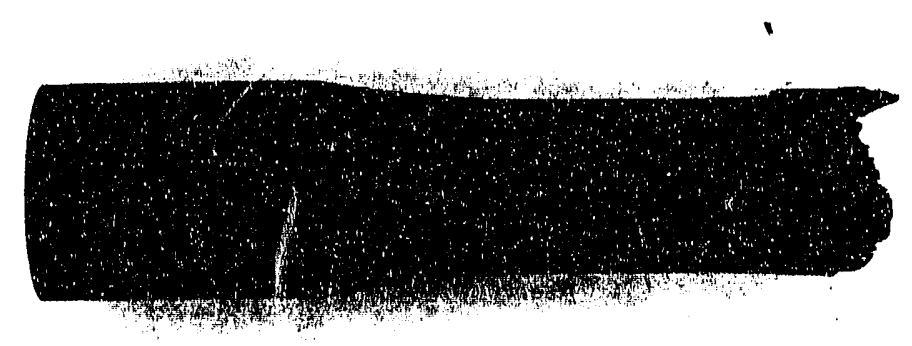

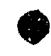

-

-

C

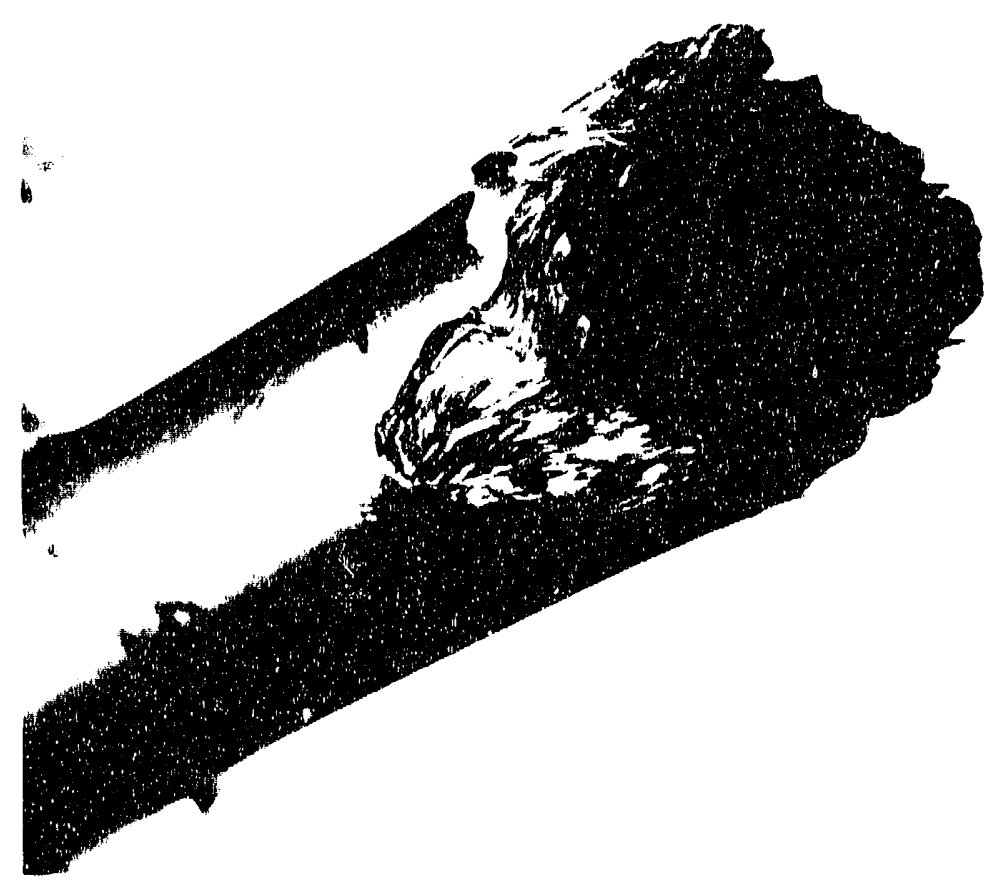

Fig. 6.14 Specimen 261-89 After Failure. 

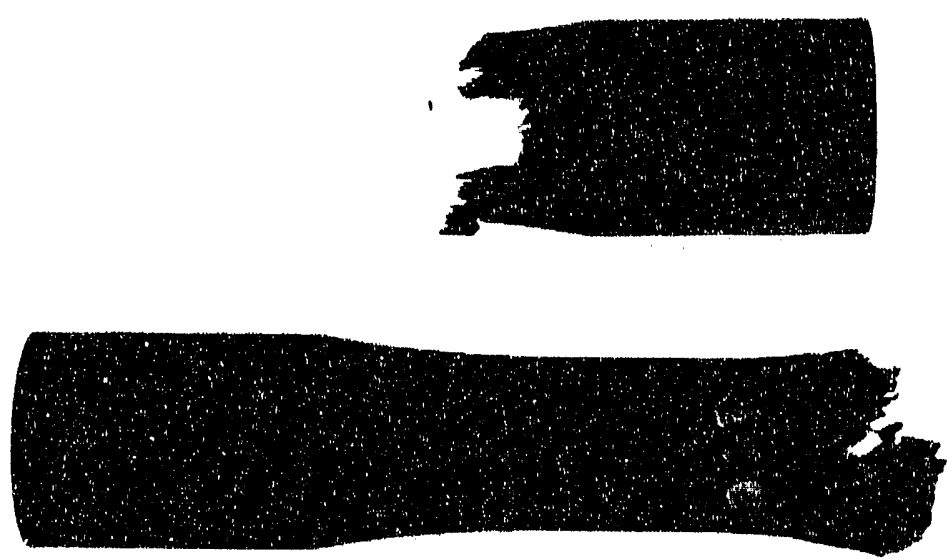

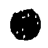

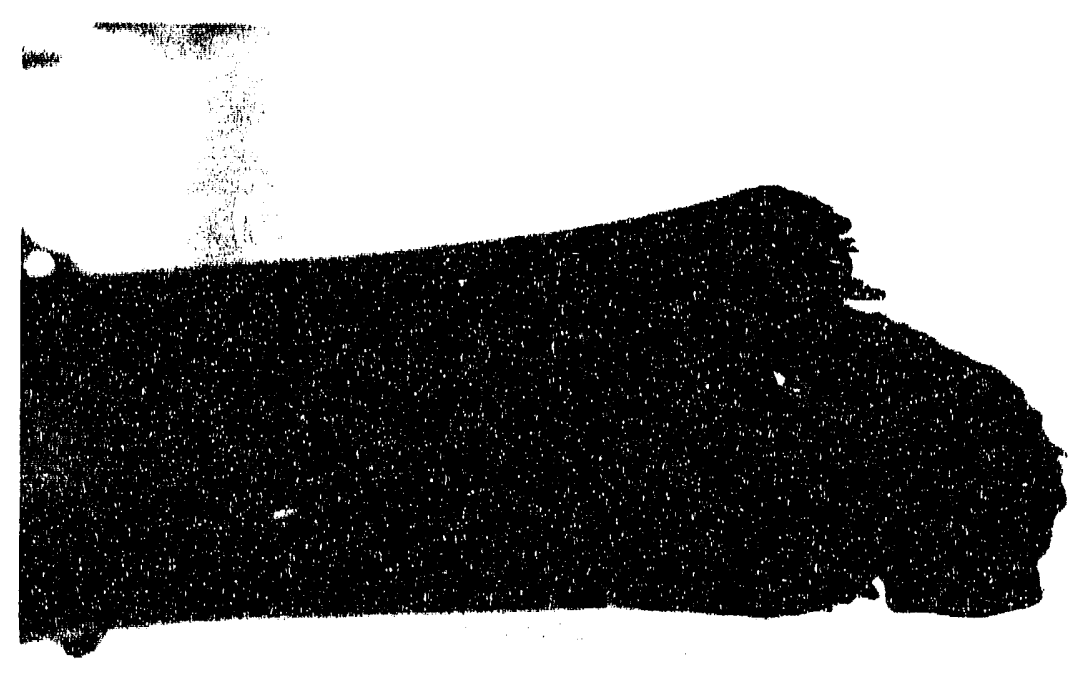

-

-

-

-

Fig. 6.15 Specimen 260-89 After Failure. 

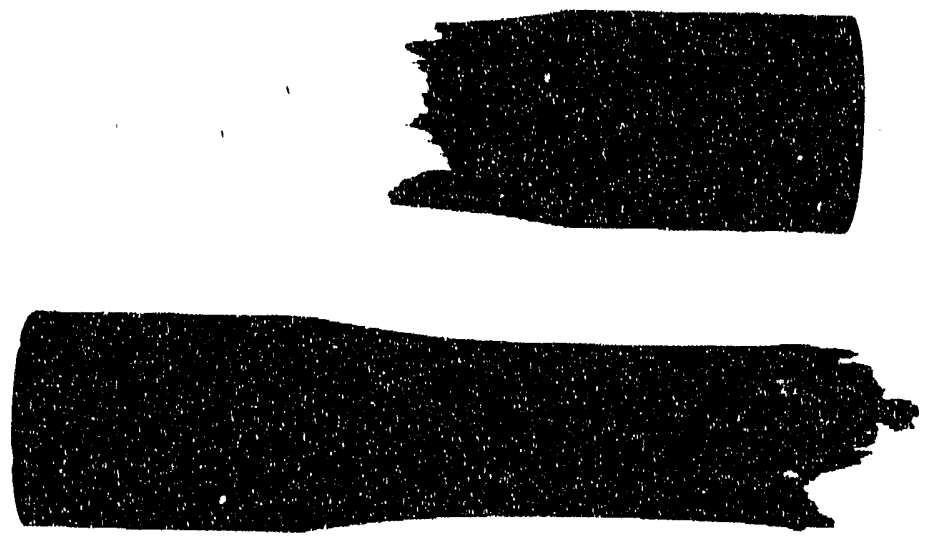

$-$

6

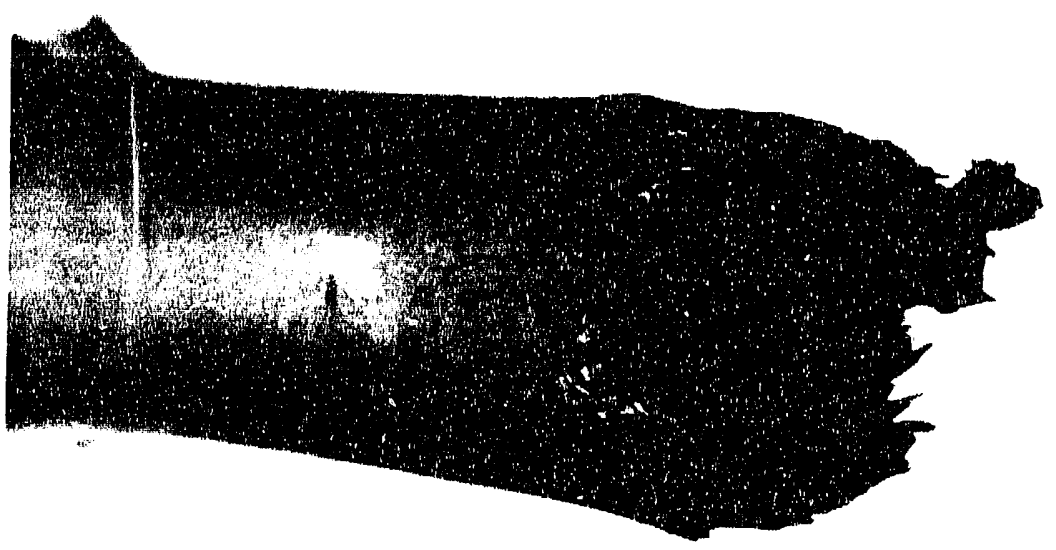

Fig. 6.16 Specimen 258-89 After Failure. 
location of the failure surface in specimen 258-89 tends to be closer to the gage section than the other two failure surfaces.

A magnified examination of the failure surfaces indicates two different types of fiber pullouts. Examples of these fiber pullouts are shown in Figures 6.17 and 6.18. In Figure 6.17 from specimen 118-89, the pullouts appear to be grouped in large fiber bundles where all of the fibers in a bundle are oriented in the same direction. 'The ends of these fiber bundles are fairly blunt and are primarily located on the upstream side of the failure su iace. In addition, the downstream side of the failure surface appears as a wide, but shallow, canyon. The failure region from Specimen 260-89 shown in Figure 6.18 is slightly different. In this case, exposed fiber bundles are more straw-like, and the canyon along the failure surface in the downstream end of the specimen is much deeper and narrow than observed in Figure 6.17.

Correlation of the above fractography results with the micrographs of the sectioned specimen showing out-of-plane fiber swirling indicates the failure modes in Figures 6.17 and 6.18 may be significantly different. Figure 6.19 presents a drawing of out-of-plane fiber swirling, and two possible failure modes in connection with this type of fiber swirling. In mode "A" the failure is located at the cusp of the fiber swirl and consists of a transverse failure of the matrix. This type of failure would produce the klunted fiber bundles and the wide, sliallow canyons shown in Figure 6.17. A mode "B" failure occurs at the tail of the swirled fiber. This type of failure mode would produce the deeper canyons and the straw-like exposed fibers shown in Figure 6.18. Notice, the mode "B" failure would be located closer the gage section than the mode "A" failure.

In addition to the two failure modes described above, several regions of "in-plane" failure modes were observed. These failures occurred along the edge of particularly dominate fiber swirls. 


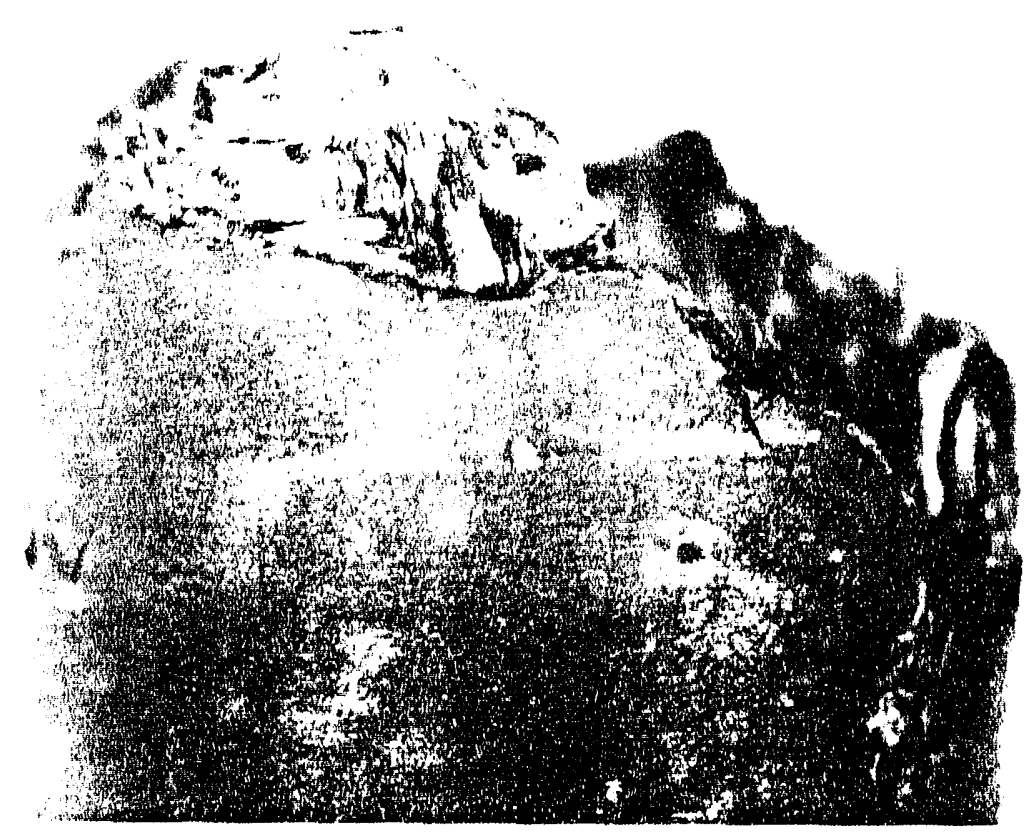

Fig. 6.17 Fiber Pullout Regions with Blunted Ends in Specimen 118-89.

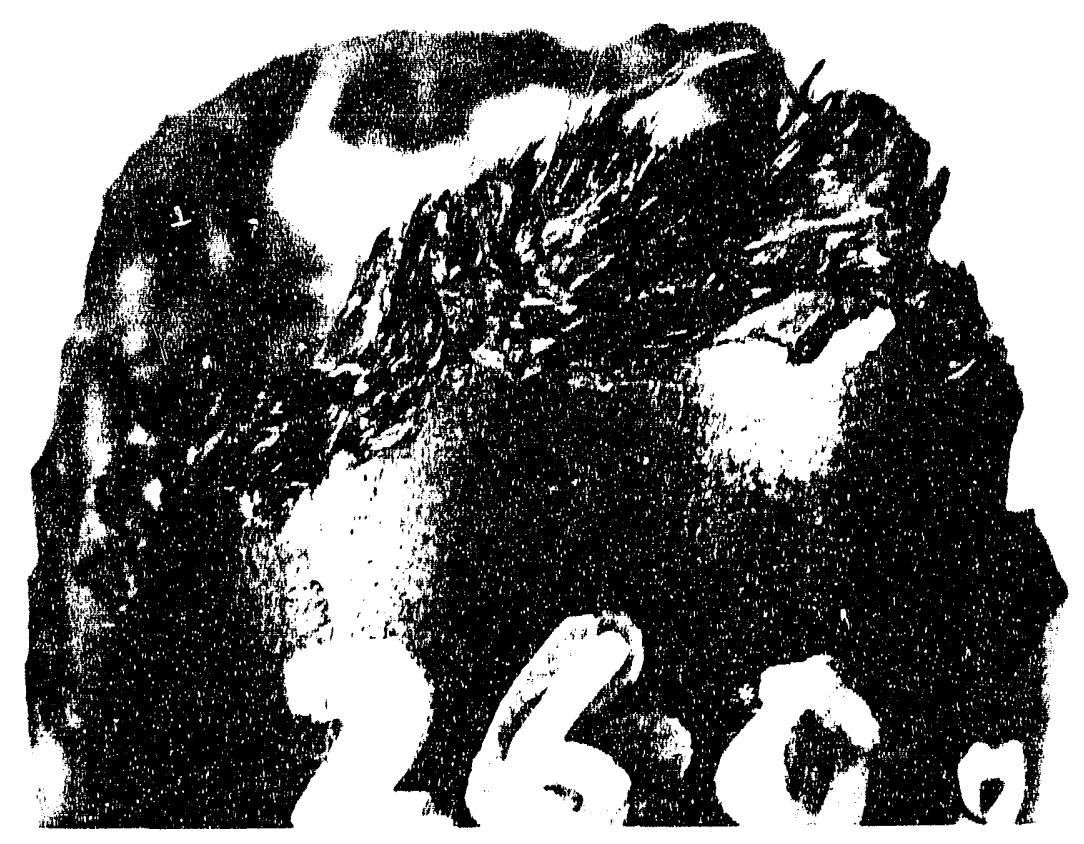

Fig. 6.18 Straw-like Fiber Pullout Regions in Specimen 260-89. 
MODE "A" FAILURE AT THE CUSP OF A FIBER SWIRL

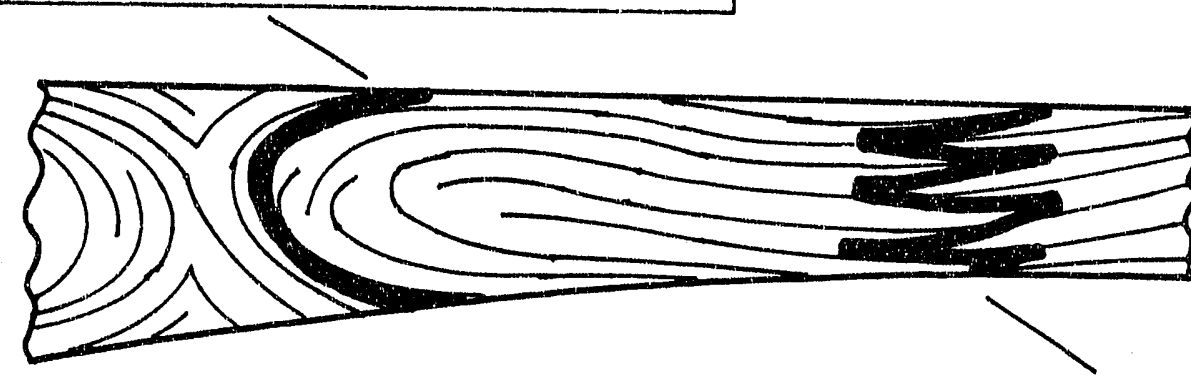

MODE "B" FAILURE AT THE

TAIL OF A FIBER SWIRL

Fig. 6.19 Possible Failure Modes Associated with out-of-plane Fiber Swirling.

Figure 6.20 presents a micrograph of one of these failure regions where the fibers are oriented transversely to the loading direction of the tube. Evaluation of Figure 6.20 indicates a transverse failure of the matrix. Similarly, Figure 6.21 presents a micrograph of a failure region where the fibers are aligned with the loading direction, suggesting a shear failure of the matrix.

In all of these cases, highly magnified SEM images of fiber ends indicate the fiber-matrix interface at the end of the fiber has failed, and the fiber has not failed. Although all the specimens exhibited a combination of the failure modes described above, the general trends in the failure surfaces of the quasi-static specimens and the high cyclic load specimens are different. The failure surfaces of the quasi-static and the cyclic specimen at $60 \%$ of the UTS tend to be dominated by "in-plane" 


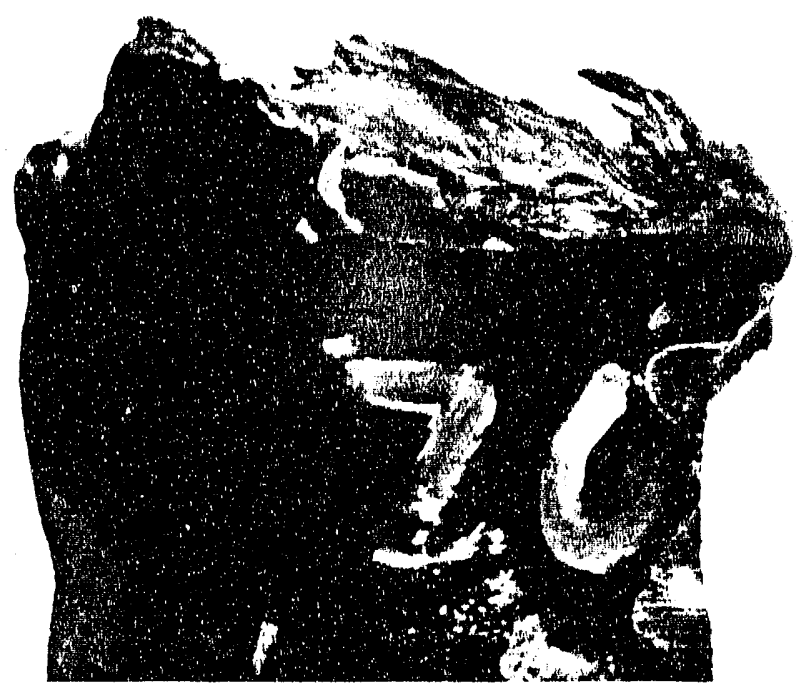

Fig. 6.20 Micrograph of a Failure Region where the Fibers are oriented Transverse to the Loading Direction.

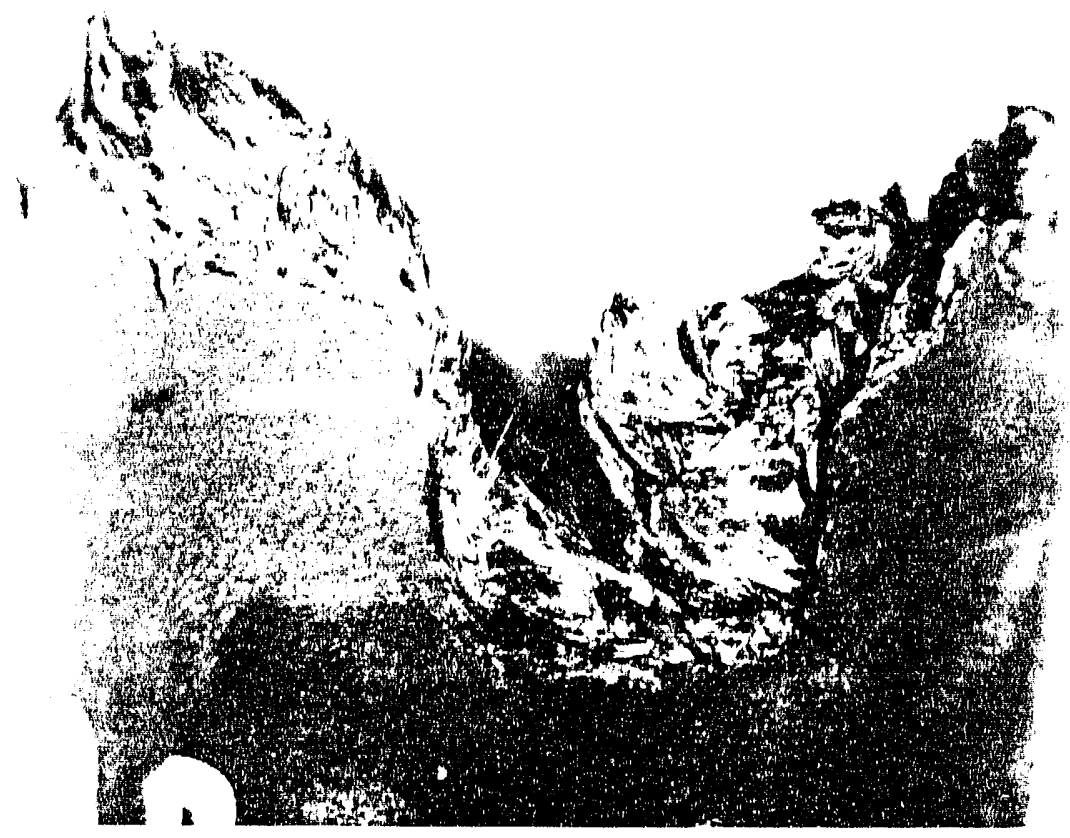

Fig. 6.21 Micrograph of a Failure Region where the Fibers are Aligned with the Loading Direction. 


\section{Transverse Cracks \\ Develop at the Cusp of the Fiber Swirl}

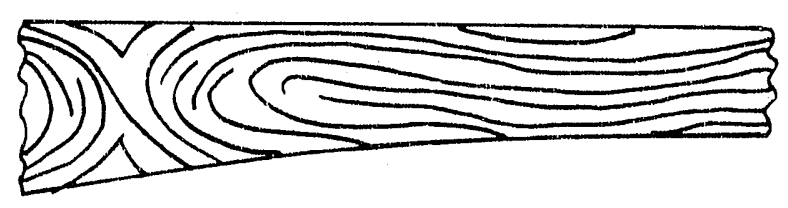

The Transverse Cracks Propogate as Matrix Cracks

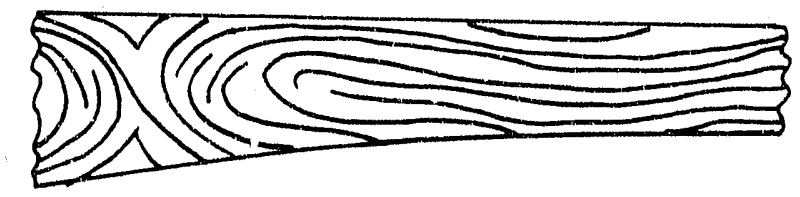

Load is Now Transfered by Fiber Bridging and the Stress concentration at the Cusp is Reduced

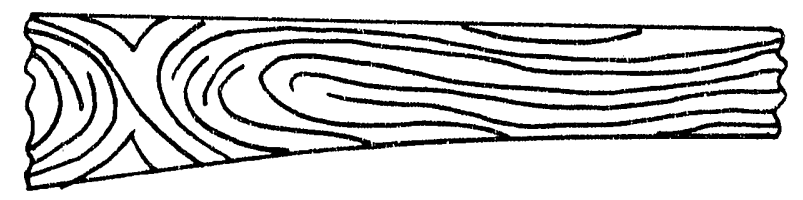

The Failure site is then Moved Closer to the Gage Section and the Failure Mode Changes

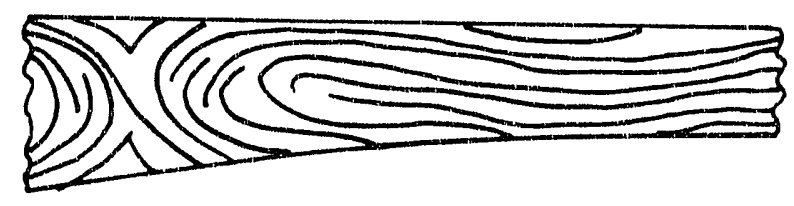

Fig. 6.22 Postulated Wear-in Phenomenon for Specimen 258-89. 
failure modes and mode "A" out-of-plane failure modes shown in Figure 6.19. Conversely, the high stress cyclic specimens are dominated by the mode "B" straw-like fiber pullout and deep, narrow canyons. In addition, the amount of "in-plane" failures in the high stress cyclic specimens seems significantly less, and the failure surfaces tend to be located closer to the gage section, than in the quasi-static specimens with the mode "B" failures.

This change in failure modes between specimens 258-89, cycled at $85 \%$ of UTS, and 260-89, cycled at $60 \%$ of UTS, could be the result of the wear-in phenomenon shown in Figure 6.22. Early in the load history, transverse cracks develop at the cusp of a fiber swirl. As the load is cycled, these matrix cracks propagate normal to the loading direction and into stronger regions of the material. The load is then transferred across the matrix cracks by fiber bridging. As a result, the stress concentrations associated with the fiber swirl have been reduced, and the failure mode changes to a Mode "B" type failure.

In the case of specimen 260-89, which was cycled at $60 \%$ of UTS, transverse cracks initiated at the cusp of a fiber swirl. However, the load was not great enough to propagate the matrix cracks into the stronger regions of the material. As a result, the failure modes of specimen 260-89, due to quasi-static loading after one million cycles, are very similar to the failure modes of the quasi-static specimens. Unfortunately, the limited number of specimens available in this program severely precluded any additional characterization or understanding of this wear-in mechanisin. 


\subsection{ANALYTICAL MODELING OF DAMAGE DEVELOPMENT IN COMPOSITE COMPONENTS}

Quasi-static and fatigue failures of anisotropic, fiber reinforced composite materials are very complex and difficult problems to address. Unlike metals, for which failure is generaliy controlled by a single flaw growth, composite materials show a variety of damage modes, and interaction between these modes, which lead to failure. In addition, the internal stress state is highly dependent on the geometric configuration and the material. For injection molded composite components, the problem is further complicated by the non-uniform fiber distributions throughout the component. In this section, a model is developed to predict damage development within a composite component and to determine the effects of the damage on strength, stiffness and life of the component. Due to the progressive nature of the damage development process, a progressive failure analysis is performed. In addition, to make the approach applicable to composite components with complex geometries and loadings, the analysis is based on an approximation technique such as the finite element method. The solution technique parallels the ply discount schemes developed for laminated polymeric composites, except a failed element is discounted instead of a failed ply. The resulting approach can randle complex geometries, complex loadings, and local materiai property degradations.

The remainder of this section contains detailed descriptions of the formulation, execution, and results of the method. Section 7.1 presents an overview of the method and the steps involved in the execution of an analysis. Section 7.2 describes the mechanics which form the basis of the analysis. Section 7.3 presents the results of the method applied to an injection molded tube specimen subjected to quasi-static tensile loading. The final section, section 7.4, discusses the problem areas, limitations, and advantages of the approach. 


\subsection{General Methodology}

The approach is based on the simple methodology depicted by the flow chart shown Figure 7.1. A computer program using this approach was developed on the sun $3 / 60$ machine and is written in $C$ language. The analysis starts with the development of a standard finite element model using a typical preprocessor. The model is then written to a file which is subsequently divided into several. smaller files with a text editor. The contents of these smaller files will be discussed later in the program. These steps are performed outside of the actual c program. Next, the global load history, stress-life (S-N) parameters, and output file names are specified in the initialization subroutine or procedure. The program is then compiled and executed. During execution, the program generates a unit loading on the specified loaded elements and calculates the state of stress throughout the structure via a finite element solution for each load step. The stress results are then linearly scaled in order to produce the actual applied loading. Next, the elements are checked for failure using a pre-selected failure criterion. If elements fail, the first element to fail is identified, and the elastic properties of this element are reduced. The stress state is then re-calculated throughout the entire component, and the failure checks are repeated. Once the failure iteration procedure has been completed, the actual state of stress and the state of material throughout the component at the end of the load step is known.

In the evaluation of the element failures, two types of loadings must be considered. First, a load increase from one load step to another is considered. Therefore, failures may be predicted in the first half cycle of the loadstep. This failure is referred to as a quasi-static failure. The second type of failure is the result of the strength degradation due to the number of cycles in the load step. This type of failure is referred to as a residual strength failure. 


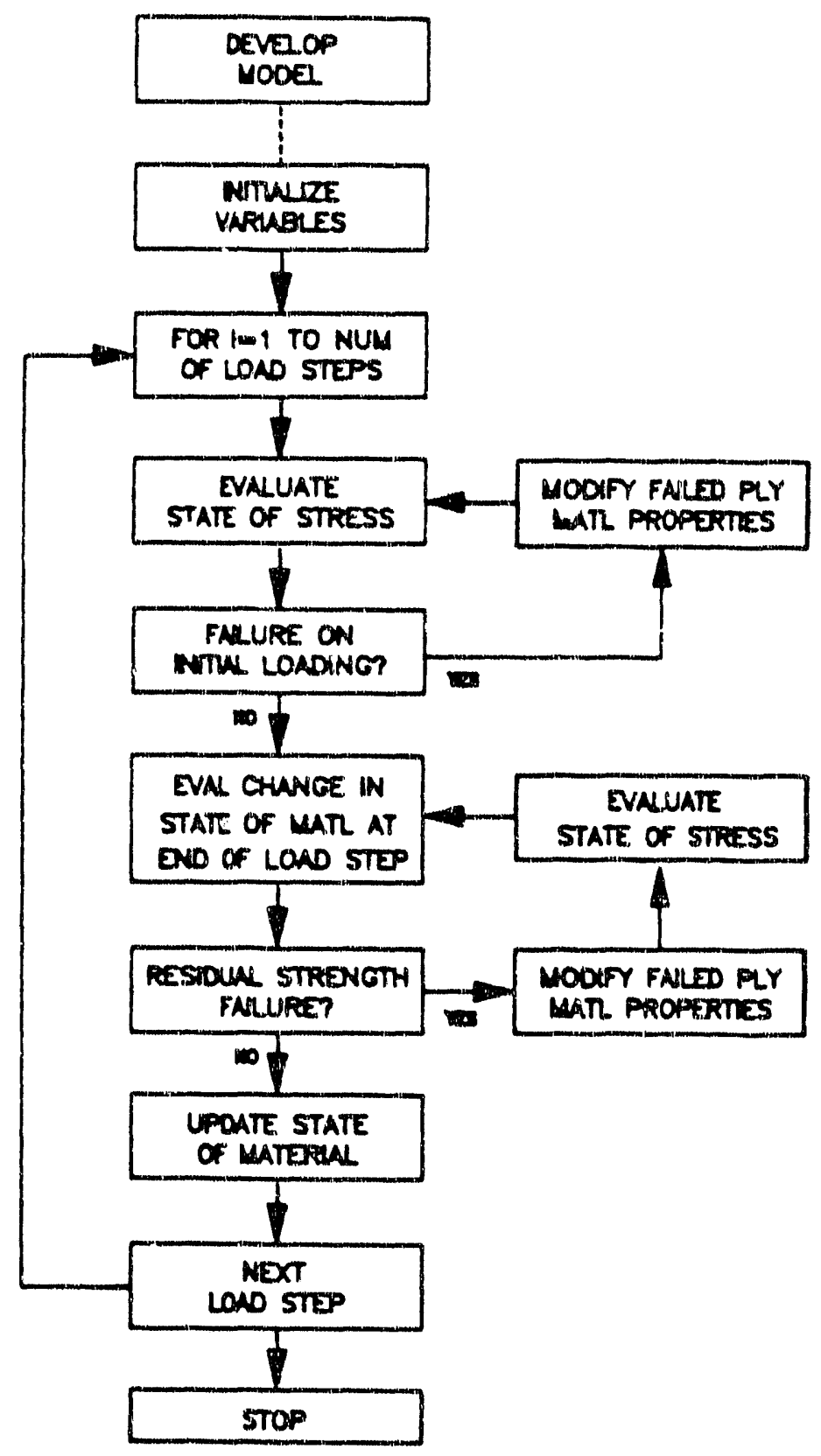

8

iiv

FALURE ON

MOOFY FALED PLY

6

NTWLEE

no

in

UPOATE STATE

Fig. 7.1 Flow Chart of the Analytical Solution Methodology. 
The quasi-static failure is based on the state of material at the beginning of the load step, and the residual strength failures is based on the state of material at the end of the load step. Therefore, if an incremental loading occurs, with no additional cycles in the load step, it is not necessary to calculate residual strength failure potentials since the residual strengths will not change over the load step. Likewise, if the applied global loads do not change from the previous load step, it is not necessary to calculate the quasi-static failure potential since the stress states and failure potentials will be identical to the stress states and failure potentials at the end of the previous load step.

The main advantage of this approach is the simplicity of a linear elastic analysis and the capability of the finite element method to handle complex problems. The damage model idea can be extended to the damage development in laminated composite materials. In the analysis of laminated composites, the ply-level elastic properties of failed elements are reduced. In both cases, by degrading a single element or ply, damage development on a local level can be modeled throughout the component.

\subsection{Mechanics}

In the development of this approach many difficult selections vere made with regard to mechanics. The mechanics issues can be divided into two distinct areas, stress evaluation and failure mechanics. The stress evaluation considexations primarily involved the selection of a finite code to solve for the stress distributions. Failure mechanics considerations include failure modes, quasi-static and residual strength failure criteria, and elastic property reduction schemes to model a failure. Each of these areas is discussed in detail.

Although the damage development analysis is fairly involved, the stress evaluation portion of the analysis is a straight-forwara 
linear elastic analysis of a structural component. Therefore, most finite element codes would be acceptable for this analysis, including miny of the commercially available finite element codes such as MS-Nastran, ANSYS, ABACUS, Marc, and others. The commercially available general-purpose codes also have the advantage of excellent pre- and post-processing capabilities. For this work, the ANSYS Finite Element code (54) was selected because of experience with the code. For an injection molded component, the finite element model is constructed with 8-node brick elements (STIF45) where the fiber orientations in the element are specified using the ANSYS ESYS command. The most difficult portion of the analysis is the transfer of the fiber orientations, as measured on the radiographs, to the finite element model. In general, each of the fiber orientations must be specified individually. The reader: is referred to Reference 55 for the details of the element. formulation and guidelines on the use of these elements.

The failure modes for composite materials can be very complex and show extensive amounts of interaction. However, for this analysis, the failure modes were limited to fiber failure, matrix cracking parallel to fibers, and shear failure of the matrix. other failure modes such as laminate buckling or delamination were not observed.

The first type of failure to consider is quasi-static failure due to monotonically increasing loads. Two different failure criteria are included in the analysis. The first uriterion is the maximum stress criterion for which failure is predicted when at least one of the following conditions is satisfied:

$$
\begin{aligned}
S_{1} / X_{1} \geq 1, \quad S_{1} / X_{c} \geq 1, & S_{2} / Y_{t} \geq 1, \\
S_{2} / Y_{c} \geq 1, \quad S_{3} / Z_{1} \geq 1, & S_{c} / Z_{c} \geq 1, \\
\mid S_{4}: / S_{23} \geq 1, \quad & \text { or } \quad \mid S_{5}: / S_{13} \geq 1, S_{12}>1,
\end{aligned}
$$


where,

$S_{1} \ldots S_{0}$ are stresses defined with respect to the principal material directions 1,2 , and 3 .

$X_{1}$ and $X_{c}$ are 1-direction tensile and compressive strengths;

$Y_{1}$ and $Y_{c}$ are 2-direction tensile and compressive strengths;

$z_{1}$ and $z_{c}$ are 3 -direction tensile and compressive strengths;

$S_{23}$ is the shear strength in the 2-3 plane;

$S_{13}$ is the shear strength in the 1-3 plane;

$S_{12}$ is the shear strength in the 1-2 plane;

The second, quasi-static failure criterion is the Hill Failure criterion where failure is preaicted when

$$
(G+H) S_{1}^{2}+(F+H) S_{2}^{2}+(F+G) S_{3}^{2}+2 L_{1} S_{4}^{2}+2 M S_{5}{ }^{2}+2 N S_{6}^{2} \geq 1
$$

where,

$$
\begin{aligned}
& 2 \mathrm{H}=1 / \mathrm{X}^{2}+1 / \mathrm{Y}^{2}-1 / \mathrm{Z}^{2} \\
& 2 \mathrm{G}=1 / \mathrm{X}^{2}+1 / \mathrm{Z}^{2}-1 / \mathrm{X}^{2} \\
& 2 \mathrm{~F}=1 / \mathrm{Y}^{2}+1 / \mathrm{Z}^{2}-1 / \mathrm{X}^{2} \\
& 2 \mathrm{~L}=1 / \mathrm{S}_{23}{ }^{2} \\
& 2 \mathrm{M}=1 / \mathrm{S}_{13}{ }^{2} \\
& 2 \mathrm{~N}=1 / \mathrm{S}_{12}{ }^{2}
\end{aligned}
$$

In this case, the selection of tension or compression values for $x$ is less obvious. However, in this analysis, $S_{1} \geq 0$ implies $X=X_{1}, S_{1}<0$ implies $X=X_{c}, S_{2}>0$ implies $Y=X_{1}$, and so on.

The second type of failure to consider is strength degradation due to the cyclic loading. A normalized residual strength reduction expression was used (56).

$$
S_{x j}=1-\int_{0}^{\beta}\left(1-S_{j} / S_{u j}\right) i(n / N)^{i-1} d(n / N)
$$


where,

$s_{j}$ is the stress in the $j-t h$ direction for $j=1, \ldots, 6$;

$\mathrm{S}_{\mathrm{r} j}$ is the $j$-th direction residual strength parameter;

$s_{u j}$ is the quasi-static strength in the $j$-th direction;

$\mathrm{n}$ is the number of cycles imposed at stress $\mathrm{s}_{\mathrm{i}}$;

$\mathrm{N}$ is the cycles to failure at stress $\mathrm{S}_{\mathrm{j}} ;$

$B=$ the life fraction $(\mathrm{n} / \mathrm{N})$ at which residual strength is to be determined; and,

$i$ is a sudden death parameter generally equal to 1.2 .

More details on the residuai strength approach are given in Section 8. Specific, working details on the application of the quasi-static and residual strength failure criteria in the damage model are given in reference 57 .

Once the new strength at the end of the load step has been calculated, either the maximum stress criterion or Hill's criterion can be used to calculate failure potentials for each element ply. If any of the failure potentials are greater than unity, failure is predicted. 'io simulate a failure, the appropriate elastic properties of the failed element are reduced by 90 percent. The elastic properties that are reduced correspond to the failure mode. Thexefore, in the pre-processing phase of the method, several sets of material properties are generated. Each material property set corresponds to a specific failure mode for an element.

As previously stated, fiber failure, matrix failure, and shear failure are considered. In addition, these failure modes may be coupled. For example, if a shear failure is predicted by the maximum stress criteria, the shear loads generate a matrix crack in the ply. Therefore, the shear stiffness, the transverse stiffness, and the 2-3 poisson's ratio are reduced by $90 \%$ or more to simulate the failed ply.

This completes the development of the mechanics for the solution process. In summary, the stress state is calculated with 
a linear elastic sinite element model. Failure is then predicted with either a maximum stress criterion or a Hill's criterion at the element level. If a failure is predicted, the load redistribution due to failure is simulated by reduced local element properties. The entire procedure is built on relatively simple, but sound, mechanics.

\subsection{Application of the Method to the Injection Molded Tubes}

The damage modeling technique was applied to the injection molded tube subjected to quasi-static loading. A finite element model was constructed to represent the tube. Eight node brick elements (stif45) were used to model the 5.0 inch portion of the tube extending outside the grips. A picture of the model is shown in Figure 7.2. For these models, the radial stress gradients were assumed to be small. Therefore, one element through the thickness was sufficient.

The most difficult task in the construction of the model involved the determination of the fiber orientations based on the $x$-ray radiograph of specimen 118-89. For this analysis, the finite element grid was positioned over the $x$-ray radiograph, and a fiber orientation was assigned to each element (Figure 7.3). The arrow head in each element points in the fiber direction. In some cases, a dominating fiber orientation was not evident, and the fiber orientation was assigned bared on the orientations in the adjoining elements. In this analysis, the out-of-plane material properties were oriented in the radial direction. The elastic properties for the undamaged material were based on the information provided by UTRC described in section 3 and summarized in Table 7.1. Notice the properties are presented in material coordinates. These undamaged elastic proprieties were identified as Material property set 1 . 


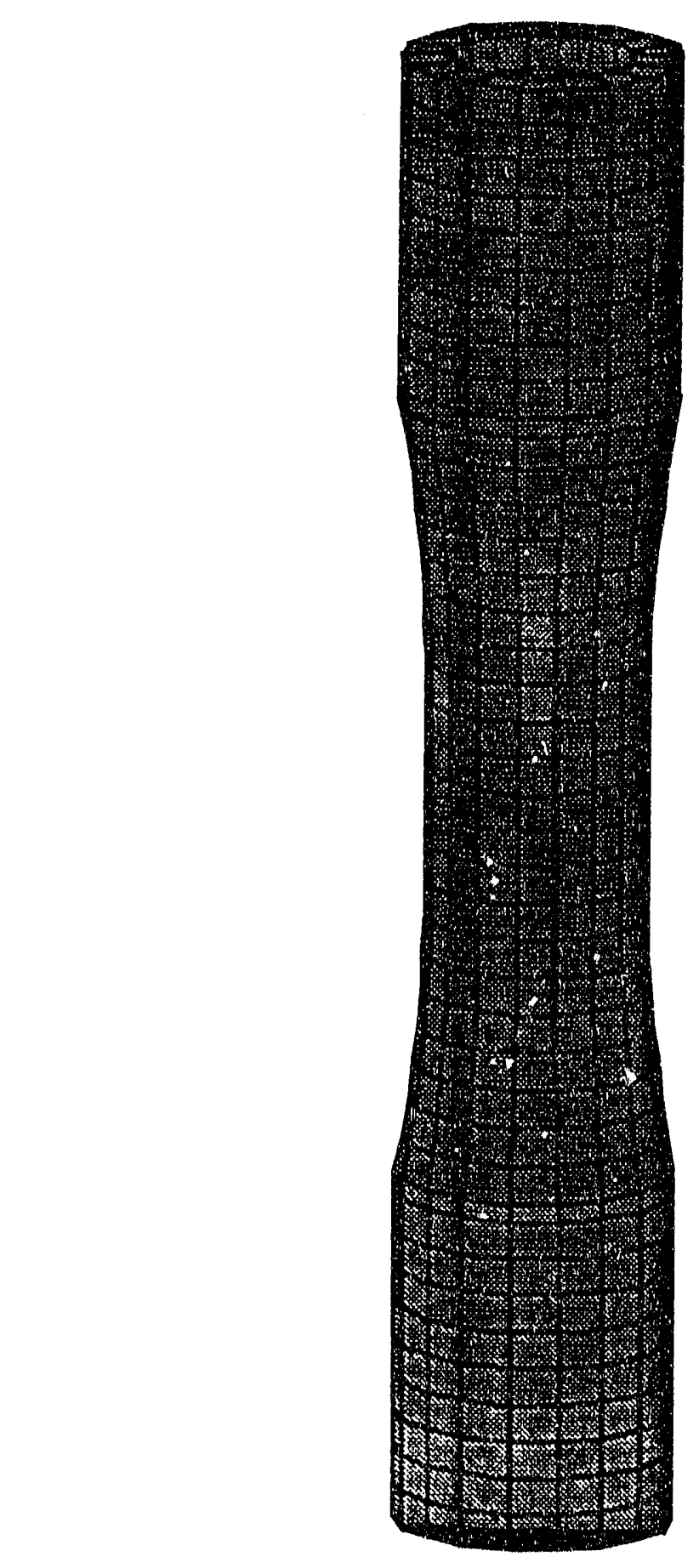

9

Fig. 7.2 The Finite Element Model of the Tube.

$\stackrel{1}{=}$ 


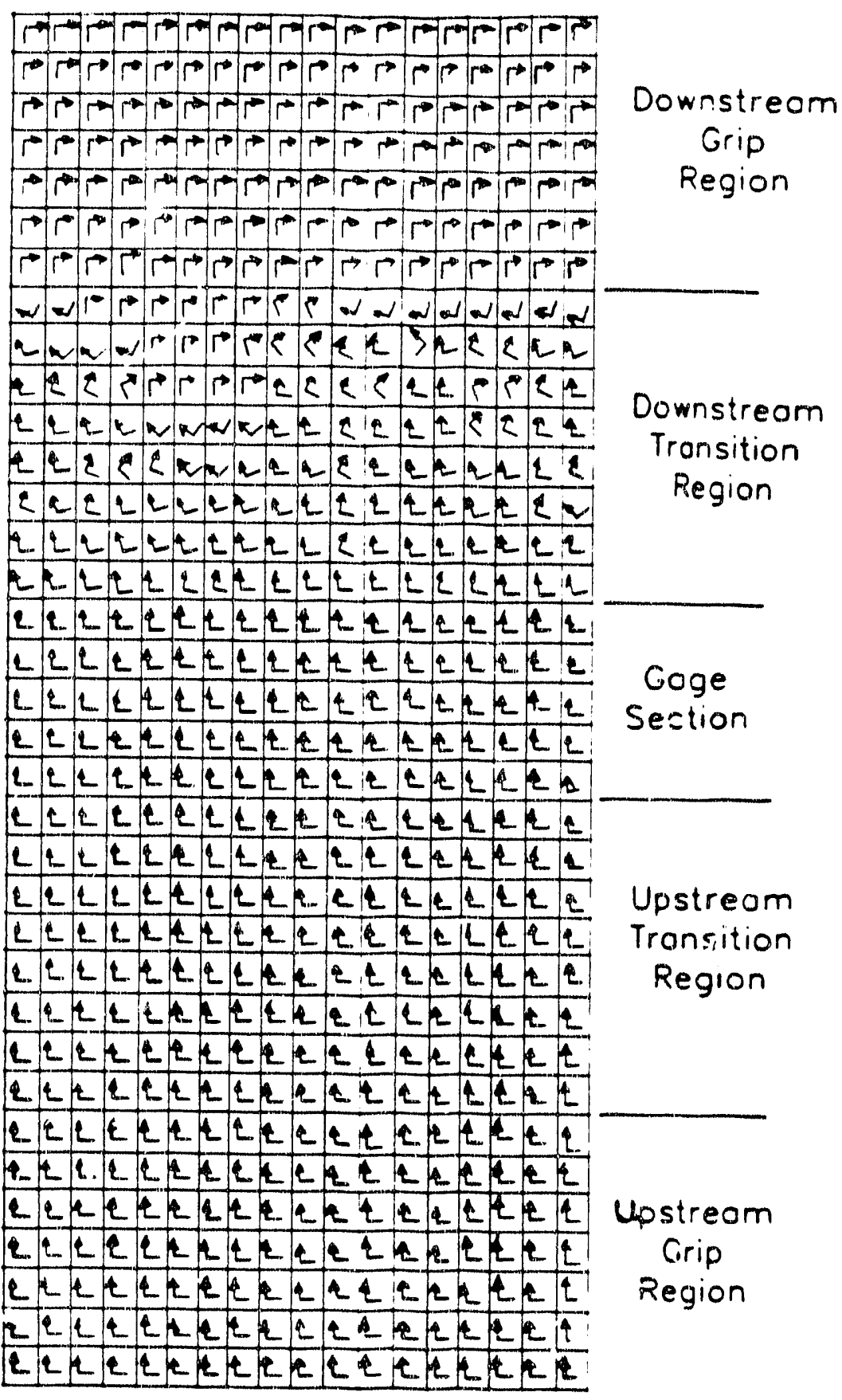

Fig. 7.3 Material Axes for the Elements in the Model. 
The longitudinal tensile and shear strengths for the fajlure analysis were based on the data provided by UTRC, and the transverse tensile strength was based on the tension bar test results (57). These strengths are also summarized in Table 7.1 . For the tensile loading investigated in this program, the radial tensile strength and the compressive strengths were not required.

Table 7.1 Material properties for the Tube Analysis.

$$
\begin{aligned}
& \text { Undamaged Material - Material Property set } 1 \\
& \begin{array}{llll}
E_{1}=8500 \mathrm{ksi} & G_{12}=800 \mathrm{ksi} & v_{12}=0.30 \\
E_{2}=5000 \mathrm{ksi} & G_{13}=800 \mathrm{ksi} & v_{13}=0.43 \\
E_{3}=5000 \mathrm{ksi} & G_{23}=800 \mathrm{ksi} & v_{23}=0.43
\end{array} \\
& \text { Tensile and shear strength properties } \\
& X_{t}=15.0 \mathrm{ksi} \quad Y_{t}=2.57 \mathrm{ksi} \quad S=5.50 \mathrm{ksi} \\
& \text { Damaged Material - Material Property set } 8 \\
& \begin{array}{llll}
E_{1}=85.0 \mathrm{ksi} & \mathrm{G}_{12}=8.0 \mathrm{ksi} & v_{12}=0.30 \\
\mathrm{E}_{2}=50.0 \mathrm{ksi} & \mathrm{G}_{13}=8.0 \mathrm{ksi} & v_{13}=0.43 \\
\mathrm{E}_{3}=50.0 \mathrm{ksi} & \mathrm{G}_{23}=8.0 \mathrm{ksi} & v_{23}=0.43
\end{array}
\end{aligned}
$$

The Hill failure criteria was used throughout the analysis, and if a failure was predicted, a $99 \%$ reduction factor was applied to the longitudinal and transverse properties. Other failure modes were not included in the model.

The boundary conditions for the model consist of $U_{z}=0.0$ displacement constraints along the bottom edge of the model. In addition, two nodes were fixed to eliminate any rigid body motion. The loads were applied in a two step process in order to simulate the loading sequence in a servo-hydraulic test frame. In the model, one end of the specimen was given a uniform displacemert, and the finite element analysis is performed to determine the 
stress state throughout the specimen and the reaction forces at the imposed displacements.

The analytical results are presented in the form of damage maps. A shaded element in a damage map indicates a predicted failure for that element. The initial predicted damage is shown in Figure 7.4 and occurs at 1470 pounds. This damage is located in a heavily swirled region seen on the radiograph (Figure 6.1). The next failure is predicted at 1510 pounds and propagates until the specimen completely fails. The first several failure locations at the ultimate load of 1510 pounds are shown in Figure 7.5.

Comparison of the analytical and experimental results shows a mixed correlation between the two results. On one hand, the predicked failure loads are significantly lower than the measured failure loads. The first element failure is predicted at 1470 pounds axial force, whereas, in the actual test specimen, the first failure, as indicated by an increase in the acoustic emissions activity, was thought to occur at approximately 2400 pounds. In this case, the predicted ultimate load for the tube is 1510 pounds, and the measured ultimate load is 4150 pounds. Sources of these discrepancies vill be discussed in section 7.4 .

Comparison of the predicted and actual failure surfaces shows a much better correlation. Figure 7.6 overlays the predicted failure path on the failure surface as determined from an $\mathrm{X}$-ray 


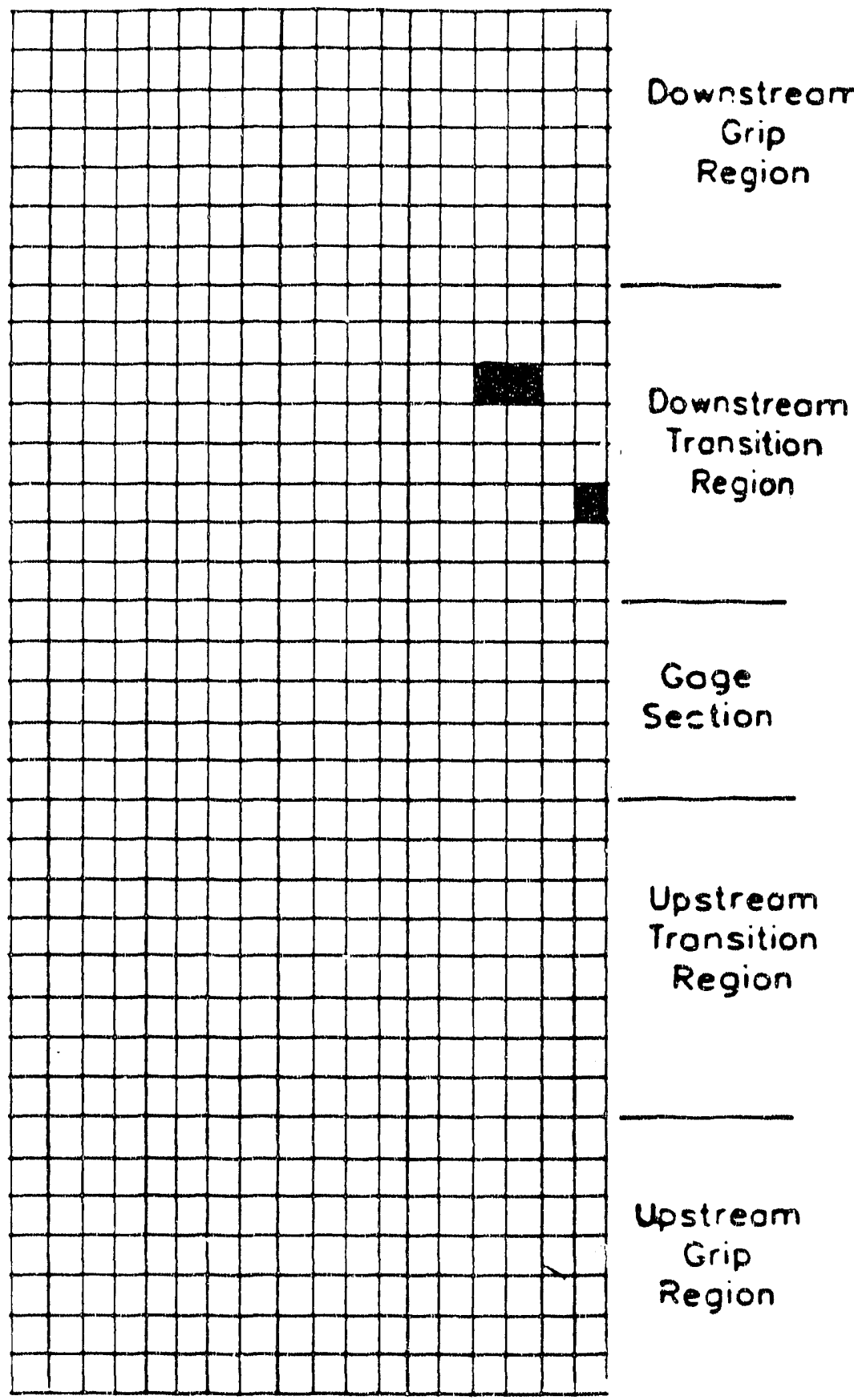

Fig. 7.4 Predicted Location of the Initial Damage. 


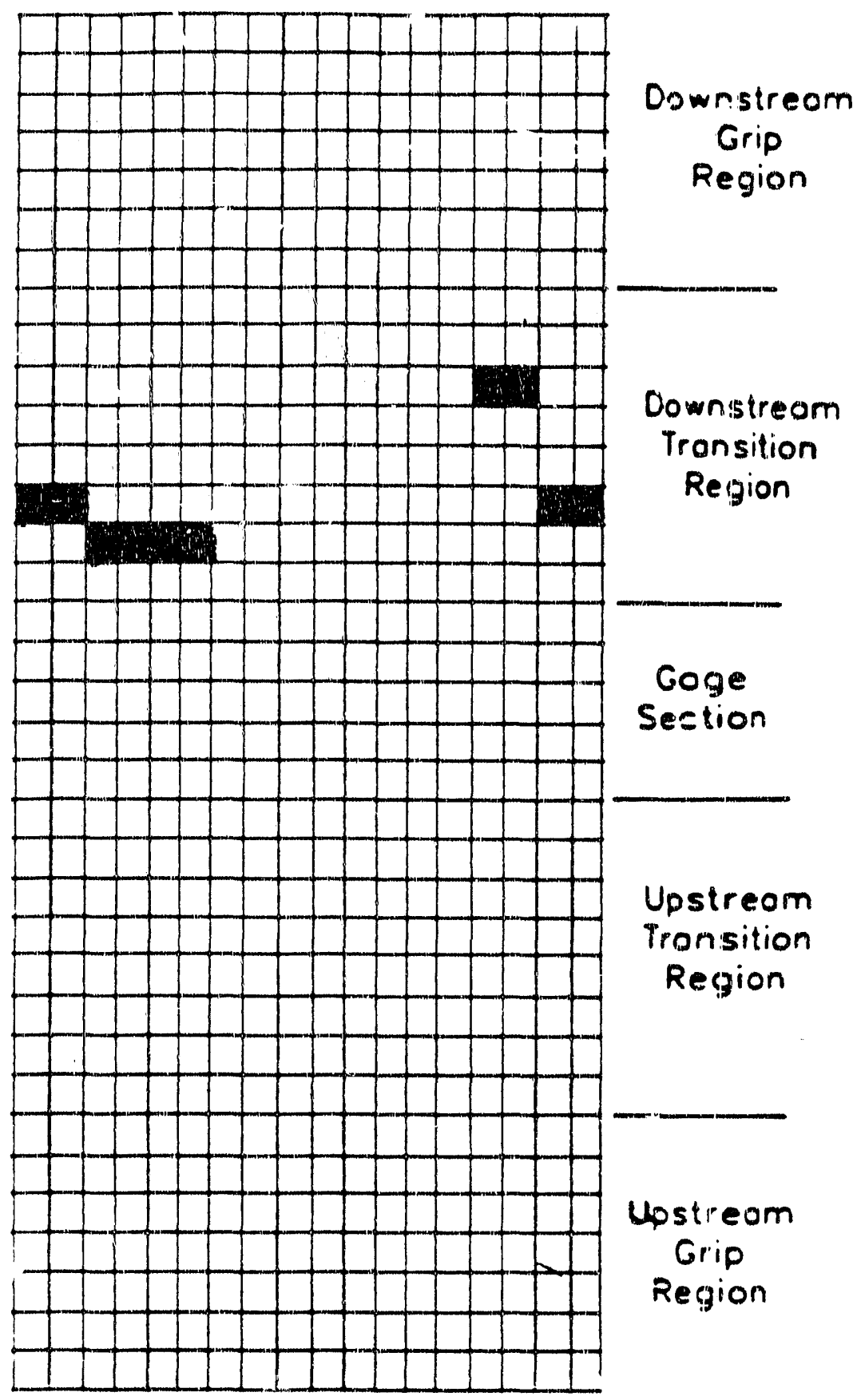

Fig. 7.5 Predicted Damage sites at 1510 pounds. 


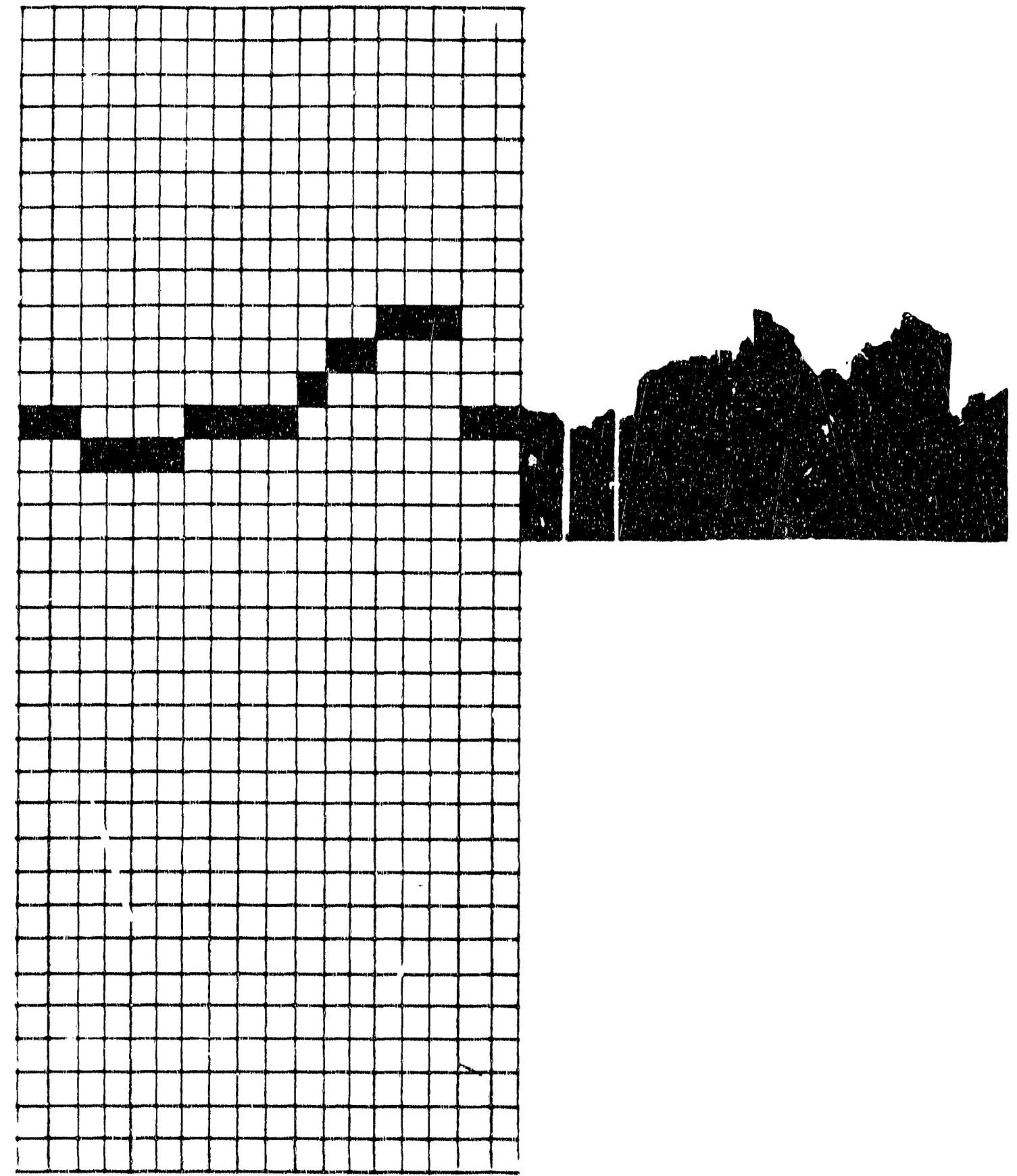

6

Fig. 7.6 Comparison of the Predicted and Observed Failure Locations. 
radiograph of the failed tube. The corresation between the predicted and experimental results is excellent.

\subsection{Discussion of the Modeling Approach}

Two classes of problems were identified in the approach to damage modeling. The first class of problems deals with the material considerations, and the second class involved mechanics issues. The material considerations suci as material properties and fiber orientations are critical due to the limited amount of material and data. The applicability of the available properties to the injection molded tubes with fairly well-defined local fiber orientations is certainly suspect. In addition, the in-plane transverse and shear strengths were based on specimens dominated by through-the-thickness properties. As a result, it is difficult to determine if the lack of correlation between the predicted and the measured values of strengtn is due to the modeling approach or to the material properties used in the model.

Similarly, the limited ability to determine fiber orientations could be another source of large errors. Although the radiographs give an excellent indication of the global trends in the fiber orientations, the local fiber orientations in most of the specimens were extremely difficult, and sometimes impossible, to accurately quantify. Secondly, several elements had more than one apparent. fiber orientation, and the dominate orientation used in the model. Lastly, and probably most importantly, the radiographs indicated only in-plane fiber swirling. The out-of-plane fiber swirling was not indicated and not modeled. Unfortunately, this out-of-plane swirling greatly influenced the failure mode of the specimen as described in the previous section.

The damage model provides a good prediction of damage sites and failure locations. This observation, along with the three dimensional nature of fiber orientations and a successful 
application of the model to laminated composites (57), suggests that the modeling approach is fundamentally sound." poor quantitative predictions in this example are due to inaccurate input data. The damage model has the capability of predicting damage in large-scale engineering components and, thereby, reduces the need for full-scale component testing. 


\subsection{PERFORMANCE SIMULATION MODEL}

The objective of the modeling part of this program was to establish an approach to the prediction of remaining strength and life of ceramic composite components under long-term loading conditions, and to create a model that can be used as the basis for reliability, safety, and durability analysis and predictions, as well as for sensitivity studies to support material system design for performance. That objective has been fully met with the creation and validation of a critical element model for remaining strength and life prediction, and the incorporation of that model into a performance simulation code callec MRLife. The steps followed in that effort were as follows:

1. Damage and failure modes were identified in the laboratory. (This task is discussed in other sections of this report.)

2. Stiffness and strength changes due to damage were modeled.

3. Time-dependent (viscoelastic) stiffness change was modeled.

4. Time-dependent strength change was modeled to represent creep rupture effects.

5. Data for a demonstration material was recovered.

6. The individual models were assembled into a performance simulation code, using the existing MRLife framework and a critical element approach. 
7. The performance model was validated for LASII/graphite composite materials to affirm the establishment of a working capability, as proposed.

In the section below, we will provide a background discussion of the concepts behind the performance modeling, and outline the critical element approach. Results of the modeling validation effort will be presenced in a later section.

\subsection{Background}

High temperature composite ( $\mathrm{HTC}$ ) material systems are widely regarded as the next major opportunity for major advancement in the performance, reliability, durability, and damage tolerance of engineering components which must operate under severe service conditions that jnclude high temperatures and aggressive environments, especially when those environments are applied over long time periods. Interest in this topic in the united states has been acute. Two recent studies by panels of the National Research Council have highlighted needs in this area $(58,59)$. (Dr. Reifsnider, one of the principal investigators on this program, served on both of those panels.) one panel was concerned with high temperature materials, especially the research needs associated with both classified and unclassified programs and directed efforts in the United states. Among other things, that panel identified a strong need for the integration of physics, chemistry, and 
mechanical behavior in efforts to represent the long-term performance of material systems which operate under severe thermal and chemical conditions. The panel devoted most of its time to the study of programs and activities associated with high temperature composite systems, in contrast to monolithic materials such as high temperature ceramics alone. The panel report makes it abundantly clear that the future of high temperature materials is defined by the future of high temperature composite material systems. However, as the report shows, research in the area of high temperature materials is difficult, and research in the area of HTC systems is even more complex and demanding.

A second panel of the National Research Council addressed life prediction methods for composite materials. This panel, which addressed the application of composite materials in all temperature ranges, identified a variety of research needs and issues which are at the base of the slow rate of application of composite materials to high performance engineering components, especially those which operate under severe conditions. It was the position of the panel that this hesitancy has its basis in a lack of understanding of the fundamental nature of damage modes and failure modes associated with the use of composite materials under severe conditions, a lack of experience on the part of designers and erigineers in the application of composite materials to primary structures, and a (severe) lack of predictive methodology which is mechanistically based and can be used to provide support for such applications. 
The panel identified severe needs in the area of the determination of long-term high temperature properties; the characterization and modeling of remaining strength in terms of damage tolerance, durability, and reliability; and the need for life prediction methodologies which can be used to describe long-term behavior in the presence of mechanical, thermal, and chemical loading. The present effort on the subject program addresses this need.

The Materials Response Group at Virginia Tech has suggested a mechanjstic approach to the prediction of strength, remaining strength, and life of composite material systems, and has demonstrated the validity and utility of such models for the prediction of damage tolerance (remaining strength, remaining life, and reliability) in polymer composite systems, as well as promising results for similar predictions for ceramic composite materials at elevated temperatures. This simulation approach is the basis for the present effort, and will be described in more detail as it has been applied to the specific objectives of this program in section 8.4. In the present section, we will briefly outline some of the salient aspects of the fundamentals behind our simulation method to provide a background for the subsequent discussion.

The first essential element of our "critical element approach" to life prediciton is a precise and comprehensive representation of micro-stress states in fiber-reinforced composite material systems, for continuous fibers and for short or broken fiber situations. This subject has received rather extensive attention in the literature, but is still inadequate for a complete description of 
the local processes which contribute to and control the damage and failure behavior of composite systems. The Materials Response Group has made majur auvances in this area. Indeed, three members of that group are in the process of preparing a manuscript which will be published as a monograph on the subject of "Micromechanics of Fibrous Composite Material systems." This monograph should be a landmark in the effort to establish firm and precise representations of the local stress fields in fibrous composites which include broken/short fiber effects, the presence of material property variations as a function of position (a critical issue for high temperature composites), interface and interphase regions, and thermal stress effects.

The second essential element for our simulation approach is a micromechanical representation of strength, i.e., a mechanistic representation of the failure process that controls both initial and remaining strength in these systems under various loading conditions and environments. We claim that interpretive models must be based on precise definitions of damage accumulation and failure modes as determined from experimental observations. We assume that the damage associated with the properties and performance of interest in our composite material systems is widely distributed, and is contributed by a variety of damage modes acting in concert and interacting in a complex fashion. We further clain that this distribution allows us to define a "representative volume" which has "average properties" of the remaining material, such that the state of material and state of stress in that representative volume 
are typical of all other such elements. We further postulate that this representative volume can be divided into critical and subcritical domains (called "critical" and "subcritical" elements). The "critical element" remains intact and contiguous in the continum sense until failure occurs at the global level, that is, the failure of the critical element defines the failure of the representative volume and the failure of our componisnt.

We further assume that the remaining material in the representative volume consists of "subcritical elements" in the sense that their failure does not cause failure of the representative volume or of the engineering component. However, damage in the subcritical elements by such mechanisms as cracking, delamination, or other irreversible behavior does cause changes in the stress state in the critical element which are quite large and important. These stress states are addressed using the micromechanical stress analysis mentioned in a previous paragraph. In general, we will describe changes in "material state" using continuum constitutive information regarding the critical element, and changes in the stress state in the critical element by attempting to describe damage development in subcritical elements using our micromechanical treatments. It should be noted that our continuum assumption regarding the critical element does not exclude discrete events from occurring on a scale which is significantly smaller that the critical element dimension. Such events which do not directly control the final remaining strength and life of the critical element or the component are grouped into 
continuum descriptions; this has the important advantage of setting a "lower limit" on the scale at which mechanics must be done, and can have the effect of greatly simplifying the necessary complexity of our analysis, as we have shown in the literature. An example of this approach is provided by our recent development of the first comprehensive micromechanical model of tensile strength in fibrous composite materials $(60,61)$.

The third and final essential element of our micromechanical approach is a predictive methodology for long-term behavior which includes the evolution of properties and performance especially the evolution which is associated with variations in material state and stress state caused by high temperature loading conditions. The approach developed by the Materials Response Group to handle this modeling challenge is a performance simulation scheme which is the basis for the MRLife code series developed over the last 11 years and in its seventh issue. The performance simulation method that we have developed is based on the critical element concepts described above and is thought to be the only mechanistic approach with reasonable generality that is presently available in the United states. This approach has garnered a great deal of attention from the technical community at the national and international levels. In the last three years this approach has been the subject of an invited plenary lecture on life prediction methodology at the International Conference on Composite Materials in London, (62); the subject of an invited plenary lecture on performance simulation in polymer based composite systems at the 
International Colloquium on Durability of Polymer Based Composite Systems for Structural Applications in Brussels Belgium (63); and the subject of an invited plenary lecture on performance simulation methods for the prediction of long-term behavior of composite material systems given at the Fifth Japan-U.S. Conference on Composite Materials in Tokyo Japan (64). In addition, recently this mechanistic approach was the subject of a paper titled "Interpretation of Laboratory Test Information for Residual Strength and Life Prediction (. Composite systems " presented at the ASTM Symposium on Cyclic Deformation, Fracture, and Nondestructive Evaluation of Advanced Materials, held in san Antonio, Texas (6E). It is clear that this approach and the results that it produces have been widely noticed and strongly embraced by the technical community at the national and in'iernational level.

\subsection{ELEMENTS OF THE CRITICAL ELEMENT APPROACH}

In the context of our subsequent discussion of this effort several elements of our approach must be briefly outlined. (other details of the critical element approach as well as our supporting work in the area of micromechanics appear in Refs. (66-68).

In general, advanced, high performance composite materials are really material systems in which the constituent materials and the interfacial/interphasal regions between them interact in such a way that their collective response is more than the linear sum of the 
response of the constituents. This fact provides the technical comunity with a remarkable opportunity to create composite material systems which are uniquely suited to perform specific engineering tasks. At the same time, the systems aspect of composite materials requires special attention when we attempt to discuss the mechanics related to properties such as stiffness and strength, and to performance such as life.

If one wishes to consider the long term response of such materials under cyclic mechanical, chemical, and thermal loading, the systems aspect of the problem introduces interactions between mechanical degradation, and any chemical or thermodynamic processes which may be occuring during the life of the component.

Achieving representations of such combined processes is a noble but challenging goal. One must begin with simple, fundamentally sound principles, and build an approach systematicaliy (if not axiomatically). We will build the present discussion on the following principles.

1. In most of the material systems of interest, the damage or degradation processes that reduce stength and life are various, widely distributed, and highly interactive.

2. These processes cause changes in stress state and changes in material state, especially at the local level.

3. These changes define the remaining strength and life of the materials.

In the section which follows, we will discuss the changes in stress state and material state associated with damage development 
using micromechanical representations. We will then use the example of tensile failure under long-term conditions to demonstrate how these micromechanical representations aan be used in a performance simulation model to estimate the remaining strength and life of material systems which demonstrate complex damage and failure modes. A few demonstrative examples will be discussed to illustrate the advantages and limitations of the approach. Results from the piesent program as well as complementary programs we are conducting will be cited in order to bring the full description of our approach to the reader.

During the long term service of composite materials, one can expect, in general, changes such as those suggested in Fig. 8.1. Initial properties are altered by damage develpment (which causes changes in local geometry, and may change constitutive behavior); by chemical activity such as compound formation, molecular linking, etc.; or by thermodynamic events such as diffusion, phase changes, or morphological variations as a function of time. Most of these changes are brought about by local processes.

The $\mathrm{x}$-ray radiograph shown in Fig. 8.2 illustrates a typical complex array of widely distributed matrix cracks in a $\left[0 / 90_{2}\right]_{3}$ composite laminate made from glass epoxy material subjected to fully reversed cyclic loading at about $60 \%$ of the static ultimate strength of the laminate. The cracks in the 90 degree plies have formed a regular array, a saturated condition identified by tre present investigators in the early 1970s, and called the "characteristic damage state for matrix cracking" (69,70). Since 
Initial

Strength

Geometry Changes

Constitutive Changes

Chemical Changes

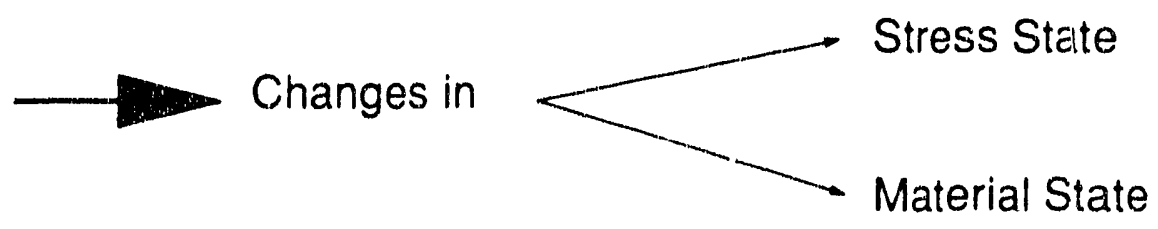

Fig. 8.1 The Evolution of Properties and Performance. 


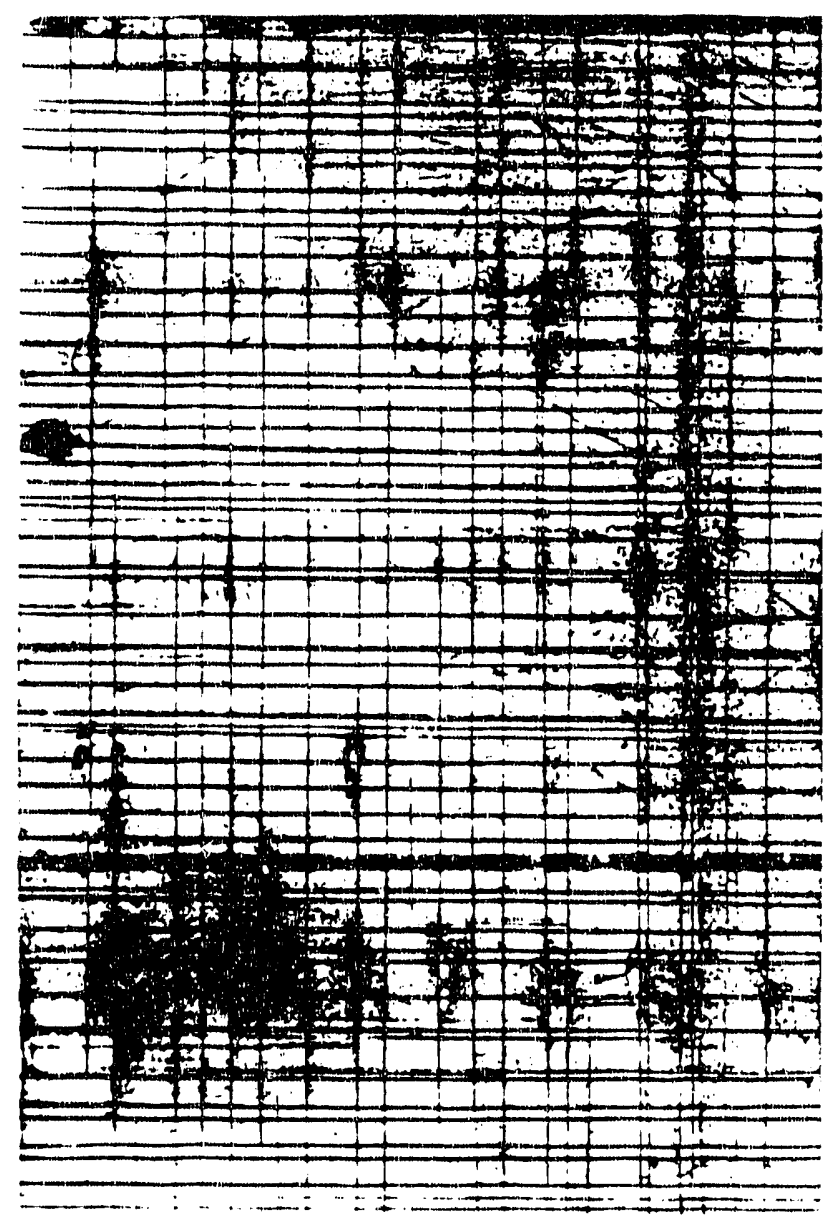

Fig. 8.2 Distributed Matrix Cracking in a Composite Laminate. 
this condition is a well defined local arrangement which is repeated from point to point throughout the laminate, one could choose a "representative vulume" for such a damage state that would include matrix cracks in off-axis plies, matrix splitting in the ply that is oriented in the loading direction, a small delamination region on the plane between two plies which have matrix cracks that cross each other at the ply interfaces, and any attendent local fiber fracture.

The changes in local stress state brought about by such damage development is substantial. The local stress state in the "representative volume" Jescribed above can be determined, using the representative volume to properly set a three-dimensional mechanics analysis. Figure 8.3 shows an example of local, interlaminar normal stress in the region in which the cracks cross. It can be seen that t.le interaction of the cracks causes a highly three-dimensional stress state in that local region, and that this stress state involves an interlaminar component which will drive delamination. This type of delamination has been observed in the laboratory, and appears as the lightly shaded region in Fig. 8.2 $(71-74)$.

The resulting local stress states must be determined, not only to establish the stress state in which the unbroken material is operating and which drives subsequent damage development events, but also as a means to determine the effective stiffness with which the local region supports its share of the global stress field. This last requirement is especially important for global 


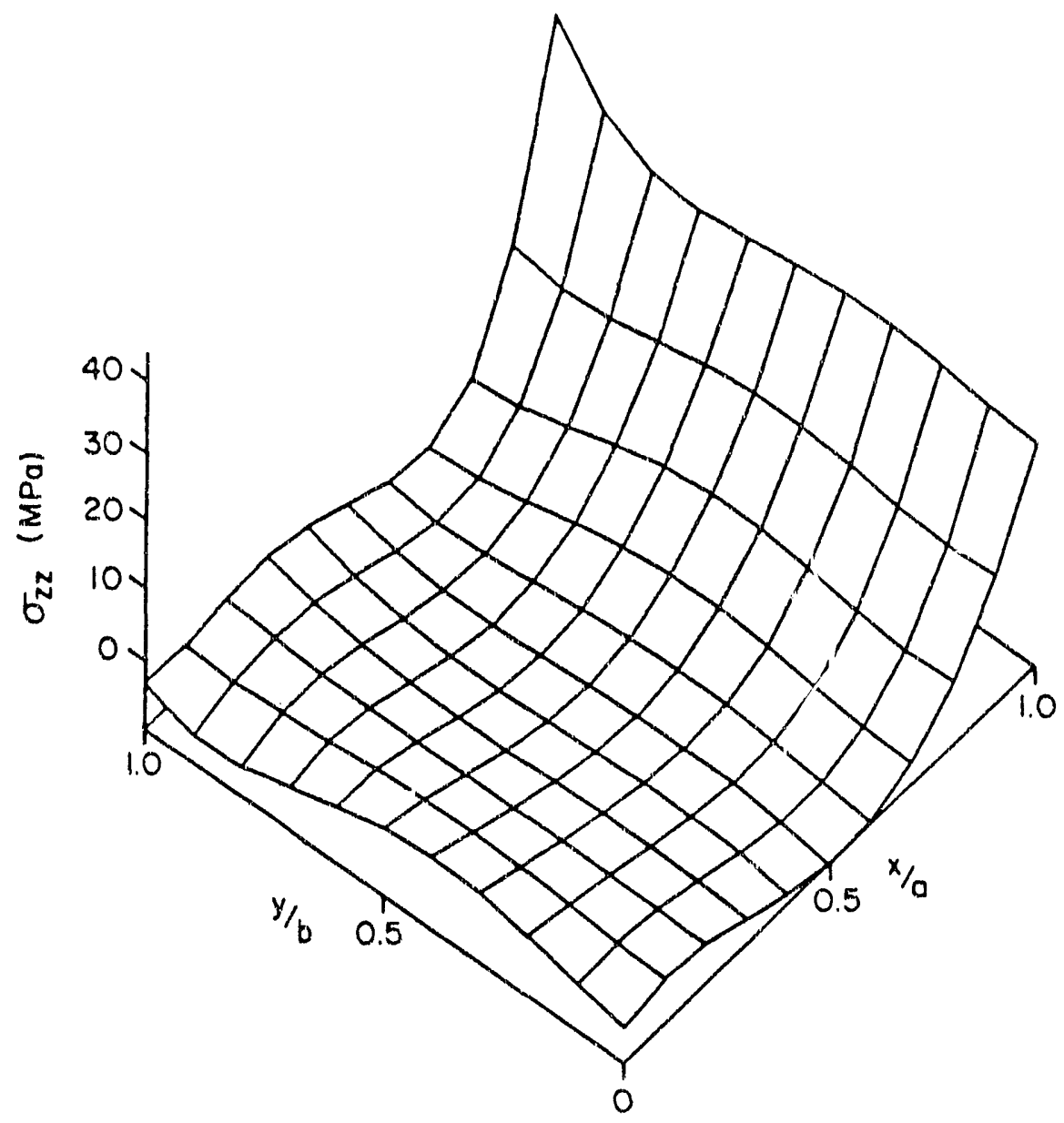

Fig. 8.3 Three Dimensional Finite Element Analysis.

local schemes, or even for input into laminate analysis in the damaged condition. The effect of matrix cracking on the effective stiffness can be represented by various methods, including discount procedures in which the matrix-dominated ply-level stiffness values are reduced in a laminate analysis. More exact representations are possible, of course. However, the most challenging part of this 
problem is associated with the effect of the fibers in typical composites, and the determination of the local stress state in the neighborhood of the fibers. This subject cannot be fully developed here, but a few points that are critical to our discussion will be made. In association with another research program, Carman has recently developed a hybrid three-dimensional short/long fiber composite micromechanics model, using the following assumptions. Each material constituent is linear elastic; the embedded fibers are transversely isotropic and the surrounding matrix material is isotropic; the fiber/matrix interface is a perfect bond; the composite is a continuous material such that displacement fields can be generated which are representative of a constant average strain state existing in the continuum; all fibers overlap in the same three-dimensional space such that generation of curvature terms due to fiber-fiber interaction are neglected. End-to-end fiber-fiber interaction is allowed by the model $(75,76)$. The three-dimensional model generated utilizes the principle of superpositon in analyzing the point-wise local stress state, and incorporates transient solution concepts similar to those presented by Whitney and Drzal (77) .

Figure 8.4 illustrates the capability of that model. Berthelut studied the effect of fiber volume fraction on the axial stiffness of model short fiber composites; the short fibers embedded in composite were misaligned at plus or minus 10 degrees with the loading axis (78). One can see that the predictions match reality well. A further validation of the analysis appears in Fig. 8.5. 
The highly nonlinear dependence of the out-of-plane poisson's ratio on volume fraction is nicely represented by the model, and correlates with accepted approaches (which do not provide the correct local stress field). This modeling approach can be used to represent the effects of fiber fracture on the effective modulus of the remaining material, and to obtain good estimates of the local stress fields for subsequent damage analysis, as we will discuss below.

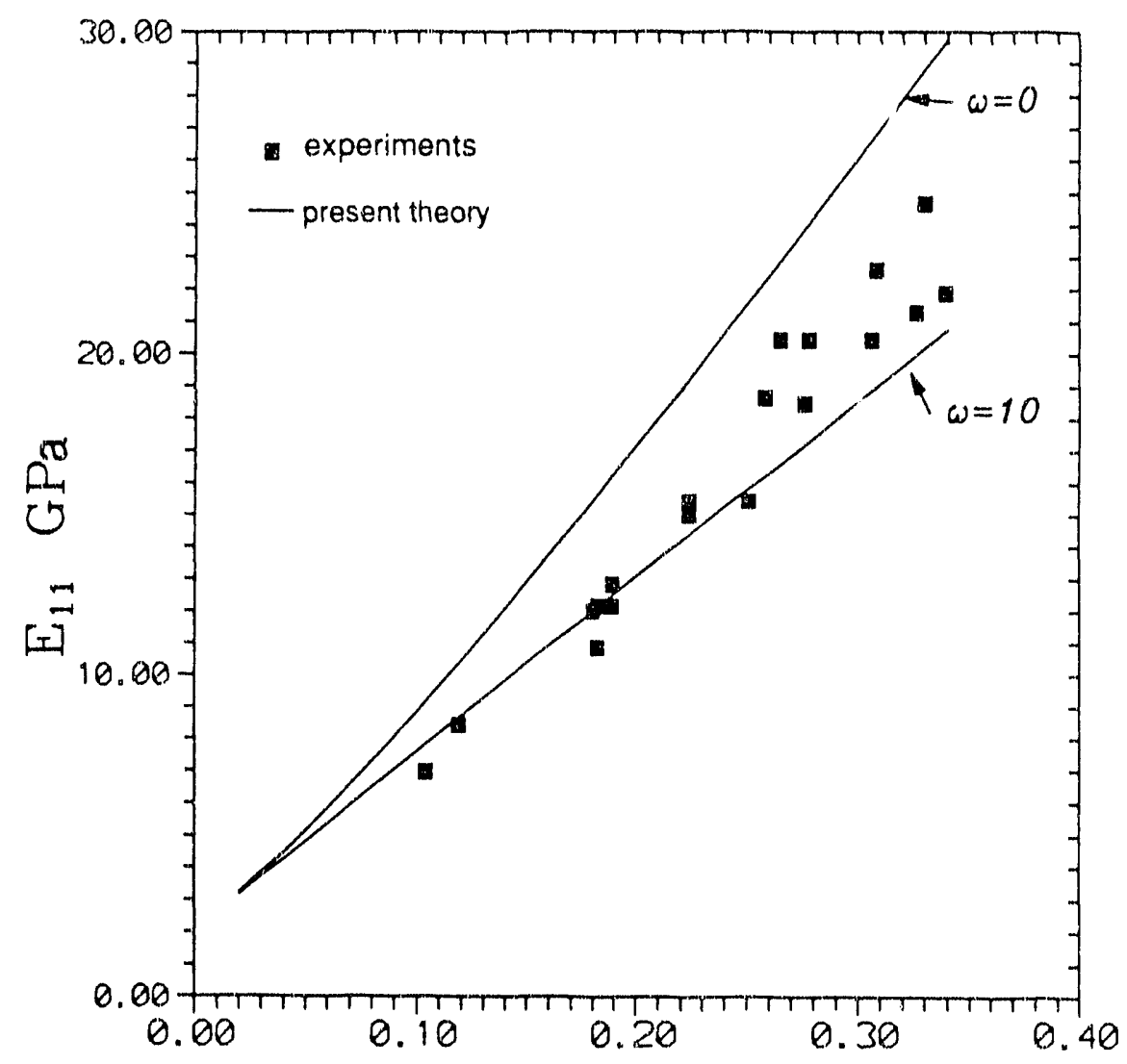

fiber vol. fraction

Fig. 8.4 Micromechanical stiffness prediction. 
It should also be mentioned that, under NSF funding, we have been successful in including the effect of interphase regions with finite dimensions and nonuniform properties in representations of the local stress fields around the fibers (79). This has particular importance for the application of performance prediction models to high temperature composite systems in which diffusion between the fiber and matrix phases, often through a fiber coating such as carbon, creates a finite region in which the properties

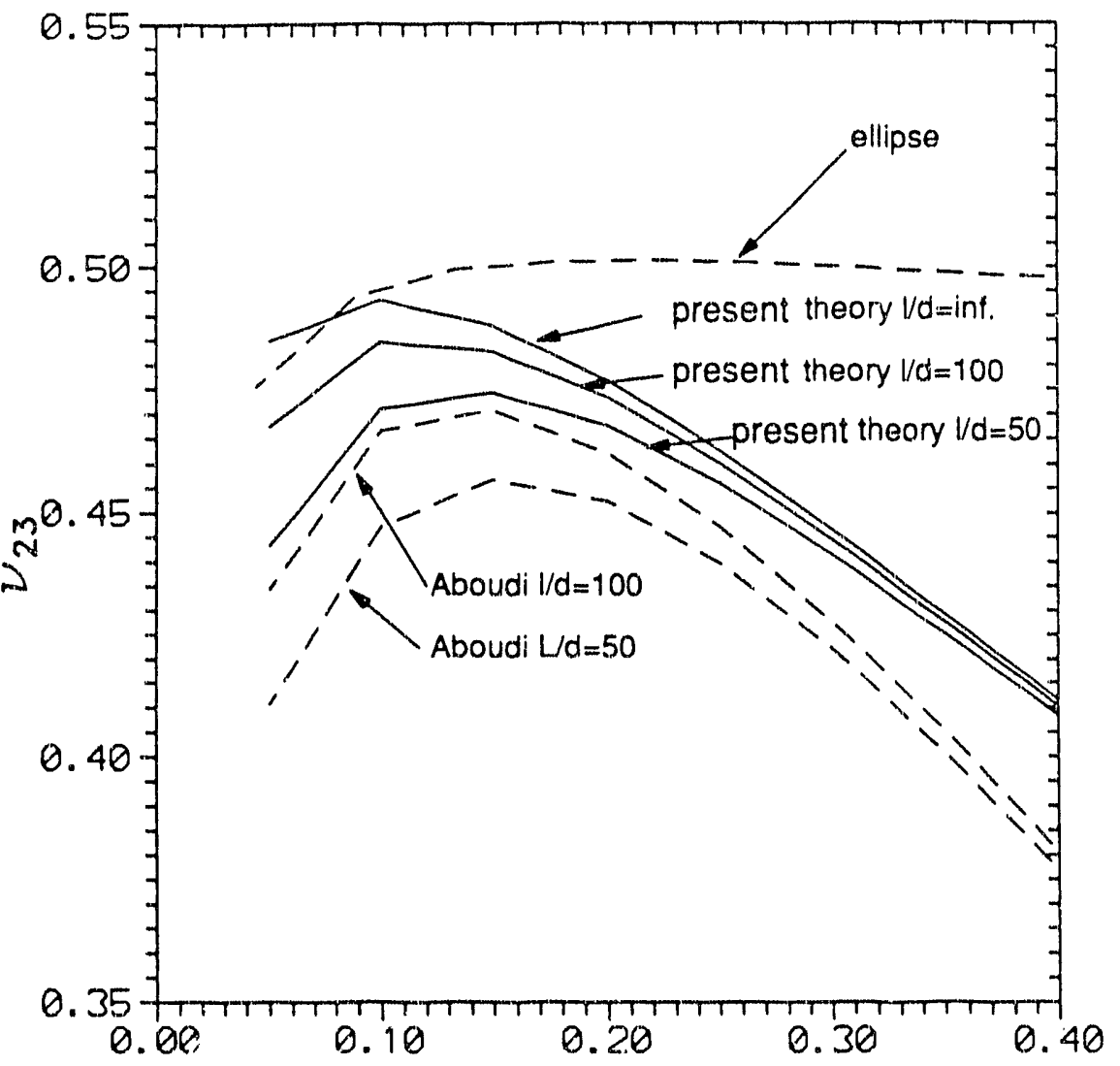

Fiber vol. fraction

Fig. 8.5 Micromechanical Prediction of Poisson's ratio. 
depend on position. Such a representation is sometimes critical to the proper representation of the changes in local stress state during service.

Time-dependent behavior can also change the local stress state. Figure 8.6 illustrates stiffness reduction in a composite material associated with viscoelastic creep. In an earlier paper, we have demonstrated that it is possible to reduce the creep compliance curve for lamina stiffness transverse to the fibers, shear stiffness, and matrix controled Poisson's ratio as a function of time (under the assumption of linear viscoelasticity) to a single master curve (77). This representation, in Fig. 8.6, can be used to specify the matrix-controlled compliance of each individual ply of a laminate as a function of time for epoxy matrix materials. The effect of temperature nay be included as a shift factor which moves our creep compliance value along the abscissa according to the time-temperature equivalence principle. These reductions in matrix stiffness typically redistribute stress in the fiber direction, especially in plies which have orientations nearly parallel to a load axis. Hence, the stress redistribution associated with viscoelastic deformation may greatly influence the behavior of the critical elements and the performance of the material. Appropriate viscoelastic behavior representations for high temperature composite material systems must be identified. For the present effort, the form of the equations used for polymer matrix materials was maintained, and the associated constants were altered to fit the behavior of the ceramic matrix at elevated 
temperature. The linear viscoelastic results shown in Fig. 8.6 have been preliminarily modified with some success, as we will demonstrate below.

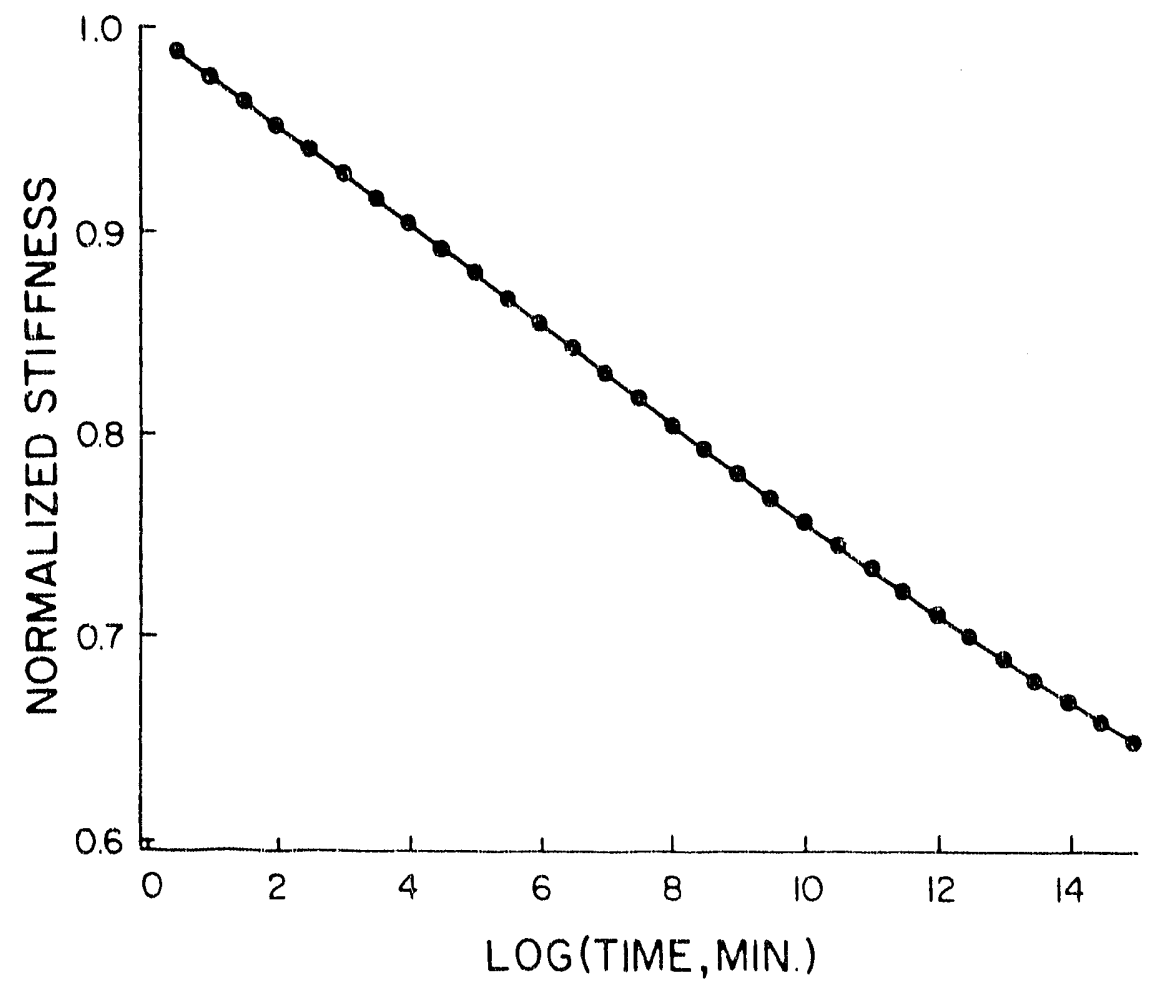

Fig. 8.6 Viscoelastic Stiffness Reduction Master Curve.

Another rate equation that is essential for our micromechanical modeling is associated with a phenomenon generally called "creep rupture." In many instances this kind of behavior is a "misnomer" in the sense that chemical and thermodynamic processes such as oxidation and chemical attack may be the physical source of such 
rupture events rather than creep in the classical sense. For a measured strength reduction, $\delta$, a reference time over which that reduction occurred, $\tau$ ref, and a stress which was applied over that period of time, $\sigma_{\text {ref, }}$ it is necessary to establish a relationship such as the one shown below.

$$
\text { REDUCTION IN STRENGTH }=f\left(\frac{\bar{\sigma}}{\sigma_{r \theta t}}\right) g\left(\frac{t}{\tau_{r e t}}\right) \delta
$$

where the functions $f$ and $g$ which scale the applied conditions to those for which data were measured must be determined from laboratory experiments or from representations of the thermodynamic processes which occur. In addition, such strength reductions must also be scaled for temperature.

A further example of a rate equation is the representation of the life of the critical element under current conditions of stress state and material state if those conditions were to remain constant. A particularly simple example of such a relationship is a representation of the $S-N$ fatigue strength-life equation for constant amplitude fatigue such as the expression below.

$$
S_{a} / S_{u}=A_{n}-B_{n}(\log N)^{P_{t}}
$$

in which $S_{a}$ is the function which specifies the local stress state, $S_{u}$ is the corresponding function which specifies the local strength 
state in the critical element, and the constants $A_{n}, B_{n}$, and $P_{n}$ are material constants which express the rate of degradation associated with the material under cyclic loading. Of course, the life of the critical element will not be constant because the state of stress, state of material, and possibly the material constants may be functions of the number of cycles of load application, generalized time, or environmental conditions such as temperature. Moreover, Eqn. 8.2 may be more appropriately replaced by life equations which are based on kinetic theory or those which are based on local slip in the case of high temperature composite material systems.

\subsection{Performance simulation}

To illustrate how we carry this approach to completion, a very brief description of the performance simulation method we use is provided. As indicated eaxlier, we take the position that life prediciton must be based on a clear and precise definition of damage accumulation mechanisms and failure modes as determined from experimental observations. The critical element aproach begins with the premise that life prediction modeling should be concerned with representative volumes or units of material that control the ultimate failure process, defined by each distinct failure mode. We use a generalized expression for the normalized remaining strength in the critical element for a given failure mode 


$$
F_{Y}^{\prime}=1-\int_{1}^{0}\left(1-\frac{S_{a}\left(\sigma_{i j}(n)\right)}{S_{u}\left(X_{i j}(n)\right)}\right) i\left(\frac{n}{N}\right)^{i-1} d\left(\frac{n}{N}\right)
$$

It should be noted that in this expression we have written the function which represents the local state of stress, $s_{a}$, in terms of its arguments, the tensor values of local stress, $\sigma_{i j}$, and that we have indicated that these local stress values are functions of the number of cycles, $n$. This recognizes the fact that the local. stress state in the critical element may be changing as damage develops in the subcritical elements around it. For example, the stress in the fibers will be altered greatly by the presence of matrix cracks in the off-axis plies and by matrix splitting in the axial plies. Further, the function which represents the local state of strength in the critical element $s_{u}$, is written in terms of the material strength tensor, $x_{i j}$, which is also a function of the number of applied cycles, since the strength in the critical element may be degraded due to processes such as oxidation, chemical degradation, or other degradation events. These details can be determined from experimental measurements.

We can simplify Eqn. 8.3 by representing the ratio of the local state of stress to the local state of strength as a "normalized failure function," $F_{a}$, and write the expression

$$
F_{r}=1-\int_{1}^{0}\left(1-F_{a}\right) i\left(\frac{n}{N}\right)^{i-1} d\left(\frac{n}{N}\right)
$$


It should be noted that the total life of the critical element under current conditions, represented by $\mathrm{N}$ in Eqn. 8.4, is also a function of the number of cycles, since the life will be altered by changes in both the local stress state and local material state. That fact will also be demonstrated in subsequent examples. Hence, we see from our expression that we need to determine the local state of stress in the critical element, the local state of strength in the critical element, the changes in that stress state and strength state as a function sf applied cycles or generalized time, and the life of the critical element under specific conditions of stress and strength. The state of strength and state of stress of the material, represented by the generalized failure $F_{a}$, involves a criterion which is chosen to represent a specific failure mode. Indeed, Eqn. 8.4 must be written for each failure mode independently. However, it should be noted that the interaction of failure modes is included in the single integral in Eqn. 8.4 for a given failure mode in the sense that any stress state alteration or material state alteration associated with some damage event or other failure mode would be included in proper representations of the stress state and material state in the critical element, since our approach is a mechanistic one. Therefore, if a proper experimental investigation is conducted and the mechanics problem is properly set for a given failure mode, interactions will be included in a normal fashion and no artificial additions or interaction terms are required.

Figure 8.7 illustrates how these three essential elements of our 
approach can be combined in a mechanistic prediction of strength and remaining strength, and ultimately a prediction of life for high temperature materials. Careful observations of laboratory experiments to determine damage and failure modes are the basis for defining critical elements (modeled by continuum constitutive relations) and subcxitical elements (modeled by micromechanics). The stress state changes caused by damage development in the subcritical elements and by time-dependent stiffness changes in the critical and subcritical elements determine the state of stress in which the critical elements operate, as a function of time or cycles of loading. The constitutive changes (such as strength reduction) in the critical elements define the state of material as a function of time (or cycles). A "failure criterion" which is appropriate for the failure mode that is considered is used to compare the state of stress and state of material to estimate remaining strength. Comparison of that remaining strength with the state of stress in the critical element provides a method of estimating remaining life. This sequence is repeated for each distinct failure mode. Interactions of failure modes are inherent in the process of considering the fundamental changes in stress and material state, i.e., the damage in a specimen may contribute to-and bring about-several different failure modes. The "winning" failure mode is determined by the ratges of development of the individual damage events and the manner in which they combine to cause a given failure mode. Generally, several failure modes are modeled, and the controling mode is defined by the lowest 
resulting remaining strength and life. Failure mode conversions have been predicted by the model and observed in the laboratory (for fatigue of notched thermoplastic composites).

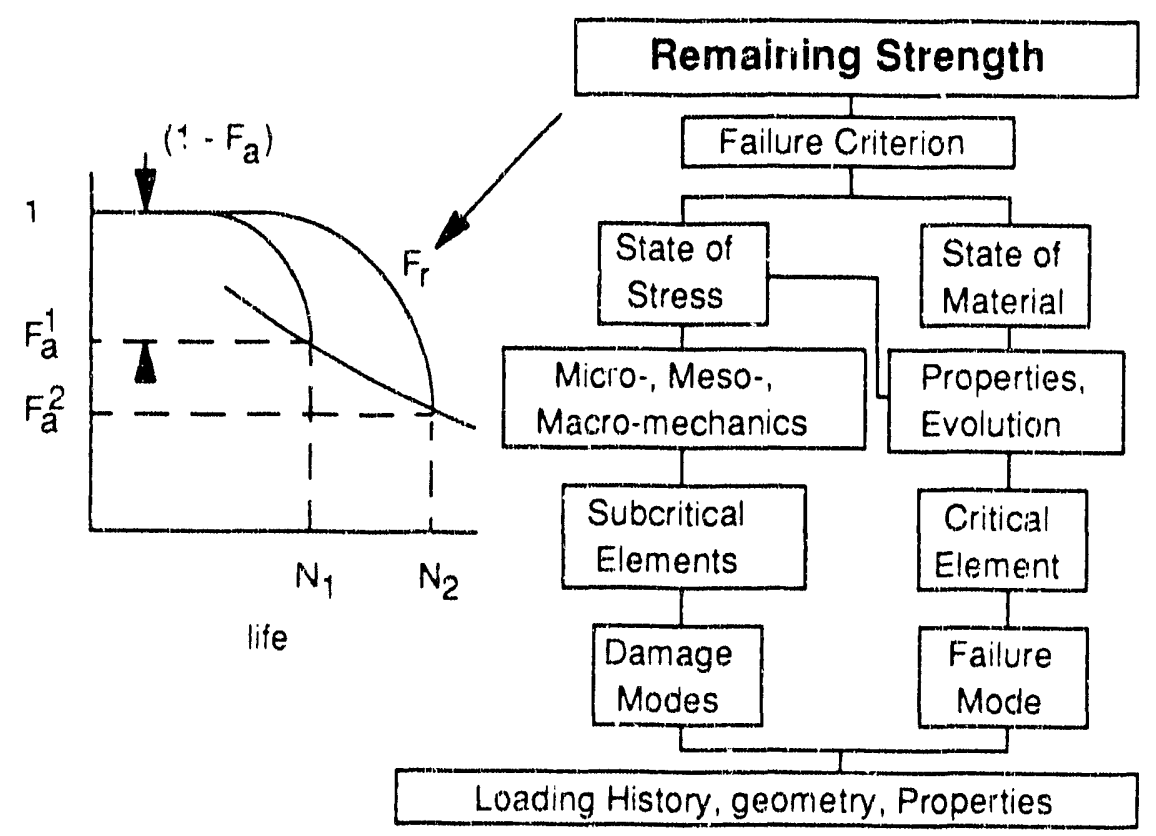

Fig. 8.7 Critical Element Approach to Remaining Life Prediction.

\subsection{Model Results - Performance}

The general philosophy of the modeling approach has been explained in section 8.2. In order to validate the approach, and to firmly establish the capability to model the damage development and time-dependent effects associated with elevated temperature and cyclic loading, the initial version of the performance simulation 
code was applied to the problem of predicting the performance of a sic reinforced LASII glass ceramic composite system. The properties and performance were taken from the literature, primarily from the work performed at United Technologies (80).

Several interpretations of the published data were needed in order to run the simulation code. At high temperature, the material system exhibited time-dependent stiffness change (of a viscoelastic nature). This behavior was modeled with a simplified Iinear viscoelastic stiffness reduction algorithm. In particular, all matrix-dominated components of stjffness were reduced (equally) as a function of time at temperature and load according to the relationship

$$
\frac{E}{E_{0}}=1-2.17 \times 10^{-2} X-7.969 \times 10^{-4} X^{2}+7.237 \times 10^{-5} X^{3}-1.81 \times 10^{-6} X^{4}
$$

where $X=\log (m i n u t e s)$ and $E_{0}$ is the initial stiffness value. The temperature dependence of the stiffness reduction was modeled with a shift factor, which has four constants. These constants were used to fit the available data, yielding the form

$$
\begin{aligned}
\text { shift factor }=-4.87 & +0.0234 \mathrm{~T}-1.85 \times 10^{-5} \mathrm{~T}^{2}+1.126 \times 10^{-8} \mathrm{~T}^{3} \\
& -2.936 \times 10^{-12} \mathrm{~T}^{4}
\end{aligned}
$$


in which the temperature, $T$, is given in degrees centigrade. This shift factor was added algebraically to the log(minutes) variable that is used in Eqn. 8.5. The resulting $E / E_{0}$ ratio was used to multiply the $E_{2}$ and $G_{12}$ stiffness values of the laminae in $a$ laminate as a function of time and temperature. The resulting redistribution was calculated for each such reduction.

The strength of the laminae was also reduced as a function of time and temperature. In the present case, this reduction was made on the basis of the fiber-direction reduction data published for this material; very little such information was available. The general reduction equation used for strength had the form

$$
\frac{X}{X_{0}}=1-(\Delta)(\text { scale factor })
$$

where

$$
\text { scale factor }=1.86\left(\frac{T-298}{1764-T}\right)
$$


in which the temperature is in degrees absolute. The temperature dependence has two adjustable constants which are used to match the existing data.

Figure 8.8 shows an example of the nature of the predictions made by the performance simulation code. The "Residl" remaining strength prediction uses the Tsai-Hill criterion as the basis of the prediction for the critical element and the specimen. The "Reside2" prediction is made on the basis of the ratio of the stress in the direction of the fibers to the current value of the fiber-direction strength (as reduced as described above). The "Avfail 1" and "Avfail 2" parameters are the current values of the failure criterion which is used for the comparison of the state of stress and state of material in the critical element, for a given failure mode. The values of those criteria change as the material state and stress state are updated due to changes in stiffness, strength, or damage-related local geometry, as discussed earlier. The predictions are for unidirectional plate specimens loaded along the fiber direction with tensile cyclic loading at 10 cycles per second.

A large number of these predictions were made for several temperatures. The resulting data were reduced by taking only the Iife prediction from each prediction, defined by the crossing point of the state of stress in the critical element and the remaining strength, as shown in Fig. 8.8 by the crossing of the Resid and Avfail curves. (The fiber stress criterion was used for this exercise.) 


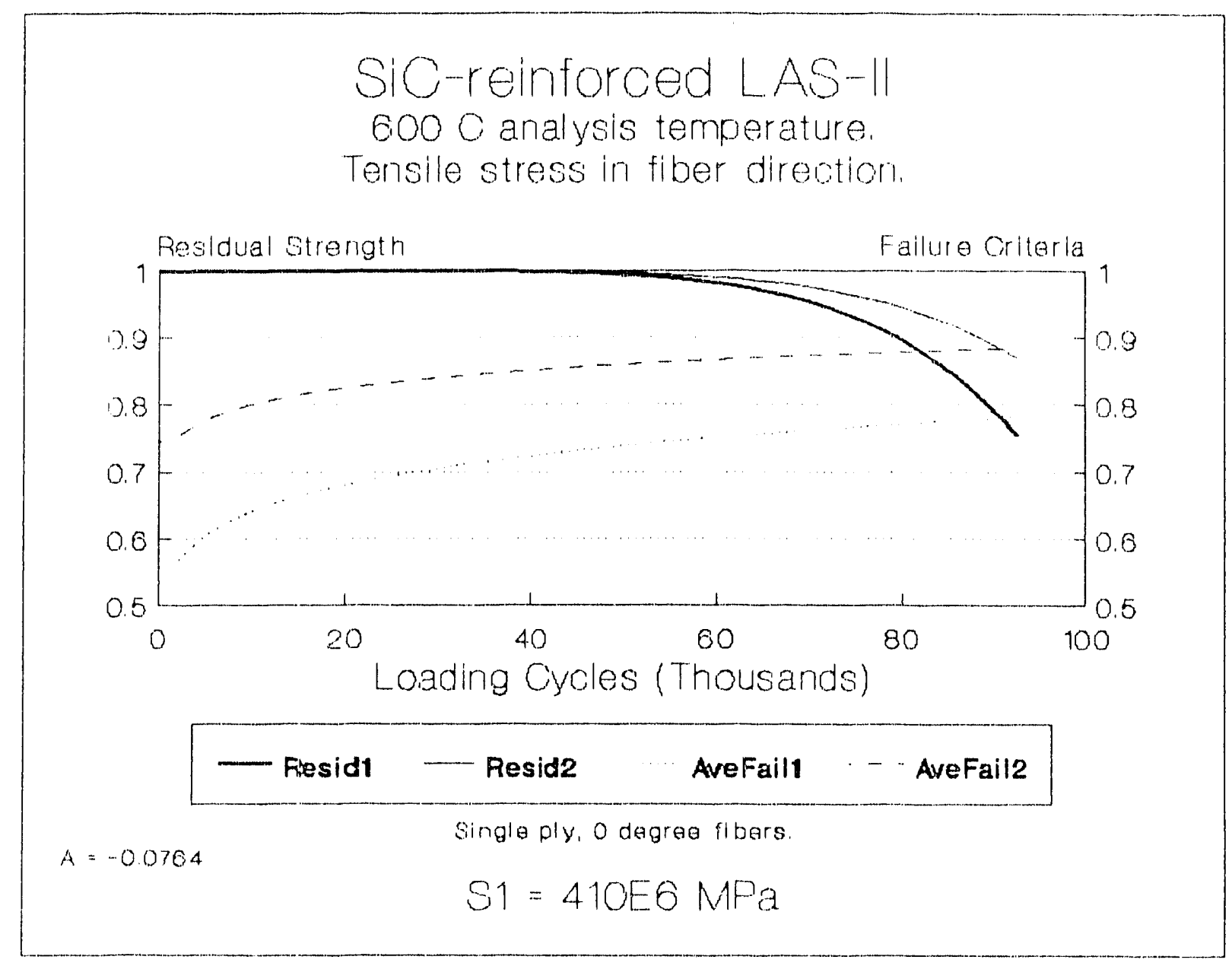

Fig. 8.8 Performance simulation Results for LAS-II Glass
Ceramic Composites.

Figure 8.9 shows predicted $S-N$ curves for this silicon-carbide-reinforced LAS glass composite, tt elevated temperatures which cause oxidation and degradation of the composites. The results for $600^{\circ}$ and $900^{\circ} \mathrm{C}$ represent the combined 133 
effect of the temperature degradation and the damage caused by cyclic mechanical loading. That figure shows a variety of predicted $S-N$ curves for several temperatures above and below the 600 and $900^{\circ}$ results, for which some data are available. The curves converge to the monotonic tensile strength at one-half cycle. The predicted results agree remarkably well with the available data (circles and triangles). Moreover, the other results allow the researcher and the engineer to anticipate behavior under a variety of other temperatures with some confidence. These data are very difficult (expensive and time consuming) to get. The present model, which is mechanistic, can provide guidance in the prediction of results under many such conditions, and can also provide guidance in the planning of tests to obtain data which may be critical ior tinalization of a design. Moreover, and most important, this method can provide guidance to material designers in the selection of constituents, their arrangement, their bonding and processing, manufacture, and final. assembly into an engineering component to achieve specific performance characteristics under severe loading conditions such as long-term exposure to cyclic loading and high temperature environments. 


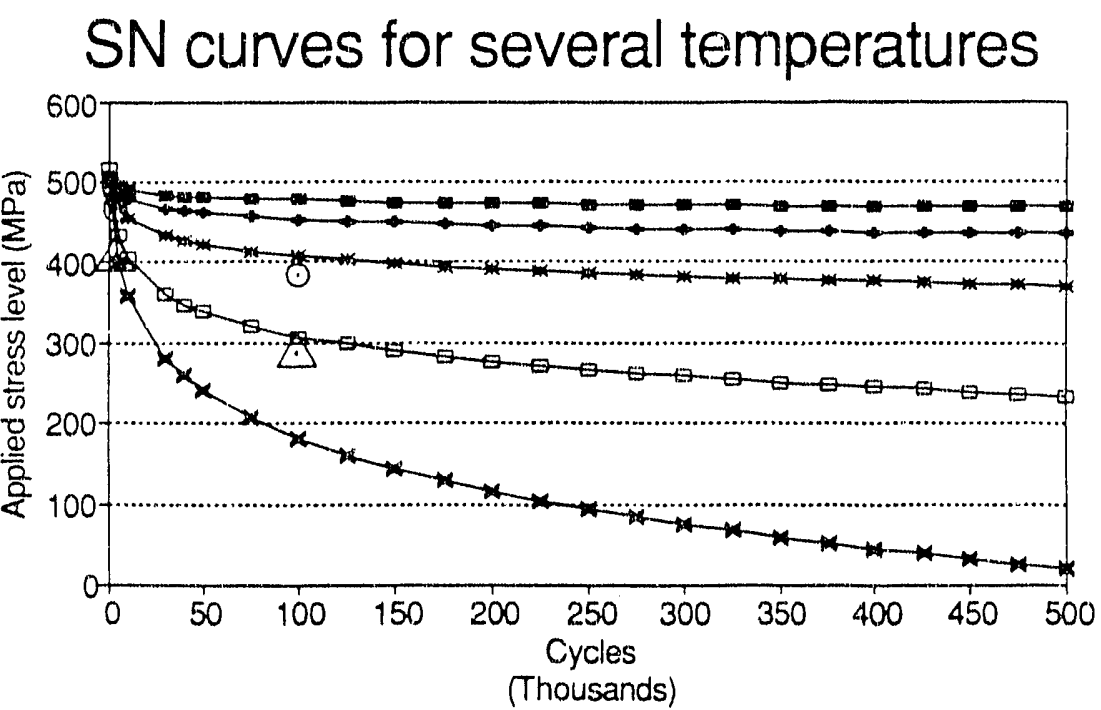

$$
\begin{aligned}
& -25 C \rightarrow 300 C \rightarrow-600 C \\
& \square 900 C \rightarrow 1200 C
\end{aligned}
$$

Fig. 8.9 Predicted and Observed Fatigue Life of LAS-II Glass Ceramic composites.

\subsection{Some New Directions}

The manner in which mechanics should be used to describe strength is not firmly established for homogeneous materials, and is less well understood for composite materials. Moreover, if one wishes to describe the degradation of strength over long periods of time (say, during the engineering lifetime of such materials) this fundamental weakness precludes definitive systematic use of mechanics for that purpose as well. 
The use of various local mechanics approaches seems to offer hope of overcoming these limitations. Present efforts suggest that it is possible to describe the strength of composite materials using micromechanical representations of the failure modes that control the strength of those materials. In fact, it appears that it may be possible to construct such micromechanical models in such a way that the changes in the parameters in those models during long-term loading can be measured and used to estimate the changes in the strength of the global composite. In addition, those parameters may be related, in many cases, to the manner in which the composites were synthesized and manufactured, so that a means of "designing" material systems for specific long-term performance may be provided by this approach.

\subsubsection{Refinement of Mechanistic Models}

One of the directions taken in our general approach is to develop a micromechanical representation of the tensile-strength-controlled remaining strength and life of fiber reinforced composite laminates with typical constituent properties. The sensitivity of the predicted results to various micro-parameters (including some statistical ones) is of special interest.

Reifsnider and Gao have postulated an approximate method of finding a relationship between the stress concentration in a fiber next to a broken one and the ineffective length under that 
condition, and have used stress concentrations from micromechanical relationships to determine ineffective lengths from the relationship

$$
\Phi=\left[C+\frac{(1-C)}{(\delta \eta)}\right][1-\exp (-\delta \eta)]-\frac{(1-C)}{(\delta \eta)}[(\delta \eta+1) \exp (-\delta \eta)-1]
$$

where $\mathrm{C}$ is the stress concentration, $\delta \eta$ is the ineffective length of fiber created by the fracture, and $\Phi$ is a quantity defined by the boundary conditions of the problem.

When this approach is taken, a maximum is predicted in the specimen strength as a function, for example, of the ratio of the fiber stiffness to matrix stiffness (81). Good agreement with experimental data was found.

Quite recently, Gao and Reifsnider have generated a new model which allows plastic deformation at the micro-level, and calculates the local stress concentration and the ineffective length as fibers break and the matrix yields. Although this model is still only one dimensional, much more information is obtained from the analysis (82). For example, the predicted composite strength as a function of the interface or matrix strength, for two different fiber shape parameters, shows a maximum in the strength which is very pronounced. To the right of the maximum, the local stress concentration controls strength (as it does for many ceramic composite materials, while to the left side of the peak in the curve, the length of the ineffective region around the break 
becomes large because the weak matrix or interface is yielding over a large region. It was also found that the ineffective length changes with the number of broken fibers (which is found by iteration by the nonlinear model). For low values of matrix. strength, that length becomes quite large as the fibers break, while it grows slowly for high-strength (elastic) conditons. Changes in local stress concentration as a function of fiber fracture were also found for several values of matrix or interface strength. The stress concentration grows sharply for very strong material around the fibers (and causes failure), but the local yielding actually reduces the stress concentration for a large number of fiber fractures for very weak matrix materials. These results clearly show how the stress concentration controls in one case (for high strength matrix / interface materials) and the ineffective length controls the strength for the contrasting case of low matrix / interface strength. Moreover, the model identifies the micro-properties and behavior that controls this balance, and specifies the right combination for the material systems designer.

However, this type of micromechanical modeling does one other very critical thing, in the context of the present effort. The micromechanical models of strength can also be used in models of remaining strength and life in a special way. Since the parameters (such as constituent and interface or interphase properties, geometry, and axrangements) that define how a composite material system is made appear in those relationships, the variations in those parameters caused by mechanical damage, aging, chemical 
activity, or thermodynamic changes during long-term loading in mechanical, thermal, or chemical environments can be used to predict the remaining strength and life of the composite materials and components in terms of those constituent changes. This is a powerful tool, since it offers the hope of providing a systematic and mechanistic method of designing material systems for known long-term performance. This is, in fact, the primary essence of our approach.

As described earlier, the Materials Response Group at Virginia Tech has provided leadership in the development of micromechanical strength models for fiber reinforced composite materials. In general, these models apply to ceramic composite materials to the extent that they include situations wherein the stress concentration in the fibers caused by other broken fibers dominates the strength, as it is known to do for many ceramic composite systems. However, many additions to the model are needed. A few are listed below:

- A representation of matrix-dominated crack propagation including the case when matrix cracks are bridged by other unbroken fibers under tensile loading is needed. This will require a corrected micromechanics analysis of local stresses in the presence of matrix cracks, some broken fibers, and some unbroken fibers. A recent model we have developed could be modified for this task (60).

- The interphase region in ceramic composites usually includes a fiber coating (such as carbon) which has properties which are 
very different from the fiber and the matrix around it. our current tension model does not include this region, but our local stress analysis is so constructed that it can represent such a region easily. Moreover, we have the only known solutions for such a region in the presence of spatial variations of properties from point to point through the thickness of the interphase region; it may be necessary to incorporate this model into the strength model (83).

- The present model addresses only failure modes which are precipitated by an overload of the fibers, either because the local stress field increases or because the strength of the fibers decreases (due to oxidation, thermal weakening, etc.). If other failure modes dominate, entirely new models may have to be formulated.

In addition to the refinement of the local stress state representations to account for new damage and failure modes, refinements to the relationships used to represent material states and their evolution (as described by the appropriate rate equations) are needed. In an earlier section, we discussed several such rate equations. Presently, we have linear viscoelastic models for stiffness changes, and creep rupture equations which reduce the ply-level strength of the composite to account for such things as oxidation effects or other chemical degradation. Both of these 
representations are known to be inadequate for HTC systems in some cases.

\section{5 .2 Other New Directions}

our research indicates the presence of a distinct nonlinear creep rupture effect in certain ceramic composite systems at temperatures close to their upper limit use temperature. An example of such a systems is Sic reinforced CAS. The nonlinearity shows up as a applied stress level dependence on the rate of strength loss as a function of temperature and time, the form of the degradation rate equation is different at different levels of applied static or cyclic loading. This is an anomaly in a certain sense, and will be given special attention in our continuing work.

Another current direction (funded by the Virginia Institute for Material systems) is the development and refinement of a model of cyclic loading as a forced vibration problem. This is an entirely new concept which we have pioneered, and it has given birth to an important new experimental method for monitoring the rate of damage development in specimens during high temperature testing. The approach considers the dynamic response of the test machine and the specimen together as a compound system. The forced vibration problem is posed with material nonlinearity so that the problem is nonlinear and becomes an initial value problem. In the laboratory, 
measurements are made by using the dynamic load and displacement signals used by the controller of the servohydraulic test machine to control the test. No attachments are made to the specimen. This is a very great advantage, since it is very difficult (essentially impossible) to fasten something to the specimen at very high temperature without interfering with the test results, and usually disturbing the uniformity of the temperature field. Moreover, the results are reproducible, and consistent to an extent that the data can be used to determine the percent of life left for a given specimen and a given test. This is a critical feature, since some method of this rype must be used to terminate tests to recover comparable data from test to test.

Another direction of our research is the refinement of the models that we use to interpret measurements of interface/interphase strength using multifiber penetration methods for HTC systems (67). This characterization, also conceived and developed in our laboratory under Air Force funding, has shown great promise as a method of measuring not only interfacial strength, but also for the measurement of compression strength and possibly for the measurement of shear strength. The approach involves a ball penetration in which a group of fibers are displaced with measured displacement and force to produce a force-displacement diagram as shown in Fig. 8.10. The details of that record can be directly related, with our micromechanical models, to the interfacial strength. Figure 8.11 shows such data for three types of composite which have different levels of 
interfacial strength. The figure also shows measurements made by other means. We are concentrating on the development of this method for testing of properties at elevated temperatures, and on the modeling of such test data to make possible the inteipretation in terms of interfacial strength. Special attention will be given to the question of how time-dependent behavior enters this characterization method, and how our models can be used to isolate this important effect in HTC systems.

\section{Meso-Indentation Testing of Composites}

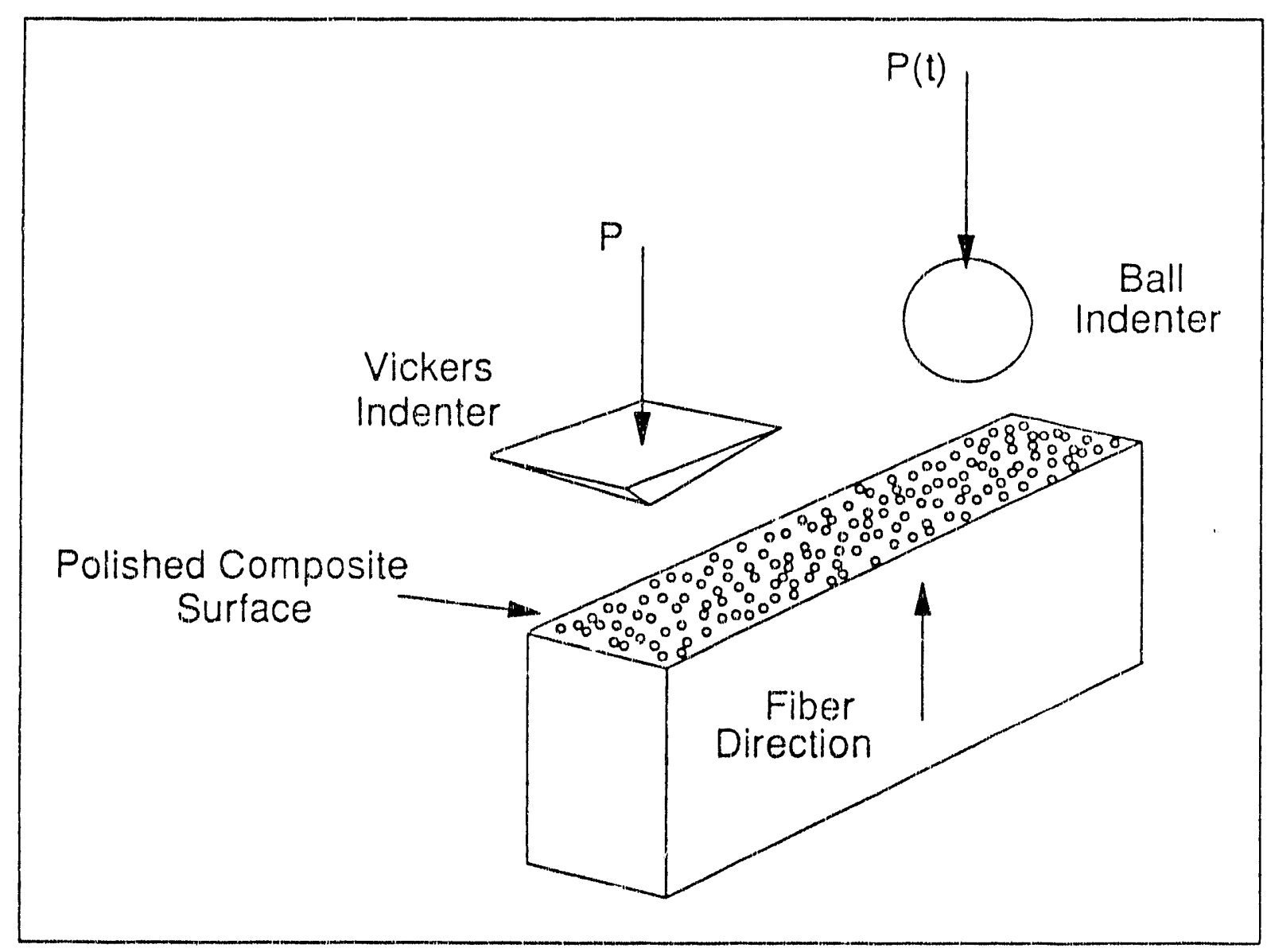

Fig. 8.10 Multifiber Penetration Methor. 


\section{Comparison of ISS Values from Various Techniques}

for AU-4/Epon 828 mPDA Composite

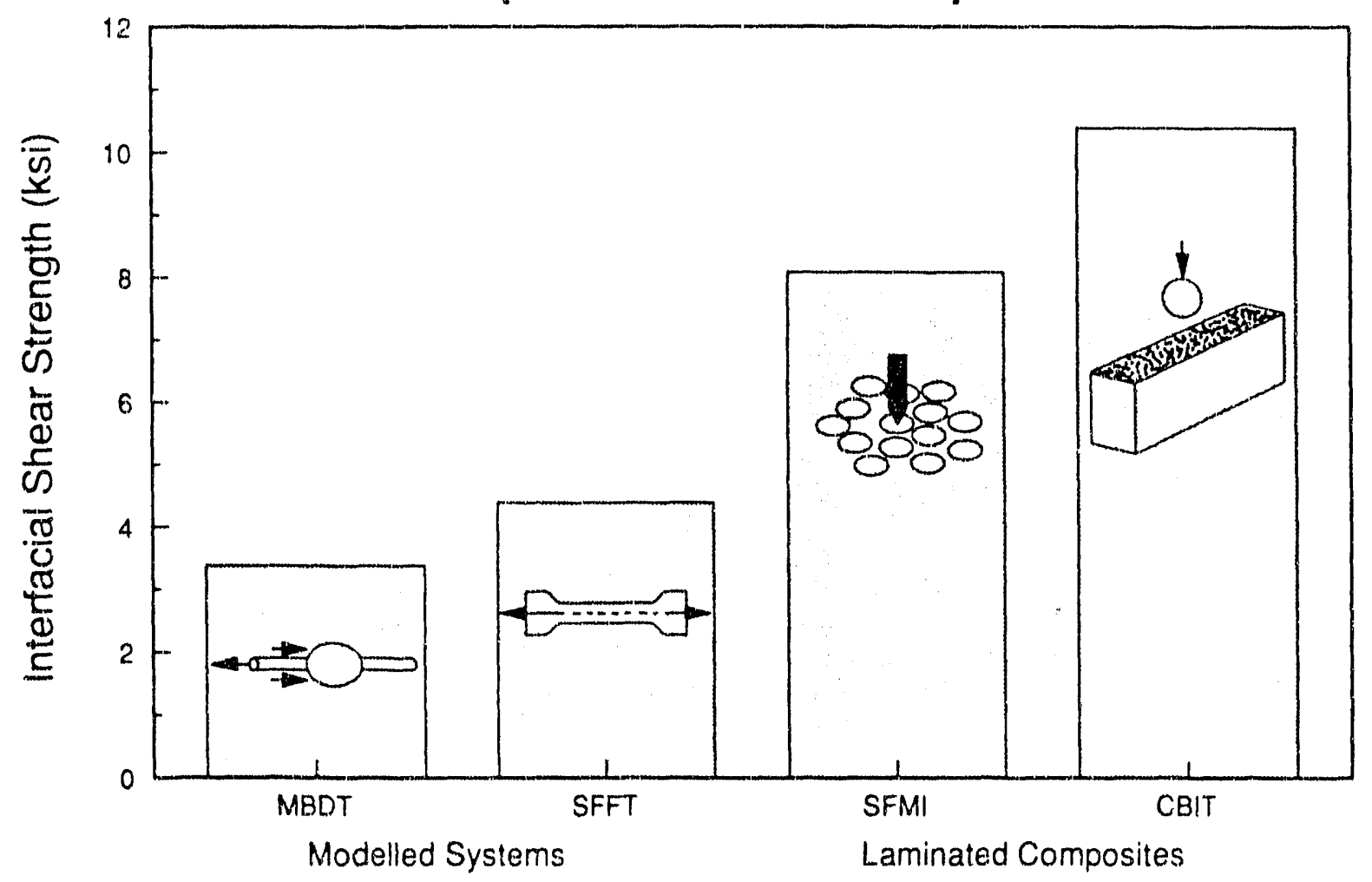

Fig. 8.11 Comparative Interfacial strength. 


\subsection{Accomplishments and Discussion}

The properties and performance program addresses the need for reliable and durable structural ceramic composites to perform in high temperature environments. The research effort provides an experimental and analytical basis for the transition from properties to performance. The program is a pioneering effort to make a first step beyond the limited characterization of small samples and coupons to a comprehensive characterization of the mechanical performance of complex engineering components such as ceramic composite tubes subjected to static and cyclic multi-axial loading and elevated temperature over various time periods. characterization of the mechanical performance of ceramic composite components includes both experimental observations and measurements of long-term behavior and predictions of remaining strength and life under realistic service environments.

The characterizations were conducted using two unique capabilities developed during the program:

- a high temperature, multiaxial mechanical test facility, and

- a mechanistic, performance simulation code (MRLife) which brings together the research results in a simulation model for the performance of ceramic composite components.

\subsection{Accomplishments}

The objective of integrating the anaiytical and experimental capabilities to support the development of the MRLife code for the prediction of remaining strength and life of ceramic composite components at elevated temperatures has been met, with notable success. Specific accomplishments include:

- extensive literature reviews in the areas of test methods, nondestructive evaluation, failure mechanisms, and modeling of ceramic composites, 
- design, fabrication, and evaluation of chopped graphite fiber (Hercules HMU-PVA-3k)/borosilicate glass matrix (Corning CGW7070) composite tubes,

- design, construction, installation, and acceptance testing of an Instron computer controlled, high stiffness biaxial test facility with hydraulic grips, high temperature $\left(1500^{\circ} \mathrm{C}\right)$ furnace, and extensometer,

- completion of the room temperature, monotonic and cyclic axial load test series,

- investigation and application of nondestructive test methods to monitor the damage development process,

- demonstration of the high temperature, biaxial testing capabilities of the Instron testing facility,

- development and evaluation of a high temperature damage model based on the critjcal element concept,

- development and validation of a performance simulation model (MRLife) for ceramic composites.

The accomplishments are discussed in the following sections.

\subsection{Discussion}

\subsubsection{Material System, Specimen Geometry, and Test Methods}

A concurrent engineering approach was taken to the development of a testing capability for ceramic composite components. A team of experts in ceramic composites processing and fabrication, testing equipment design and fabrication, and composite materials test methods studied and evaluated the specia features and 
problems associated with measuring long term performance of ceramic composites at high temperatures. The product of this cooperative effort is a unique, high temperature, multiaxial servohydraulic testing facility for composite tubes.

The facility has the capability to apply monotonic and cyclic axial and torsional loading to ceramic composite tubular specimens. A high temperature furnace provides capability to test at temperatures up to $1500^{\circ} \mathrm{C}$. The extensive capabilities are suited to address the critical shortage of engineering data on the properties and performance of ceramic composites under service conditions, especially over periods typical of high temperature, long term service.

The facility has been used successfully to test short graphite fiber reinforced borosilicate glass tubes subjected to monotonic and cyclic axial loads at room temperature.

9.2.2 Characterization of Performance, Including Defects and Damage Development

The investigation of the performance of ceramic composite tubes includes the measurement of strength and life and the identification, description, and evaluation of the factors which affect performance by changing strength and limiting life. Initial defects due to manufacturing and damage initiation and growth due to mechanical loading have been detected using an array of complementary nondestructive inspection techniques. Relationships between damage and performance also have been developed. These relationships describe the change in tensile strength due to damage during cyclic loading and are key inputs to the mechanistic models to predict remaining strength and life. 


\subsubsection{Models and Predictions}

A damage development model and a performance simulation model have been developed to provide a predictive capability for ceramic composite components.

Damage Development Model: The damage development model was developed and used to accurately predict locations of damage initiation and growth in a ceramic composite component subjected to quasi-static loading. The agreement between predicted and observed damage sites is very good. A progressive failure analysis was used to accurately model the damage development process. Due to the complexity of the geometry and the nonuniform fiber orientations, the analysis is based on the finite element method. The solution technique parallels the ply discount schemes developed and successfully used for laminated polymeric composites, except a failed element is discounted instead of a failed ply. The resulting approach can handle complex geometries, complex loadings, and local material property degradations associated with composite components. The methodology is developed for the general case of quasi-static and cyclic loading.

The main advantage of this approach is the simplicity of a linear elastic analysis and the capability of the finite element method to handle complex problems. The agreement between values of loads at predicted and observed damage events was not good. The loads predicted by the model depend on the accuracy of property and material orientation data input to the model. In this program, some of the data needed was not available and values were estimated for the purpose of demonstrating the model.

Performance Simulation Model: A major accomplishment of the properties and performance program is the demonstration of a capability to model remaining strength and life of a ceramic composite material system under combined cycle and time dependent 
conditions. The model provides an accurate solution to the problem of predicting the remaining strength and life of fiber-reinforced composite material systems. The approach is based on experimental determination of failure modes and damage modes, and the use of that information to establish critical elements of material which control the failure event. These representations are comhined by a single integral equation which represents the remaining strength as a function of time and loading history. This integral equation is solved by discretizing the equation, updating parameters at each increment of time, and using the method of simulation to estimate the physical behavior as various changes in the stress state and material state occur during the loading history. The approach has the advantage of being able to represent highly nonlinear and interactive phenomena which contribute to the total reduction in remaining strength.

The simulation approach has been used to solve such problems in the presence of mechanical, thermal, and chemical environments, which are constant or cyclic in time. The generality of the method is an especially appealing feature, and shows some promise as a generic approach to the problem of predicting such engineering behavior as damage tolerance, durability, and reliability of ceramic composite components. 


\subsection{REFERENCES}

1. ASTM D 3039 - 76, "Standard Test Method for Tensile Properties of Fiber-Resin Composites," 1989 Book of ASTM Standards, Vol. 15.03 , pp. 117-121.

2. J.J. Brennan and K.M. Prewo, "Silicon Carbide Fibre Reinforced Glass-Ceramic Matrix Composites Exhibiting High Strength and Toughness," J. of Materials Science, Vol. 17, 1982, pp. $2371-2383$.

3. K.M. Prewo, J.J. Brennan and G.K. Layden, "Fiber Reinforced Glasses and Class-Ceramics for High Performance Aplications," Ceramic Bulletin, Vol. 65, No. 2, 1986, pp. 305-313.

4. R.N. Singh ana A.R. Gaddipati, "Mechanical Properties of a Uniaxially Reinforced Mullite-silicon Carbide Composite", J. of the American Ceramic Society, Vol. 71 , No. 2, 1988, pp. C100-C103.

5. A.S.D. Wang and M. Barsoum, "Matrix Cracking Initiation in Brittle-Matrix Composites - Experiment and Predictions", Symposium on High Temperature composites, Proceedings of the American Society for Composites, Dayton, Ohio, June, 1989, pp. $166-175$.

6. J.N. Harris, et. al. "Development of Advanced Fiber Reinforced Ceramics", ONRL/FMP-89/1, July, 1989, pp. 53-64.

7. S.S. Sterret, Presentation at the Annual Review for the Mechanical Behavior of Composites at Elevated Temperatures, Wright Patterson Air Force Base, Dayton, Ohio, August 29, 1989 .

8. P.A. Bartolotta, P.K. Brindley and J.R. Ellis, "Verification of High-Temperature Structural Analysis Procedures", Proc. of the HITEMP Review, Cleveland, Ohio, November, 1988, pp. $399-415$.

9. J. W. Holmes, T. Kotil and W.T. Foulds, "High, Temperature Fatigue of SiC Fiber-Reinforced Si3N4 Ceramic Composites", symposium on High Temperature composites, Proc. of the American Society for, Composites, Dayton, Ohio, June 1989, pp. $176-186$.

10. G.A. Hartman, L.P. Zawada and S.M. Russ, "Techniques for Elevated Temperature Testing of Advanced Ceramic composite Materials", Proc. of the 5th Conference on Testing in Hostile. Environments, Society of Experimental Mechanics, Costa Mesa, California, March 1988, pp. 31-38. 
11. D.C. Phillips and R.W. Davidge, "Test Techniques for the Mechanical Properties of Ceramic Matrix Fibre Composites," Transactions and Journal of the British, Ceramic Society, vol. $85,1986, \mathrm{pp} .123-130$

12. M.G. Castelli, et. al, "Development of Thermomechanical Testing Technjques for Advanced Composites", Proc. of the 2 nd Annual HITEMP Review, Cleveland, Ohio, October 31 - November 2, 1989, pp. 43-1 to 43-14.

13. T. Kotil and J.W. Holmes, "A Technique for Measuring High-Frequency Elevated Temperature Fatigue Strains in Ceramic composites, to be published.

14. D.C. Larsen, S.L. Stuchly and J.W. Adams, "Evaluation of Ceramics and ceramic composites for Turbine Engine Applications," AFWAL-TR-88-4202, December 1988.

15. R. Ellis and J. Gayda, "Test Methods Overview," Proc. of the 2nd Annual HITEMP Review, Cleveland, Ohio, october 31 November 2, 1989, pp. 11-1 to 11-14.

16. W.W. Stinchcomb, (Editor) Mechanics of Nondestructive Testing, Plenum Press, New York, 1980.

17. N. Tsangarakis, J.J. Gruber and J. Nunes, "Non-destructive Evaluation of Fatigue Damage in Alumina Fiber Reinforced Aluminum," J. of Composite Materials, Vol 19, May 1985, pp. $251-268$.

18. S.J. Klima, "NDE of Advanced Ceramics," Materials Evaluation, Vol. 44, April, 1986, pp. 571-576.

19. S.J. Klima, G.Y. Baaklini and P.B. Abel, "Nondestructive Evaluation of structural Ceramics, NASA-TN-88978, 1987.

20. W.A. Ellingson, et al., "Recent Developments in Nondestructive Evaluation for structural Ceramics," ANL/FE-87-2, Argonne National Lab, Argonne, IL, May 1987.

21. J.B. Walter and L.A. Lott, "Nondestructive Evaluation of Advanced Ceramic Composite Materials," proc. of the Fossil Energy Materials Conference, ORNL/FMP-87/4, Oak Ridge, TN, August 1987.

22. M. Faudree et al., "Characterization of Damage and Fracture Processes in Short Fiber BMC Composites by Acoustic Emission", J. of Composite Materials, Vol, 22, December 1988, pp. $1170-1195$. 
23. D.C. Larsen, S.L. Stuchly and J.W. Adams, "Evaluation of Ceramics and Ceramic Composites for Turbine Engine Applications," AFWAL-TR-88-4202, December 1988.

24. R.W. Pepper and T.W. Shahood, "Correlation of NDE Results on Metal/Matrix and 2-D Carbon-Carbon Composites," symposium on High Temperature Composites, Proc. of the American Society for Composites, Dayton, Ohio, June 1989, pp. 223-232.

25. J.H. Williams, S.L. Sampson and T.K. WAng, "Quantitative Nondestructive Evaluation of Automotive Glass Fiber Composites," J. of Composite Materials, Vol. 16, 1982, pp. 20-39.

26. P. Vipond and C.J. Daniels, "Nondestructive Examination of Short Carbon Fiber-Reinforced Injection Molded Thermoplastics," Composites, Vol. 16, No, 1, Jan. 1985, pp. $14-18$.

27. W.A. Ellingson, et al., Development of Nondestructive Evaluation Methods for and Effects of Flaws on the Fracture Behavior of Structural Ceramics," ORNL/FMP-89/1, July, 1989, pp. 11-33.

28. H.E. Kautz and S.J. Klima, "NDE of Ceramic Matrix, Composites," Proc. of the 2nd Annual HITEMP Review, cleveland, Ohio, October 31 - November 2, 1989, pp. 42-1 to 42-11.

29. E. Minford and K.M. Prewo, "Fatigue Behavior of silicon Carbide Fiber Reinforced Lithium-Alumino-Silicate Glass-Ceramics," Tailoring, Muliphase and Composite Ceramics, Proc. of the Twenty-first University Conference on Ceramic Science, Pensylvania State University, University Park, PA, July, 1985, pp. 561-570.

30. K.M. Prewo, "Fatigue and stress Rupture of silicon, Carbide Fibre-Reinforced Glass-Ceramics," J. of Materials Science, Vol. 22, 1987, pp. 2695-2701.

31. S.S. Wang, E.S.-M Chim and N.M. Zahlan, "Fatigue Crack Propagation in Random Short-Fiber SMC Composite," J. of Composite Materials, Vol. 17, May 1983, pp. 250-266.

32. S.S. Wang, D.P. Goetz and H.T. Corten, "Shear Fatigue Degradation and Fracture of Random Short-Fiber, SMC Composite," J. of Composite Materials, Vol. 18, Jan. 1984, pp. $2-20$.

33. K. Freidrich, et al., "Fatigue Behavior of Aligned Short Carbon-Fibre Reinforced Polyimide and Polyethersulphone Composites," J. of Materials Science, Vol 20, 1985, pp. $3353-3364$. 
34. R.B. Freeman, "Shear Fatigue Evaluation of SMC," Proc. of the 42 nd Annual Conference, Composites Institute, The Society of the Plastics Industry, Inc., Feb. 2-6, 1987, pp. 1-5 of Session 1.1-B.

35. S.S. Wang, H. Suemasu and E.S.M. Chim, "Analysis, of Fatigue Damage Evolution and Associated Anistotropic Elastic Property Degradation in Random Short-Fiber, Composite," J. of Composite Materials, Vol. 21, December 1987, pp. 1084-1105.

36. S.S. Wang and E.S.M. Chim, "Fatigue Damage and, Degradation in Random Short-Fiber SMC Composite," J. of Composite Materials, Vol. 17, March 1983, pp. 114-134.

37. R.W. Lang, J.A. Manson and R.W. Hetrzberg, "Mechanisms of Fatigue Fracture in Short Glass Fibre-Reinforced Polymers," I. of Materials Science, Vol. 22, 1987, pp. 4015-4030.

38. H.T. Hahn, "On Approximations for Strength of Random Short Fiber Composites," J. of Composite Materials, Vol. 9, Oct. 1975, pp. 316-326.

39. H. Fukuda and T. Chou, "A Probabilistic Theory for the strength of Short Fibre Composites," J. of Materials Science, Vol 16, 1981, pp. 1088-1096.

40. J.M. Hedgepeth, "Stress Concentrations in Filamentary Structures," NASA TN-D882, Langley Research Center, Hampton, VA, 1961.

41. J.M. Hedgepeth and P. Van Dyke, "Local Stress Concentrations in Imperfect Filamentary Composite Materials," J. of Composite Materials, Vol. 1, 1967, pp. 294-309.

42. H. Fukuda and T. Chou, "Stiffness and Strength of Short Fibre Composites as Affected by Cracks and Plasticity," Fibre Science and Technology, 1981, pp. 243-256.

43. P.W. Manders and T.W. Chou, "The strength of Aligned Short-Fiber Carbon, Glass and Hybrid Carbon/Glass Composites," progress in Science and Engineering of Composites, ICCM-IV, Tokyo, Japan, 1986, pp. 1075-1082.

44. A.R. Sanadi and M.R. Piggott, "Interfacial Effects in Carbon-Epoxies: Part 1: Strength and Moduduls with short Aligned Fibres," J. of Materials Science, Vol. 20, 1985, pp. $421-430$.

45. A.R. Sanadi and M.R. Piggott, "Interfacial Effects in Carbon-Epoxies: Part 1: strength and Moduduls with short Random Fibres," J. of Materials Science, Vol. 20, 1985, pp. $431-437$. 
46. S.S. Wang, et al., "Fracture of Random Short-Fiber SMC Composite," J. of Composite Materials, Vol. 17, July 1983, pp. $299-315$.

47. K. Kageyama and T. Chou, "Modeling and Analysis of Fracture Toughness of Short-Fiber Reinforced Ceramic-Matrix. Composites," 6th International $2.60-2.69$ Conferen ye on Composite Materials, ICCM-VI, London, 1987, pp. 2.60-2.0́.

48. ANSYS PC-Linear Finite Element Code, Revision 4.3, Swanson Analysis systems, Incorporated, 1988.

49. M.W. Hyer, "Hydrostatic Response of Thick Laminated Composite Cylinders," J. of Reinforced Plastics and Composites, vol. 7, July 1988, pp 321-340.

50. T.J. Dunyak, K.L. Reifsnider and W.W. Stinchcomb, "An Examination of selected NDE Methods for ceramic Composite rubes," ORNL/Sub/87-SA946/01, Virginia Polytechnic Institute and State University; Blacksburg, VA, April 1990.

51. D.B. Marshall and A. G. Evans, "Failure Mechanisms in Ceramic-Fiber/Ceramic-Matrix Composites," J. of the American Ceramic Society, Vol. 68, No. 5, May 1985, pp 225-231.

52. C.E. Bakis, "Fatigue Response of Notched Composite Laminates Subjected to Tension-Compression Loading," MS Thesis, Virginia Polytechnic Institute and State University, oct. 1984.

53. "ASTM E 1012-89, "Standard Practice For Verification of Specimen Alignment Under Tensile Loading," 1989 Book of ASTM standards Vol 03.01 , pp 770-776.

54. Ansys 4.4 Finite Element Code, Revision 4.4, Swanson Analysis systems, Incorporated, 1989.

55. Ansys 4.4 Theoretical. Manual, Swanson Analysis systems, Incorporated, 1989 .

56. K.L. Reifsnider and W.W. Stinchcomb, "A Critical-Element Model of the Residual Strength and Life of Fatigue-Loaded Composite Coupons," Composite Materials: Fatique and Fracture, ASTM STP 907, H.T. Hahn, Ed., 1986, pp. 298-313.

57. T.J. Dunyak, "Properties and Performance of Ceramic Matrix Composite Components," Ph.D. Dissertation, Virginia Polytechnic Institute and state University, Blacksburg, VA, May 1991.' 
58. "Life Prediction Methodologies for Composite Materials," Report of the Committee on Life Prediction Methodologies for Composite Materials, Nat. Matls. Advisory Board, Nat. Res. Council., NMAB-460, N. AC. Press, 1990.

59. "High Temperature Materials for Advanced Technological Applications," Nat. Matls. Advis. Board, Nat. Res. Council, NMAB-450, N. AC. Press, 1988.

60. Gao and K.L. Reifsnider, "Micromechanjcs of Tensile strength in Composite systems," Composite Malerials: Fatique and Fracture (No. 4), ASTM STP 1156, W. W. Stinchcomb, Ed., 1993.

61. S.B. Batdorf, "Tensile Strength of Unidirectionally Reinforced Composites - I," J. Reinforced Plastics and Composites: Vol. 1,1982 .

62. K.L. Reifsnider, "Life Prediction Analysis: Directions and Divagations," Proc. ICCM VI, London, 1987 (plenary lecture), Elsevier Applied Science, 1987, pp. 4.1-4.31.

63. K.L. Reifsnider, "Performance simulation of Polymer E.used Composite Systems," Durability of Polymer Based Composite Systems for Structural Applications, A. H. Cardon and G. Verchery, Eds., Elsevier Applied Science, pp. 3-26,

64. K.L. Reifsnider, "Performance Simulation: A New Approach to the Prediction of the Long-Term Behavior of Composite Material systems," (invited plenary paper), Fifth Japan-U.S. Conf. on Composite Materials, June 21-25, 1990, Tokyo, Japan (in press).

65. K.L. Reifsnider, "Interpretation of Laboratory Test Information for Residual strength and Life Prediction of composite systems," cyclic Deformation, Fracture, and Nondestructive Evaluation of Advanced Materials, ASTM STP 1157, M. R. Mitchell and O. Buck, Eds., 1992.

66. K.L. Reifsnider, "Life Prediction Methods for Notched Composite Laminates," Proc. Fourth Japan-U.S. Conf. on Composite Materials; May 29, 1988.

67. J. Lesko, G. Carman, D. Dillard and K.L Reifsnider, "Indentation Testing of Composite Materials as a Tool for Measuring Interfacial Quality," Composite materials: Fatigue and Fracture (No.4), ASTM STP 1156, W. W. Stinchcomb, Ed., 1993 .

68. K.L. Reifsnider, "Life Prediction Methodology for Composite Material. Systems," Proc. Indo-U.S. Conf. on Advanced Composite Materials for Aeronautical Applications, 23-25 July, 1990, (in press). 
69. K.I. Reifsnider, "Some Fundamental Aspects of the Fatigue and Fracture Response of Composite Materials," Proc. 14th An. Meeting of the Society of Engineering Science, Lehigh Univ., 1977, pp. 373-384.

70. K.L. Reifsnider and A.L. Highsmith, "Characteristic Damge States: A New Aproach to Representing Fatigue Damage in Composite Laminates," Materials Experimentation and Design in Fatique, Westbury House, Guildford, U.K., 1981, pp. 246-260.

71. A.L. Highsmith and K.L. Reifsnider, "On Delamination and the Damage Localization Process," Fracture of Fibrous Composites, AMD-Vol. 74, American Society of Mecilanical Engineers, 1985, pp. $71-87$.

72. K.L. Reifsnider and R.D. Jamison, "Fracture of Fatigue-Loaded Composite Laminates," Int'1. Journal of Fatique, Vo1. 4, 1982, pp. 187-198.

73. R.D. Jamison, A.L. Highsmith and K.L. Reifsnider, "Strain Field Response of 0 Degree Glass/Epoxy Composites under Tension," Composites Technology and Research, Vol. 3, 1981, pp. $158-159$.

74. R.D. Jamison, "Damage Develpment and Failure of Fiber-Reinforced Composite Materials," PhD Dissertation, Dept. of Engineering Science and Mechanics, Virginia Polytechnic Institute and State University, Blacksburg, Virginia, 1982.

75. G.P. Carman and K.L. Reifsnider, "Micromechanics of short Fiber Composites," Fiber Science and Technology, Vol. 43, $1992, \mathrm{pp}$.

76. G.P. Carman, "Micromechanics of Finite Length Fibers in Composite Materials," PhD Dissertation, Dept. of Engineering Science and Mechanics, Virginia Polytechnic Institute and State University, Blacksburg, Virginia 1992.

77. J.M. Whitney and L.T. Drzal, "Axisymmetric Stress Distribution Around an Isolated Fiber Fragment, "Toughened Composites, ASTM STP 937, W. S. Johnson, Ed., 1987, pp. 179-196.

78. J.M. Berthelot, "Effect of Fibre Misalignment on the Elastic Properties of Oriented Discontinuous Fibre Composites, "Fibre Science and Technology, Vol. 17, 1982, pp. 25-39. 
79. K. Jayaraman and K.L. Reifsnider, "Micromechanical Stress Analysis of Continuous-Fiber Composites with Local Material Property Gradients," Achievements in Composites in Japan and the United States, A. Kobayashi, Ed. Japan Society for Composite Materials, Tokyo, 1990, pp. 4: j-436.

80. K. Prewo, "Fatigue and Stress Rupture of SiC Fiber Reinforced Glass Ceramics," J. Materials Science, 22 (1987) pp. 26952701 .

81. 2. Gao and K.I. Reifsnider, "Composites with Different Interfacial Bonding," Proc. Sixth Technical Conference of the Am. Soc. for Composites, Technomic Press, Inc., October 15, $1991, \mathrm{pp} .742-750$.

82. R. Swain, K.L. Reifsnider, K. Jayaraman and M. El-zein, "Interface/Interphase Concepts in Composite Material Systems," Proc. of the Fourth Technical conf. of the American Society for Composites, Technomic Press, 1989, pp. 377-386. 


\section{Appendix A: Test Facility Specifications}

The multiaxial test facility was designed and built by the Instron Corporation for high temperature testing. The servo-hydraulic facility is uniquely suited for axial-torsion testing of ceramic matrix composite tubes at temperatures up to $1500^{\circ} \mathrm{C}$. Features of the facility include:

- Instron s2-7858 high stiffness, axial/torsional load frame with load capacities of $100 \mathrm{kip}$ axial and 50 in/kips torsional. The stiffness of the frame is rated at $5.0 \times 106 \mathrm{lbs} /$ in axial and $3.8 \times 106 \mathrm{in}-1 \mathrm{bs} / \mathrm{deg}$ torsional at 40 inches separation between crosshead and baseplate.

- Top mounted, high stiffness, axial/rotary actuater load rated at $50 \mathrm{kips}$ axial and $25 \mathrm{kip}-$ in torsionul.

- Biaxial load cell rated at $50 \mathrm{kip}$ axial and $25 \mathrm{kip}$-in torsional.

- Six channel servo-controller provides options for axial load, strain or stroke control and rotary torque, strain, or angular displacement control. Control mode, range, selection, and range change can be set while system is in operation.

- Digital readout of all channel signals.

- Multiple waveform function generator with frequency range between $\mathrm{DC}$ and $1000 \mathrm{~Hz}$.

- Intelligent computer/test system interface incorporating a general purpose interface bus.

- PC computer (IBM and Hewlett Packard) compatible software for machine operation and control, data storage, and data post-processing.

- On-line PC computer: Hewlett Packard Vectra with color monitor, printer, and math coprocessor.

- High lemperature furnace: short furnace design with Kanthal elements rated at $2730^{\circ} \mathrm{F}$ maximum temperature.

- Specially designed axial/torsion hydraulic grips for gripping ceramic tubes based on the existing Instron cesign for high temperature ceramic rods.

- High temperature, axial extensometer to be upgraded to provide axial/torsional capability.

$$
\triangle-1
$$


A.P. GREEN REFRACTORIES COMPANY

Green Blvd.

Mexico, MO 65265

J. L. Hill

AIR PRODUCTS AND CHEMICALS

P.O. BOX 538

Allentown, PA 18105

S. W. Dean

S. C. Weiner

ALLISON GAS TURBINE DIVISION

P.O. Box 420

Indianapolis, IN 46206-0420

P. Khandelwal (Speed Code W.5)

R. A. Wenglarz (Speed Code W.16)

AMA RESEARCH \& DEVELOPMEN'T CENTER 5950 McIntyre Street

Golden, CO 80403

T. B. Cox

ARGONNE NATIONAL LABORATORY

$9700 \mathrm{~S}$. Cass Avenue

Argonne, IL 60439

W. A. Ellingson

J. P. Singh

ARGONNE NATIONAL LABORATORY-WEST

P.O. BOX 2528

Idaho Falls, ID 83403-2528

S. P. Henslee

ARMY MATERIALS TECHNOLOGY

LABORATORY SLCMT-MCC

Watertown, MA 02172-0601

D. R. Messier

\section{AVCO RESEARCH LABORATORY}

2385 Revere Beach Parkway

Everell, MA 02149

R. J. Pollina

BABCOCK \& WILCOX

1562 Beeson St.

Alliance, $\mathrm{OH} 44601$

T. I. Johnson

BABCOCK \& WILCOX

Domestic Fossil Operations

20 South Van Buren Avenue

Barberton, $\mathrm{OH} 44(023$

M. Gold
BABCOCK \& WIICOX

Lynchburg Research Center

P. O. Box 11165

lynchburg, VA 24506

H. M. Moeller

BRITISH COAL CORPORATION

Coal Research Establishment

Stoke Orchard, Cheltenham

Glochester, England GL52 4RZ

M. Arnold

C. Bower

A. Twigg

BRITISH GAS CORPORATION

Westfield Development Center

Cardenden, Fife

Scotlana KY5OHP

J. E. Scolt

BROOKHAVEN NATIONAL LABORATORY

Department of Applied Science

Upton, Long Island, NY 11973

T. E. O'Hare

CANADA CENTER FOR MINERAI \& ENERGY TECHNOLOGY

568 Booth Street

Ottawa, Ontario

Canada K1A OG1

R. Winston Revic

Mahi Sahoo

COMBUSTION ENGINEERING

1000 Prospect Hill Road

Windsor, CT 06095

D. A. Canonicos

\section{DOW CORNING CORPORATION}

3901. S. Saginaw Road

Midland, MI 48686-0995

H. Atwell

EC TECHNOLOGIES

3614 Highpoint Drive

San Antonio, TX 78217

D. J. Kenton

ELECIRIC POWER RESEARCH INSTITUTE

P.O. BOX 10412

3412 Hillvicw Avenue

Palo Alto, CA 94303

W. T. Bakker

J. Stringer 
EUROPEAN COMMUNITIES JOINT RESEARCH CENTRE

Petten Establishment

P.O. BOX 2

1755 ZG Pelten

The Nelheriands

M. Van de Voorde

GA TECHNOIOGIES. INC.

P.O. BOX 85608

San Diego, CA 92138

T. D. Gulden

GEORGIA INSTITUTE OF TECHNOLOGY

Georgia Tech Research Institute

Allanta, GA 303.32

I. L. Start

IDAHO NATIONAL ENGINEERING

LABORATORY

P. O. BOX 1625

Idaho Falls, ID 83415

D. W. Keefer

KENNAMETAL, INC.

Philip McKenna Laboratory

1011 Oid Salem Road

P. O. Box 639

Greensburg, PA 15601

B. North

LAVA CRUCIBLE-REFRACTORIES CO.

P.O. BOX 278

Zelienople, PA 16063

T. Mulholland

LAWRENCE LIVERMORE LABORATORY

P.O. Box $808, L-325$

Livermore, CA 94550

W. A. Steele

LOS ALAM:OS NATIONAI. L.ABORATORY

P.O. Box 1663

Los Alamos, NM 87545

J. D. Katz

MASSACHUSETTS INSTITUTE OF TECHNOLOGY

Department of Civil Engineering

Room I-280, 77 Massachusetts Avenue

Cambridge, MA 02139

O. Buyukozturk

NATTONAL INSTTTUTE: OF STANDARDS AND TECHNOLOGY

Materials Building

Gaithersburg, MD 20899

L. K. Ives
NA'TIONAL MATERIALS ADVISORY BOARI)

National Research Council

2101 Constitution Avenue

Washington, DC 20418

K. M. Zwilsky

NEW ENERGY AND INDUSTRIAL

TECHNOLOGY DEVELOPMENT

Sunshine $60 \mathrm{Bldg}$.

P.O. Box 1151

1-1 Higashi-Ikebukuro 3-Chrome

Toshima-Ku, Tokyo, 170

Japan

H. Narita

S. Ueda

THE NOR'TON COMPANY

lligh Performance Ceramics Division

Goddard Road

Northborough, MA 01532-1545

N. Corbin

OAK RIDGE NATIONAL LABORATORY

P.O. Box 2008

Oak Ridge, TN 37831

P. T. Carlson

N. C. Cole

R. R. Judkins

R. A. Lawson (8 ropies)

K. C. Liu

R. W. Swindeman

OFIICE OF NAVAI. RESEARCH

Code 431,800 N. Quincy Street

Arlington, VA 22217

S. G. Fishman

RESEARCH TRIANGLE INSTITUTE

P. O. Box 12194

Research Triangle Park, NC 27709

T. W. Sigmon

SHELL DEVELOPMENT COMPANY

P.O. Box 1380

Houston, TX 77251-1380

L. W. R. Dicks

TENNESSEE VALLEY AUTHORITY

Energy Demonstration \& Technology

MR2N58A

Chattanooga, TN 37402-2801

C. M. Huang

3M COMPANY

Ceramic Materials Department

201-2C-12 3M Center,

St. Paul, MN 55144

L. R. White 
THE JOHNS HOPKINS UNIVERSITY

Materials Science \& Engineering

Maryland Hall

Baltimore, MD 21218

R. E. Green, Jr

THE MATERIALS PROPERTIES COUNCIL, INC.

United Engineering Center

345 E. Forty-Seventh Street

New York, NY 10017

M. Prager

THE TORRINGTON COMPANY

Advanced Technology Center

59 Field St.

Torrington, C'T (6679)

W. J. Chmura

UNION CARIBIDE CORPORATION

Linde Division

P.O. Box 44

175 Easi Park Drive

Tonawanda, NY 14151-00)44

Harry Cheung

UNITED TECHNOLOGIES RESEARCH CENTER

MS 24, Silver Lane

East Hartford, CI 06108

K. M. Prewo

UNIVERSITY OF WASHINGTON

Department of Materials Science and Engineering

101 Wilson, FB-10

Seattle, WA 98195

T. G. Stoebe

VIRGINIA POLYTECHNIC INSTITUTE \& STATE UNIVERSITY

Department of Materials Engineering

Blackburg, VA 24601

J. J. Brown, Jr.

K. L. Reifsnider

WESTERN RESEARCH INSTITUTE

365 N. 9th Street.

P.O. Box 3395

University Station

Laramie, WY 82071

V. K. Sethi

WESTINGHOUSE ELECTRIC CORPORATION

Research and Development Center

1310 Beulah Road

Pittsburgh, PA 15235

S. C. Singhal
WESTINGHOUSE HANFORD COMPANY

P.O. BOX 1970

W/A -65

Richland, WA 99352

R. N. Johnson

DOE

IDAHO OPERATIONS OFFICE

P. O. BOX 1625

Idaho Falls, ID 83415

R. B. Loop

DOE

DOE FIELD OFHICE, OAK RIDGE

P.O.Box 2001

Oak Ridge, TN 37831

Assistant Manager for Energy Research and Development

DOE

DOE FIELD OFFICE, OAK RIDGE

P. O. Box 2008

Building 4500N, MS 6269

Oak Ridge, TN 37831

E. E. Hoffman

DOE

OFFICE OF BASIC ENERGY SCIENCES

Materials Sciences Division

ER-131 GTN

Washington, DC 20545

J. B. Darby

DOE

OFFICE OF CONSERVATION AND

RENEWABLE ENERGY

CE-12 Forrestal Building

Washington, DC 20545

J. J. Eberhardt

DOE

OFFICE OF FOSSIL. ENERGY

Washington, DC 20545

J. P. Carr (FE-14) GTN

DOE

OFFICE OF VEHICLE AND ENERGY R\&D

CE-151 Forrestal Building

Washington, DC 20585

R. B. Schulz 
DOE

MORGANTOWN ENERGY TECHNOLOGY CENIER

P.O. Box 880

Morgantown, WV 26505

R. A. Bajura

R. C. Bedick

D. C. Cicero

F. W. Crouse, Jr.

N. T. Holcombe

W. J. Huber

M. J. Mayfieid

J. E. Notestein

J. S. Wilson
DOE

PITTSIBURGH ENERGY TECHNOLOGY CENTER

P.O. BOX 10940

Pittsburgh, PA 15236

A. H. Baldwin

G. V. McGurl

R. Santore

T. M. Torkos
Mr. Sherm Bigelow

Structures Technology, MS 82-97

Boeing Aerospace Company

P. O. Box 3999

Seattle, WA 98124

Dr. Steve E. Bold

Warrensville Research Center

BP America, Inc.

4440 Warrensville Center Road

Cleveland, OH 44128-2837

Dr. James D. Burrington

Warrensville Research Center

BP America, Inc.

4440 Warrensville Center Road

Cleveland, $\mathrm{OH} 44128-2837$

Dr. James Cecere

Defense Division

Brunswick Corporation

150 Johnston Road

Marion, VA 24354

Dr. Victoria Franchetti

Director of Technology, Plastics Division

Monstanto Chemical Corporation

730 Worcester Street

Springfield, MA 01151

Mr. Paul Giordano

Warrensville Research Center

BP America, Inc.

4440 Warrensville Center Road

Cleveland, $\mathrm{OH} 44128-2837$
Mr. Glenn C. Grimes

Dept. 72-37, Bldg. 311, B-6

Lockheed Aeronautical Systems Company

P. O. Box 551

Burbank, CA 91520-7237

Mrs. Dushanka Keane

Central Research and Development

E. I. duPont de Nemours \& Company

Chesinut Run Plaza

P. O. Box 80702

Wilmington, DE 19880-0702

Michael C. McCabe

MD M89

General Electric Company

One Neumann Way, P. O. Box 156301

Cincinnati, $\mathrm{OH}$ 45215-6301

Dr. Paul Para

FMC Corporation

2890 Delacruz Blvd.

MD P95

Santa Clara, CA 90505

Mr. Lowell Smith

Composite Materials, Bldg. 600, Dept. E78

Newport News Shipbuilding

4101 Washington Avenue

Newport News, VA 23607 

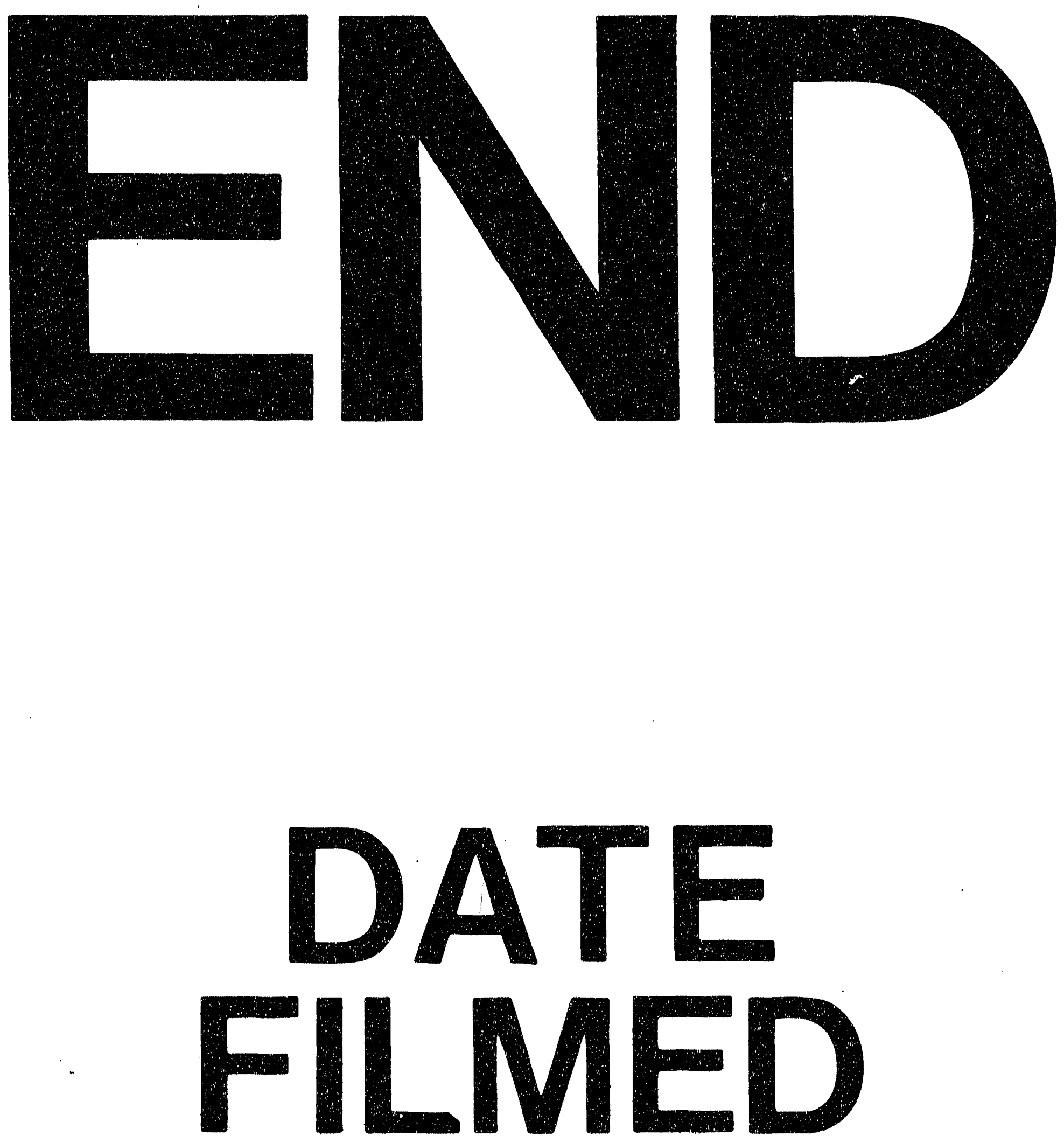

事

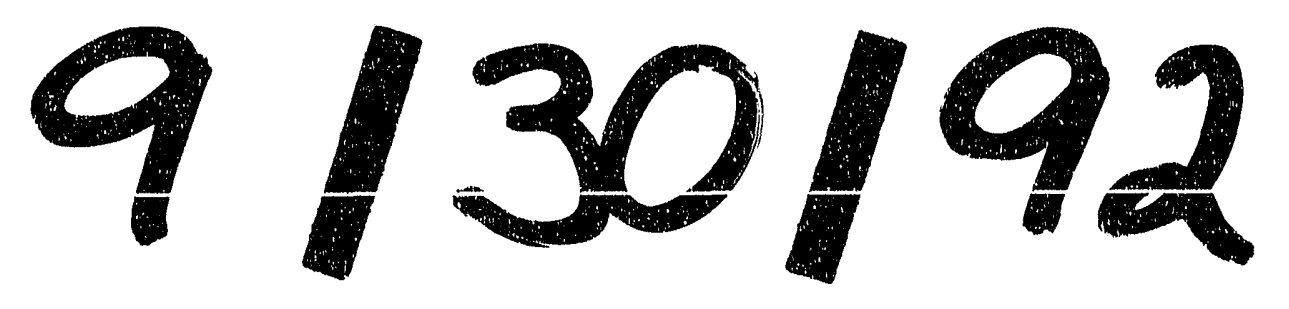


$\overline{=}$

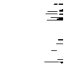

